Illinois State University

ISU ReD: Research and eData

Theses and Dissertations

$9-29-2020$

\title{
Aqueous Kinetics Of A-Hydroxyhippuric Acid Derivatives Bearing Electron-Withdrawing Groups As A Function Of Ph And Buffer Catalysts
}

Mohamad Imad Rafie

Illinois State University, rafie.mohammad@gmail.com

Follow this and additional works at: https://ir.library.illinoisstate.edu/etd

Part of the Chemistry Commons

\section{Recommended Citation}

Rafie, Mohamad Imad, "Aqueous Kinetics Of A-Hydroxyhippuric Acid Derivatives Bearing ElectronWithdrawing Groups As A Function Of Ph And Buffer Catalysts" (2020). Theses and Dissertations. 1340. https://ir.library.illinoisstate.edu/etd/1340

This Thesis is brought to you for free and open access by ISU ReD: Research and eData. It has been accepted for inclusion in Theses and Dissertations by an authorized administrator of ISU ReD: Research and eData. For more information, please contact ISUReD@ilstu.edu. 


\section{AQUEOUS KINETICS OF $\alpha$-HYDROXYHIPPURIC ACID DERIVATIVES BEARING ELECTRON-WITHDRAWING GROUPS AS A FUNCTION OF pH AND BUFFER CATALYSTS}

\section{MOHAMAD IMAD RAFIE}

\section{Pages}

It has been shown that carbinolamides are intermediates in the enzyme-catalyzed synthesis of $\alpha$-amidated peptides. Although carbinolamides are important intermediates in the production of these hormones and have roles in other biological venues, little attention has been given to their mechanisms of reaction in water, and, thus, it is difficult to speculate how their reaction would be enzymatically catalyzed. The purpose of the work presented here was to synthesize structural analogs of the biological intermediates and study their mechanism of breakdown in water. $\alpha$-Hydroxyhippuric acid, a substrate for the enzymatic system, provides an easily modified template for the study of the breakdown of this carbinolamide system. The $\mathrm{pH}$ rate profiles for various aromatic substituted derivatives of $\alpha$-hydroxyhippuric acid will be presented, and the mechanism of the acid, hydroxide and buffer catalyzed reactions discussed.

KEYWORDS: Carbinolamide; $\alpha$-Hydroxyhippuric acid; Kinetics; Aqueous; Amide; Synthesis; Peptidylglycine- $\alpha$-amidating monooxygenase; Buffer; Catalysis. 
AQUEOUS KINETICS OF $\alpha$-HYDROXYHIPPURIC ACID DERIVATIVES BEARING

ELECTRON-WITHDRAWING GROUPS AS A FUNCTION OF pH AND BUFFER CATALYSTS

MOHAMAD IMAD RAFIE

A Thesis Submitted in Partial

Fulfillment of the Requirements

for the Degree of

MASTER OF SCIENCE

Department of Chemistry

ILLINOIS STATE UNIVERSITY 
(C) 2020 Mohamad Imad Rafie 
AQUEOUS KINETICS OF $\alpha$-HYDROXYHIPPURIC ACID DERIVATIVES BEARING

ELECTRON-WITHDRAWING GROUPS AS A FUNCTION OF pH AND BUFFER CATALYSTS

MOHAMAD IMAD RAFIE

COMMITTEE MEMBERS:

Richard W. Nagorski, Chair

Christopher G. Hamaker

Jonathan J. Mills 


\section{ACKNOWLEDGMENTS}

Huge shout out goes to Dr. Richard Nagorski. Working with him in a research setting and combining what I have learned from the pharmaceutical industry, has equipped me with the skills I need to further my career as a professional in the chemistry field. Thanks Boss! Additional thanks go out to my committee members: Dr. Mills, and Dr. Hamaker. I appreciate you taking the time to read through this thesis and challenge me during my thesis defense.

Lastly, I would like to thank my friends and family for providing me with an enormous amount of support over the years I have spent here at Illinois State University. Thank you to each and every one of you. A special thank you goes out to my mom and dad. Love you Mama and Baba.

M. I. R. 


\section{CONTENTS}

Page

ACKNOWLEDGMENTS

TABLES

FIGURES

SCHEMES vii

CHAPTER I: AN INTRODUCTION TO CARBINOLAMIDES 1

$\begin{array}{ll}\text { Previous Mechanistic Studies } & 10\end{array}$

CHAPTER II: SYNTHESIS OF $\alpha$-HYDROXYHIPPURIC ACID DERIVATIVES 23

$\begin{array}{ll}\text { Introduction } & 23\end{array}$

$\begin{array}{ll}\text { Experimental } & 25\end{array}$

$\begin{array}{ll}\text { Material } & 25\end{array}$

$\begin{array}{ll}\text { Synthesis } & 25\end{array}$

Results and Discussion $\quad 34$

$\begin{array}{ll}\text { Conclusions } & 43\end{array}$

CHAPTER III: KINTETICS OF $\alpha$-HYDROXYHIPPURIC ACID DERIVATIVES 45

$\begin{array}{ll}\text { Introduction } & 45\end{array}$

$\begin{array}{ll}\text { Experimental } & 50\end{array}$

$\begin{array}{ll}\text { Material } & 50\end{array}$

Results and Discussion $\quad 53$

Kinetics $\quad 53$

Hydroxide Dependent and Independent Region 56

Apparent Second-Order Rate Constant $\left(k_{1}^{\prime}\right)$ 
Dissociation Constant of the Hydroxyl Group $\left(K_{\mathrm{a}}\right) \quad 64$

$\begin{array}{ll}\text { First-Order Rate Constant }\left(k_{1}\right) & 68\end{array}$

$\begin{array}{ll}\text { Conclusions } & 72\end{array}$

$\begin{array}{ll}\text { WORKS CITED } & 74\end{array}$

APPENDIX A: SUPPLEMENTAL INFORMATION 80 


\section{TABLES}

Table

Page

1. Rate Constants for the Hydroxide-Independent and Dependent Reactions of $\alpha$ Hydroxyhippuric Acid Derivatives Under Aqueous Conditions, at $25{ }^{\circ} \mathrm{C}$ and $I=1.0 \mathrm{M}$ $(\mathrm{KCl})$.

2. Wavelengths Determined for $\alpha$-Hydroxyhippuric Acid Derivatives Using Initial Kinetics Method, at $25^{\circ} \mathrm{C}$ and $I=1.0 \mathrm{M}(\mathrm{KCl})$.

3. Rate Constants for the Hydroxide-Dependent Reactions of $\alpha$-Hydroxyhippuric Acid Derivatives and their $\mathrm{p} K_{\mathrm{a}}$ 's in Water, at $25^{\circ} \mathrm{C}$ and $I=1.0 \mathrm{M}(\mathrm{KCl})$ 


\section{FIGURES}

Figure

Page

1. Various $N$-(Hydroxyalkyl) Carbinolamides Used in Bundgaard Studies.

2. Various $N-\alpha-($ Hydroxylalkyl)benzamides Derived from Glyoxylic Acid, Esters, and Amides Used in Bundgaard Studies.

3. The $\mathrm{pH}$ Rate Profile for the Aqueous Decomposition of $N$-(hydroxymethyl)benzamide $(\boldsymbol{\nabla})$, 4-chloro- $N$-(hydroxymethyl)benzamide $(\bullet)$, and 2,4-dichloro- $N$ -

(hydroxymethyl)benzamide ( $\boldsymbol{\sim})$ in $\mathrm{H}_{2} \mathrm{O}, I=1.0 \mathrm{M}(\mathrm{KCl})$, at $25^{\circ} \mathrm{C}$.

4. Hydroxide-Independent $\mathrm{pH}$-Rate Profile of $N$-(hydroxymethyl)benzamide ( $\boldsymbol{\nabla}$ ), 4-chloro-

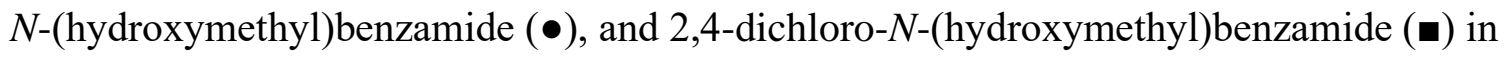
$\mathrm{H}_{2} \mathrm{O}, I=1.0 \mathrm{M}(\mathrm{KCl})$, at $25{ }^{\circ} \mathrm{C}$.

5. $\quad \mathrm{p} K_{\mathrm{a}}$ and $k_{1}$ Values of 4-chloro-, 2,4-dichloro-, and $N$-(hydroxymethyl)benzamide.

6. $500 \mathrm{MHz}{ }^{1} \mathrm{H}-\mathrm{NMR}$ Spectrum of 4-Chloro- $\alpha$-Hydroxyhippuric Acid (2b) in DMSO- $\mathrm{d}_{6}$.

7. $125 \mathrm{MHz}{ }^{13} \mathrm{C}-\mathrm{NMR}$ of 4-Chloro- $\alpha$-Hydroxyhippuric Acid (2b) DMSO-d 6 .

8. $400 \mathrm{MHz}{ }^{1} \mathrm{H}-\mathrm{NMR}$ of 2-Ethanamido-(4-nitrobenzamido)acetic Acid (23) in DMSO-d 6 .

9. $125 \mathrm{MHz}{ }^{13} \mathrm{C}-\mathrm{NMR}$ of 2-Ethanamido-(4-nitrobenzamido)acetic Acid (23) in DMSO-d $\mathrm{d}_{6}$.

10. $\mathrm{pH}$ Rate Profile for the Aqueous Reaction of 4-Chloro- $\alpha$-hydroxyhippuric Acid (2b), at $25^{\circ} \mathrm{C}$ and $I=1.0 \mathrm{M}(\mathrm{KCl})$.

11. Effect of Increasing Hydroxide Concentration on the $k_{\mathrm{obsd}}$ of $\alpha$-Hydroxyhippuric Acid Derivatives in Water, at $25^{\circ} \mathrm{C}$ and $I=1.0 \mathrm{M}(\mathrm{KCl}) .(\boldsymbol{\nabla})$ 4-Bromo- $\alpha$-hydroxyhippuric 
Acid, $(\triangle)$ 4-(Trifluoromethyl)- $\alpha$-hydroxyhippuric Acid, (匹) 3,4-Dichloro- $\alpha$ -

hydroxyhippuric Acid, () 3-Chloro- $\alpha$-hydroxyhippuric Acid.

12. Effect of $\mathrm{pH}$ on the $k_{\mathrm{obsd}}$ of $\alpha$-Hydroxyhippuric Acid Derivatives in Water, at $25^{\circ} \mathrm{C}$ and $I$ $=1.0 \mathrm{M}(\mathrm{KCl}) .(\boldsymbol{\nabla})$ 4-Bromo- $\alpha$-hydroxyhippuric Acid, $(\triangle)$ 4-(Trifluoromethyl)- $\alpha$ hydroxyhippuric Acid.

13. Hammett Plot of Apparent Second-Order Rate Constants $\left(k_{1}\right)$ for the Hydroxide Reaction of $\alpha$-Hydroxyhippuric Acid Derivatives with Electron Withdrawing Groups in Water, at $25^{\circ} \mathrm{C}$ and $I=1.0 \mathrm{M}(\mathrm{KCl})$.

14. Hammett Plot of Apparent Second-Order Rate Constants $\left(k_{1}\right)$ for the Hydroxide Reaction of all $\alpha$-Hydroxyhippuric Acid Derivatives in Water at $25^{\circ} \mathrm{C}$ and $I=1.0 \mathrm{M}(\mathrm{KCl})$.

15. Hammett Plot of Dissociation Constants $\left(K_{\mathrm{a}}\right)$ of the Hydroxyl Group for the Hydroxide Reaction of $\alpha$-Hydroxyhippuric Acid Derivatives with Electron Withdrawing Groups in Water, at $25^{\circ} \mathrm{C}$ and $I=1.0 \mathrm{M}(\mathrm{KCl})$.

16. Hammett Plot of Dissociation Constants $\left(K_{\mathrm{a}}\right)$ of the Hydroxyl Group for the Hydroxide Reaction of all $\alpha$-Hydroxyhippuric Acid Derivatives in Water, at $25{ }^{\circ} \mathrm{C}$ and $I=1.0 \mathrm{M}$ $(\mathrm{KCl})$.

17. Hammett Plot of First-Order Rate Constants $\left(k_{1}\right)$ for the Hydroxide Reaction of $\alpha$ Hydroxyhippuric Acid Derivatives with Electron Withdrawing Groups in Water, at $25{ }^{\circ} \mathrm{C}$ and $I=1.0 \mathrm{M}(\mathrm{KCl})$.

18. Hammett Plot of First-Order Rate Constants $\left(k_{1}\right)$ for the Hydroxide Reaction of all $\alpha$ Hydroxyhippuric Acid Derivatives in Water, at $25^{\circ} \mathrm{C}$ and $I=1.0 \mathrm{M}(\mathrm{KCl})$. 


\section{SCHEMES}

Scheme

Page

1. Tscherniac-Einhorn Reaction. 2

2. Utility of $N$-(hydroxymethyl)amides. 3

3. Proposed Mechanism of Bicyclomycin with Thiols. 5

$\begin{array}{lll}\text { 4. } & \text { Etheno-base Adduct Formation. } & 7\end{array}$

5. Processing of Allantoin into Urea and Glyoxylate. $\quad 8$

6. PAM Mediated Breakdown into Bioactive Peptide Hormone and Glyoxylate. $\quad 10$

7. Possible Role of Zinc Mediated Deprotonation. 10

8. Accepted Mechanism for the Hydroxide-Dependent Breakdown of Carbinolamides. 14

9. Specific-Acid Catalyzed Mechanism. 14

10. Specific-Base Catalyzed Mechanism. 17

11. General Acid Catalyzed Mechanism. 20

12. Specific-Acid followed by General-Base Catalyzed Mechanism. 21

13. Synthetic Scheme for the Synthesis of $\alpha$-Hydroxyhippuric Acid Derivatives. 24

14. Benzamide Derivative Synthesis.

15. Generic Carbinolamide Synthesis. 36

16. $\quad N$-(hydroxymethyl)benzamide Derivative Synthesis. 36

17. Potential Synthetic Route of 2-Ethenamido-(4-nitrobenzamido)acetic Acid (23). 40

18. Synthesis of $\alpha$-Hydroxyhippuric Acid Derivatives. 43

19. Accepted Mechanism for the Hydroxide-Catalyzed Reaction of $\alpha$-Hydroxyhippuric Acid. 
20. Accepted Mechanism for the Hydroxide-Catalyzed Reaction of $\alpha$-Hydroxyhippuric Acid. 


\section{CHAPTER I: AN INTRODUCTION TO CARBINOLAMIDES}

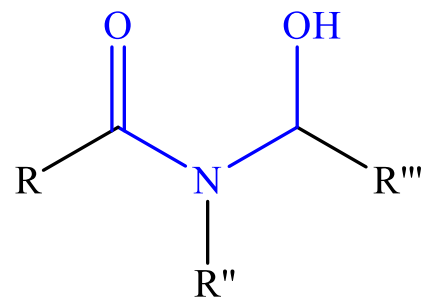

(1)

The Nagorski group has had an interest in the study of the carbinolamide functionality (1) for many years. ${ }^{1-8}$ While carbinolamides are not a well-known functional group, the functionality has been shown to be involved in several interesting biological systems ${ }^{9-16}$ and have also been shown to be present in a number of molecules possessing interesting pharmaceutical characteristics. ${ }^{17-31}$ Even with a growing number of examples of the importance of carbinolamides, the current understanding of their modes of reactivity is not well understood. Several reasons for this can be hypothesized; however, one of the primary reasons lies in the fact that carbinolamides present an interesting synthetic challenge. Most of the initial studies of carbinolamides were focused on carbinolamides generated from highly electrophilic aldehydes as these were the most easily accessible examples. ${ }^{32}$ A primary example of these easily accessible compounds are the $\mathrm{N}$-(hydroxymethyl)amides which were explored as a route to the formation of stabilized carbocations. ${ }^{32}$ One specific example involved the generation of carbocations under acidic conditions to generate an $N$-acyliminium ion that underwent electrophilic aromatic substitution and the reaction was later named the Tscherniac-Einhorn reaction (see Scheme 1). ${ }^{32}$ In the Tscherniac-Einhorn reaction, the carbinolamide was treated with a strong acid which led to the generation an $N$-acyliminium ion intermediate. The $N$-acyliminium ion would then undergo electrophilic aromatic substitution to yield the benzylamide product. ${ }^{32}$ Unfortunately the reaction suffered from relatively low yields and the lack of versatility with respect to 
carbinolamide structure which led to the reaction falling into obscurity. ${ }^{32}$ For quite some time this was the state of the knowledge surrounding the reactivity of carbinolamides. The dearth of methods to generate structurally diverse groups of compounds and a general lack of understanding with respect to their reactivity led to this lack of interest even though carbinolamides were versatile starting materials leading to a variety of unique structural entities (Scheme 2). ${ }^{32}$ While interest in the fundamental aspects of carbinolamides may have waned, as stated above, the occurrence of carbinolamides in a growing variety of venues continues. A final example of the importance of carbinolamide chemistry is in the generation of peptide hormones where a carbinolamide is generated by the bifunctional enzyme peptidylglycine- $\alpha$-hydroxylating monooxygenase (PHM, EC 1.14.17.3). ${ }^{11,16,33-45}$ The fact that an enzyme exists that is capable of catalyzing the breakdown of carbinolamides was interesting given that the accepted mechanisms of carbinolamide reaction would not be easily catalyzed. ${ }^{46-50}$ This observation has led to the study detailed herein. This report will detail the synthesis and aqueous kinetics, as a function of $\mathrm{p} H$, of a series of $\alpha$-hydroxyhippuric acid derivatives (2).

Scheme 1: Tscherniac-Einhorn Reaction.

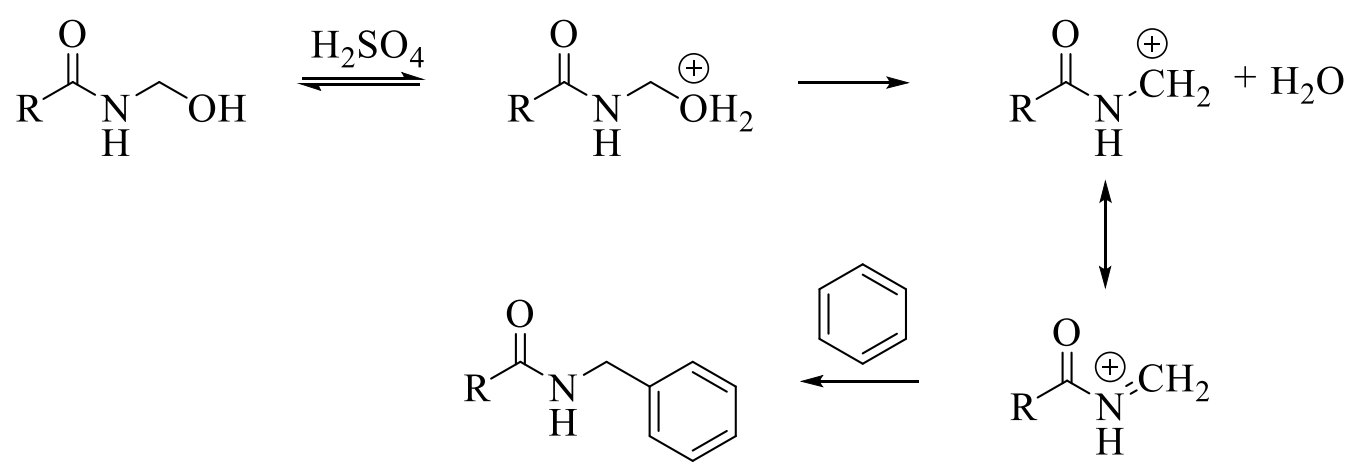


Scheme 2: Utility of $N$-(hydroxymethyl)amides.

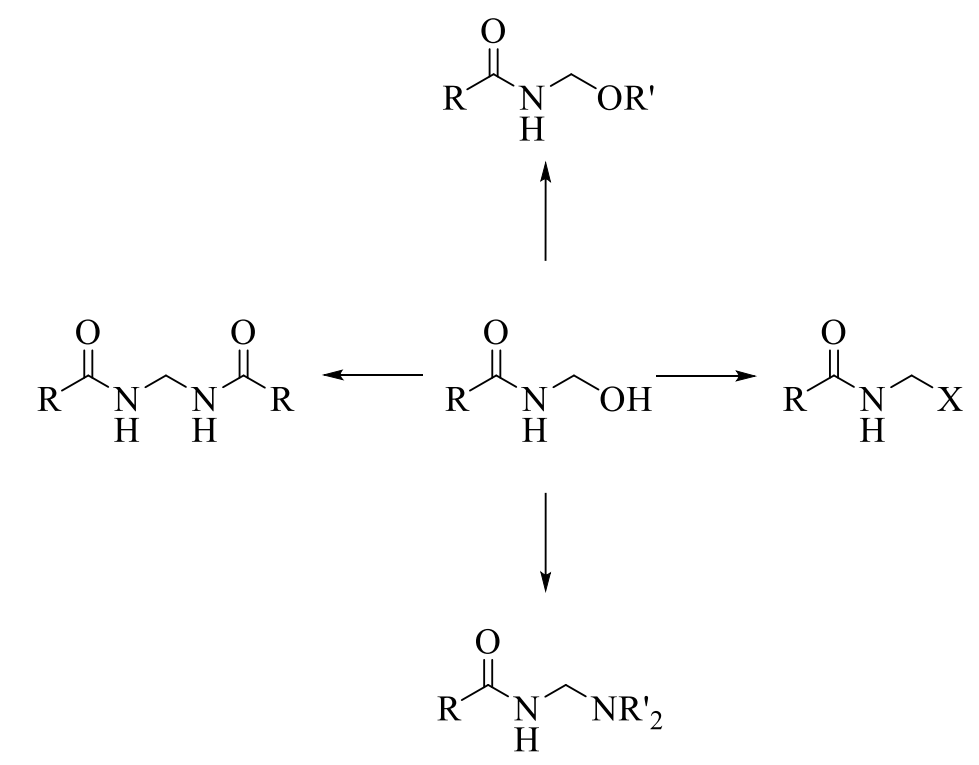<smiles>O=C(NC(O)C(=O)O)c1ccccc1</smiles>

2

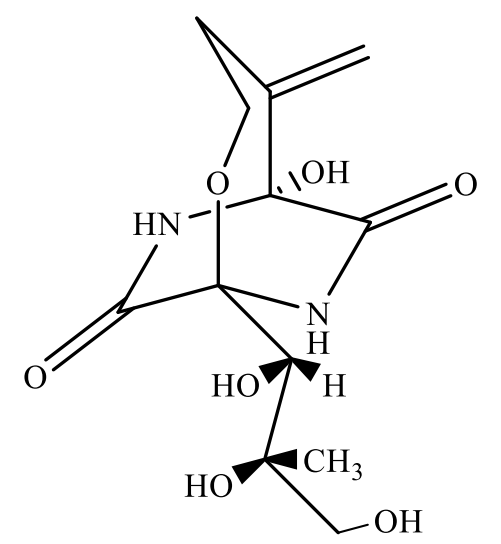

3

As stated above, the promise of carbinolamides as starting materials in reactions waned since the synthesis of the compounds proved to be quite challenging. More recently there has been a renewed interest in carbinolamides as there has been a rise in the number of biologically relevant compounds and intermediates involving the functionality. ${ }^{24,29-31,51-56}$ One such example 
is bicyclomycin (3), which is a commercially available antibiotic which is effective against gram-negative bacteria such as Escherichia coli. ${ }^{24,30}$ This water-soluble antibiotic was isolated from soil samples in Aizu, Japan. ${ }^{24}$ Its known uses are for non-specific intestinal issues in humans, with its primary use, in North America, in the livestock industry. As $\mathbf{3}$ did not fit into any of the traditional structural analogs of known antibiotics, there was a great deal of interest in its bioactivity. ${ }^{24,29-31,51-56}$

Thus, the isolation and purification of $\mathbf{3}$ led to extensive studies being performed to elucidate its structure and to understand the reactivity of the compound which could lead to an understanding of biological activity. ${ }^{24}$ Being considered a weak antibiotic, that did not seem to exhibit cross resistance with other commercially available antibiotics, bicyclomycin gained traction within the antibiotic community due to its rapid absorption into biological systems and low toxicity. This combination of factors made bicyclomycin worthy of detailed investigations into its mode of action. ${ }^{24,29-31,51-56}$

Most of the mechanistic proposals concerning the mode of action of $\mathbf{3}$ involved the olefin group alkylating nucleophilic residues within the bacteria where binding was irreversible. This binding of $\mathbf{3}$ leads to an interruption of normal cellular function and, ultimately, the death of the bacterium. ${ }^{31}$ Extensive work was performed and directed toward understanding which sites on $\mathbf{3}$ could or could not be modified to either improve or halt biological activity. It was determined that functionalization of the triol moiety decreased the biological activity of $\mathbf{3}^{31,51}$ It was postulated that a key intermediate for the functionalization of the exocyclic double bond on $\mathbf{3}$ could not be achieved due to the removal of hydrogen bonding binding sites available at the triol moiety that somehow properly orient $\mathbf{3}$ during the alkylation reaction. ${ }^{31,51}$ It was also determined that the lone hydroxyl group on the carbinolamide functionality of bicyclomycin must not be 
modified or reaction at the exocyclic double bond does not occur. ${ }^{51}$ A proposed mode of action for 3 is shown in Scheme 3. ${ }^{51}$

Scheme 3: Proposed Mechanism of Bicyclomycin with Thiols.

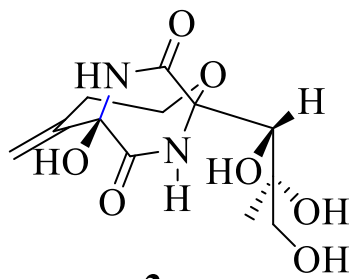

3

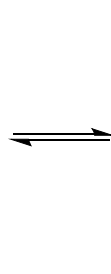

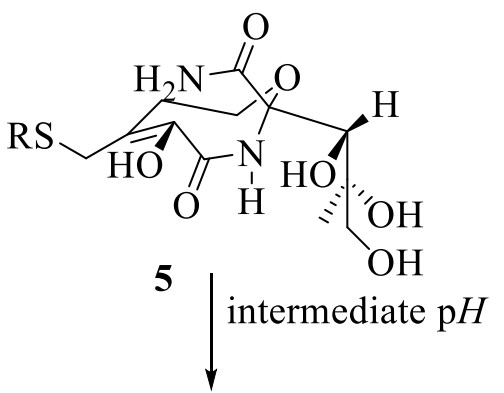
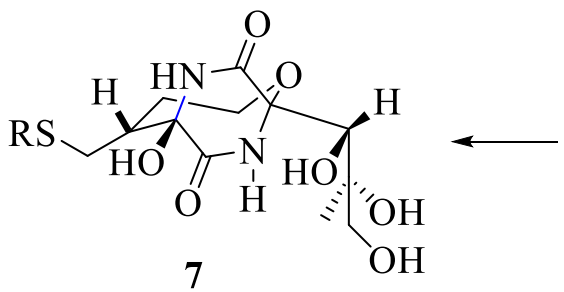

The proposed mechanism for the reaction of the exocyclic double bond and the carbinolamide moiety was developed based upon the reaction of 3 in a $\mathrm{THF} / \mathrm{H}_{2} \mathrm{O}$ system, in the presence of thiol nucleophiles. ${ }^{51}$ The reaction was postulated to occur initially through the equilibrium opening of the carbinolamide moiety (structures $3 \& 4$ in Scheme 3). Such equilibria for carbinolamides has been shown to be possible in the case of $N$-(hydroxymethyl)benzamide derivatives. ${ }^{1}$ Once the carbinolamide is open, it unmasks an $\alpha, \beta$-unsaturated carbonyl system (4) which would then be susceptible to Michael type addition reactions. It was at this point that a biological nucleophile was thought to react with the alkene leading to the enol (5) shown in Scheme 3. Compound 5 then undergoes tautomerization to generate $\mathbf{6}$, which is the open form of the 3 where the double bond has been substituted. The isolated product from the study was $\mathbf{7}$, 
indicating that the carbinolamide recloses after the substitution reaction. ${ }^{51}$ Additional work reported on the reactivity of $\mathbf{3}$ binding to nucleophilic residues such as thiols (Scheme 3), amides, and amino acids such as cysteine and lysine, shows successful binding to the olefin group on the antibiotic. ${ }^{51-56}$ These sort, of interactions showcase a mode of action for bicyclomycin with different nucleophiles that are present within biological systems, understanding the reactivity of this species could elucidate information relevant to activity within biological systems which could help determine the application. The reports of $\mathbf{3}$ interacting with cystine residues were first of their kind at the time. ${ }^{54}$

Early investigations into the mechanism of bioactivity on E. coli showed that $\mathbf{3}$ seemed to hinder the biosynthesis of murein-lipoproteins. ${ }^{57} \mathrm{~A}$ closer look into the mode of action determined that the inhibition of the murein-lipoprotein was merely a secondary function of $\mathbf{3}$ on E. coli since the antibiotic inhibited the growth of the bacteria with and without mureinlipoprotein. ${ }^{57}$ Though some reported observations of the antibiotic acting on the bacteria stated that the production of filaments could be affecting the biosynthesis of peptidoglycan, possibly affecting the mechanism, and function of the bacteria. ${ }^{57}$

More recent investigations (primarily with $E$. coli) have shown that $\mathbf{3}$ is involved in the rho dependent transcription termination factor for ATP hydrolysis. ${ }^{56,58}$ It was thought that 3 inhibits this process which has been accompanied with commentary about the implications carried over to its interference with RNA translocation. ${ }^{56,58}$ Prevention of RNA binding at the translocation site is thought to occur by separating this process from ATP hydrolysis. ${ }^{56,58}$ Of note, it was previously determined that $\mathbf{3}$ inhibits the rho-dependent ATPase activity through a rapid noncompetitive, reversable binding process with respect to ATP where the antibiotic covalently modified the bacteria at different sites. ${ }^{56}$ Understanding the role of bicyclomycin on 
rho was important due to rho's function relative to ATP. Considering the importance of this species for biological function and the involvement of a carbinolamide containing compound, these studies seem promising to incite interest into the study of different carbinolamide containing compounds that could potentially have similar effects to bicyclomycin.

The application of $\mathbf{3}$ is one positive example of the utility of carbinolamide containing compounds. On the other hand, carbinolamide intermediates have been shown to be involved in DNA modification leading to a potential cause of certain types of rare cancers. ${ }^{12,59}$ Shown in Scheme 4 is the proposed reaction of glyoxal with the guanidine residue based upon product outcomes. ${ }^{60}$ It has been shown that the carbinolamide intermediate was initially formed (8) then underwent an, as yet, unknown transformation to generate the etheno-bridged species (9). ${ }^{60}$ The modification, shown in $\mathbf{9}$, has been cited as a possible factor in carcinogenesis and mutagenesis along with the propano- and malondialdehyde derived adducts. ${ }^{10}$ These exocyclic adducts arise from covalent modification at two sites of the DNA base that are normally involved in hydrogen bonding interactions, which are required for maintaining the double helical structure of DNA. With the absence of these hydrogen bonding sites one could speculate structural changes in DNA that could be a determent to the well-being of an organism.

Scheme 4: Etheno-base Adduct Formation.<smiles>CCc1nc2c(=O)n3c(nc2[nH]1)NC(O)C3O</smiles> 
An area that gives some insight about the generation of aldehydes and involving a carbinolamide-like intermediate, within biological systems, is the processing of purines. Purines are present in DNA in the forms of adenine and guanine. These species are metabolically processed within the cell forming urate or uric acid in the protonated form. What is of importance here is the processing of this urate species ultimately leads to the generation of urea and glyoxylate shown in Scheme 5. This process involves an enzyme called ureidoglycolate lyase (UGL, EC 4.3.2.3) which acts on ureidoglycolate (shown in Scheme 5). ${ }^{14}$ The structural similarities of this intermediate, while not formally characterized as a carbinolamide, suggest that their reactivity patterns could be similar. What is very interesting, from the perspective of the work presented herein, was the $\alpha$-hydroxyhippuric acid (2) was shown to be substrate for both peptidylglycine- $\alpha$-amidating monooxygenase (PAM, EC 1.14.17.3) ${ }^{61}$ and ureidoglycolate lyase. $^{13}$

Scheme 5: Processing of Allantoin into Urea and Glyoxylate.

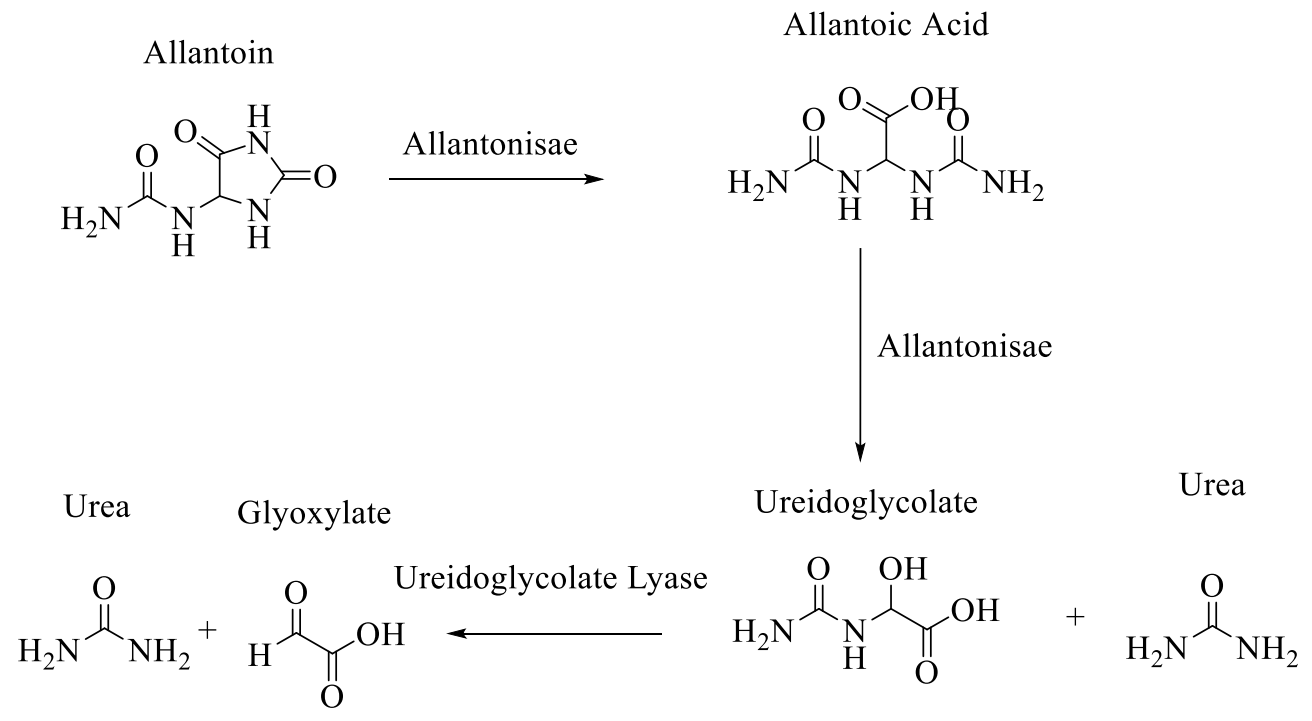


Approximately one half of all known mammalian peptide hormones require a C-terminal $\alpha$-amide functionality to be biologically active. ${ }^{11}$ Peptidylglycine- $\alpha$-amidating monooxygenase (PAM, EC 1.14.17.3) is a bifunctional enzyme that reacts with the glycine-extended peptide precursor (10 in Scheme 6) to generate a carbinolamide intermediate (11) in the first step and then catalyzes the reaction of the carbinolamide to produce the $\alpha$-amidated species and glyoxylate (Scheme 6). ${ }^{62,63}$ As stated, PAM is a bifunctional enzyme consisting of two domains which have also been isolated as separate enzymes, peptidylglycine- $\alpha$-hydroxylating monooxygenase (PHM, EC 1.14.17.3), and peptidyl- $\alpha$-hydroxyglycine- $\alpha$-amidating lyase (PAL, EC 4.3.2.5). The PHM domain has been shown to convert 10 to a hydroxyglycine residue (11), while the PAL domain is responsible for the breakdown of $\mathbf{1 1}$ to form the bioactive peptide hormone and glyoxylate (see Scheme 6). The monooxygenase domain has been extensively studied, while the lyase portion has received relatively little attention on the mode of catalysis. ${ }^{11,62}$

Structural and functional investigations into the role of metals in bifunctional rat PAM enzyme has been carried out by Merkler et. al, where these researchers sought to understand the importance of metals in the PAL domain of the enzyme. ${ }^{43,61,62,64,65}$ Treating the enzyme with ethylenediaminetetraacetic acid (EDTA) showed that catalytic ability of the enzyme was indeed inhibited. ${ }^{62}$ Researchers were able to restore the enzyme's activity by treating the metal deficient enzyme with divalent metals. Copper(II) restored the monooxygenase domains' activity (PHM), while cadmium, cobalt(II), manganese(II), and zinc restored the lyases' activity (PAL) ${ }^{62}$ Part of their rational was that the zinc metal could be acting as a lewis base by binding water or hydroxide anions, thus assisting in the deprotonation step of the breakdown (Scheme 7) ${ }^{66}$ 
Initially, the fact that the metal-ion was critical for catalysis was surprising as it had been thought that the metal-ion was not required for catalytic activity. ${ }^{62}$

Scheme 6: PAM Mediated Breakdown into Bioactive Peptide Hormone and Glyoxylate.

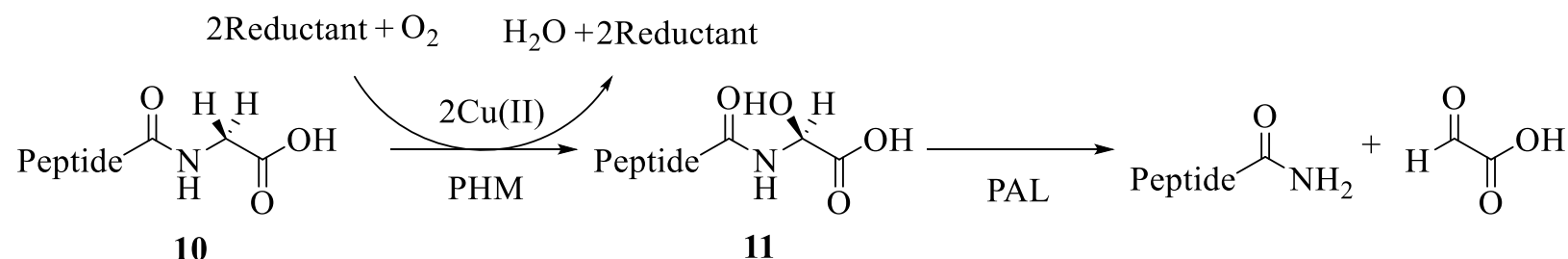

Scheme 7: Possible Role of Zinc Mediated Deprotonation.

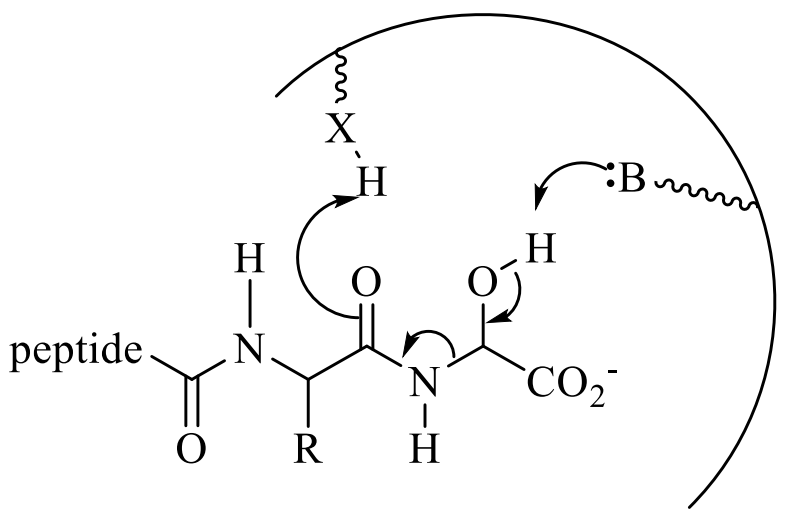

\section{Previous Mechanistic Studies}

A flaw in the studies involving PAL rested in the lack of understanding as to the operational mechanism of the lyase enzyme that was being utilized. This is a common problem and what is being probed in such studies and, thus, an observation. However, coupled to this fact was the confusion as to the exact mechanism by which the carbinolamide intermediates are themselves reacting. As a result, the speculated roles of the metal-ions coupled with a general lack of understanding of the mechanisms by which carbinolamides decompose has led to further 
confusion. Prior to the carbinolamide studies originating from this group, much of what was known about the mechanisms of carbinolamide reactions in water was developed by Bundgaard et al. ${ }^{46-50}$ Bundgaard and coworkers were interested in carbinolamides as potential pro-drug candidates and were studying their aqueous reactivity as a model for biological systems. ${ }^{46-50}$ The idea surrounding the concept of pro-drugs was to find a functionality that was both stable and unstable in terms of pro-drug delivery and efficacy, where the drug is stable before administration, but can undergo a chemical transformation to generate its active form, when introduced into the biological system. These studies utilized numerous carbinolamides (see Figure 1), with structural variation occurring on both amide and aldehyde sides of the structure, hoping to develop a drug delivery system. ${ }^{46-50}$ Several strategies were utilized with $N$ hydroxymethylation being one of the earlier attempts. ${ }^{46-50}$

Figure 1: Various $N$-(Hydroxyalkyl) Carbinolamides Used in Bundgaard Studies.<smiles>O=C(NCO)c1ccccc1</smiles>

$N$-(Hydroxymethyl)benzamide<smiles>O=C(NC(O)c1ccccc1)c1ccccc1</smiles>

$N$-(Hydroxybenzyl)benzamide<smiles>O=C(NC(O)C(Cl)(Cl)Cl)c1ccccc1</smiles>

$N$-(Hydroxy-2,2,2-trichloroethyl)benzamide<smiles>OCNC(=S)c1ccccc1</smiles>

$N$-(Hydroxymethyl)thiobenzamide<smiles>CC(O)NC(=S)c1ccccc1</smiles>

$N$-(Hydroxyethyl)thiobenzamide<smiles>OC(NC(=S)c1ccccc1)C(Cl)(Cl)Cl</smiles>

$N$-(Hydroxy-2,2,2-trichloroethyl)thiobenzamide 
Another set of compounds that Bundgaard et al. studied was the glyoxylic acid derivatives (see Figure 2) of a variety of amides. They found these compounds to be more reactive than the structurally analogous $N$-(hydroxymethyl)amide derivatives, with half-lives ranging from 22 minutes to 6.7 hours as compared to the 160 hours of $N$-(hydroxymethyl)amide at $\mathrm{pH} 7.4$ and $37^{\circ} \mathrm{C} .{ }^{47}$ The kinetic studies of the glyoxylic acid derivatives were performed over a $\mathrm{p} H$ range of 2 to 13 , wherein a $\mathrm{pH}$ rate profile was produced. ${ }^{47}$ Upon closer inspection of the Bundgaard $\mathrm{pH}$ rate profile, it was evident that under acidic and basic conditions that all the compounds underwent both acid and hydroxide dependent reactions, even if it was not noted for all compounds studied. ${ }^{47}$ Another unique observation for $\mathbf{2}$ was the broad $\mathrm{pH}$ independent reaction which has been deemed the water reaction. ${ }^{46-50}$ While problems with the nonsystematic nature of the Bundgaard studies and gaps in the $\mathrm{pH}$ ranges, where the compounds were studied, it was from these studies that the accepted mechanisms for the aqueous reaction of carbinolamides were developed (see Schemes 8 \& 9). ${ }^{46-50}$ 
Figure 2: Various $N$ - $\alpha$-(Hydroxyalkyl)benzamides Derived from Glyoxlic Acid, Esters, and Amides Used in Bundgaard Studies.<smiles>O=C(NC(O)C(=O)O)c1ccccc1</smiles>

a-Hydroxyhippuric acid (2)<smiles>O=C(NC(O)C(=O)OCc1ccccc1)c1ccccc1</smiles>

$\alpha$-Hydroxy- $N$-benzyolglycine benzylester<smiles>CCCNC(=O)C(O)NC(=O)c1ccccc1</smiles>

$\alpha$-Hydroxy- $N$-benzyolglycine propylamine<smiles>COC(=O)C(O)NC(=O)c1ccccc1</smiles>

$\alpha$-Hydroxy- $N$-benzyolglycine methylester<smiles>CCOC(=O)COC(=O)C(O)NC(=O)c1ccccc1</smiles>

$\alpha$-Hydroxy- $N$-benzyolglycine ethyl acetate ester<smiles>O=C(NC(O)C(=O)NCc1ccccc1)c1ccccc1</smiles>

$\alpha$-Hydroxy- $N$-benzyolglycine benzylamine

As stated above, the Bundgaard studies established the fundamental mechanisms by which carbinolamides undergo reaction under aqueous conditions. Shown in Scheme 8 is the accepted mechanism for the hydroxide dependent breakdown of carbinolamides. ${ }^{46-50}$ The reaction occurs via a specific-base catalyzed deprotonation of the carbinolamide hydroxyl group to produce the conjugate base (12) of the starting material. Intermediate $\mathbf{1 2}$ then undergoes rate determining breakdown, generating the aldehyde product and an amidate leaving group (13). Finally, $\mathbf{1 3}$ obtains a proton from water, forming the $\alpha$-amidated product, if this were the enzyme-catalyzed reaction. The mechanism was supported by several observations that will be more fully discussed below. 
Scheme 8: Accepted Mechanism for the Hydroxide-Dependent Breakdown of Carbinolamides.

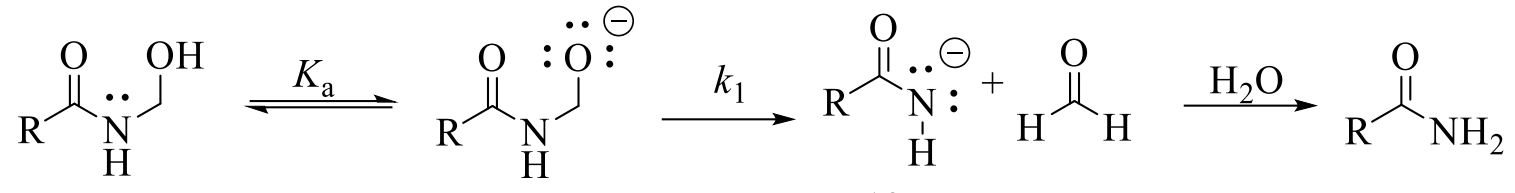

Shown in Scheme 9 is the proposed acid-dependent aqueous reaction of carbinolamides. ${ }^{46-50}$ The first step involves the specific-acid protonation of the carbonyl oxygen to produce the resonance stabilized intermediate (14). Following protonation, 14 undergoes ratelimiting breakdown to yield the tautomer of the amide and the protonated aldehyde that would subsequently lose a proton. These conclusions were based upon the observed rates for a variety of carbinolamide moieties and a lack of buffer catalysis in these same studies. ${ }^{46-50}$ In fact, Bundgaard and coworkers did not expend a great deal of time and effort in studying the aciddependent mechanism as it was generally much slower than the hydroxide-dependent reaction and was not dominant on the $\mathrm{p} H$-rate profile. ${ }^{46-50}$

Scheme 9: Specific-Acid Catalyzed Mechanism.

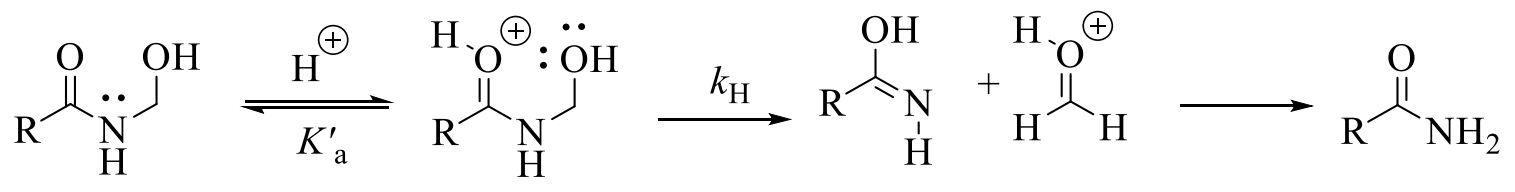


More recently, our research group has continued and expanded upon some of the preliminary work performed by Bundgaard et al. ${ }^{46-50}$ Shown in Figure 3 is the $\mathrm{pH}$-rate profile for three $N$-(hydroxymethyl)benzamide derivatives over the entire $\mathrm{p} H$ range. ${ }^{7}$ From Figure 3 , it is clear that there are four distinct regions to the $\mathrm{pH}$-rate profile. There is an acid-catalyzed region, hydroxide-catalyzed, hydroxide independent and a water-catalyzed reaction at $\sim \mathrm{pH} 4$. Studies of this type have been completed for $N$-(hydroxymethyl)benzamide derivatives, ${ }^{7,8}$ and $N$ (hydroxybenzyl)benzamide derivatives with substituents on both the aldehyde ${ }^{67}$ and amide portion of the structure. ${ }^{3}$ For all of these studies, the $\mathrm{pH}$-rate profiles have appeared to be similar to those shown in Figure 3.

Figure 3: The $\mathrm{p} H$ rate profile for the aqueous decomposition of $N$-(hydroxymethyl)benzamide ( $\mathbf{\nabla})$, 4chloro- $N$-(hydroxymethyl)benzamide $(\bullet)$, and 2,4-dichloro- $N$-(hydroxymethyl)benzamide $(\bullet)$ in $\mathrm{H}_{2} \mathrm{O}, I$ $=1.0 \mathrm{M}(\mathrm{KCl})$, at $25^{\circ} \mathrm{C}{ }^{7}$

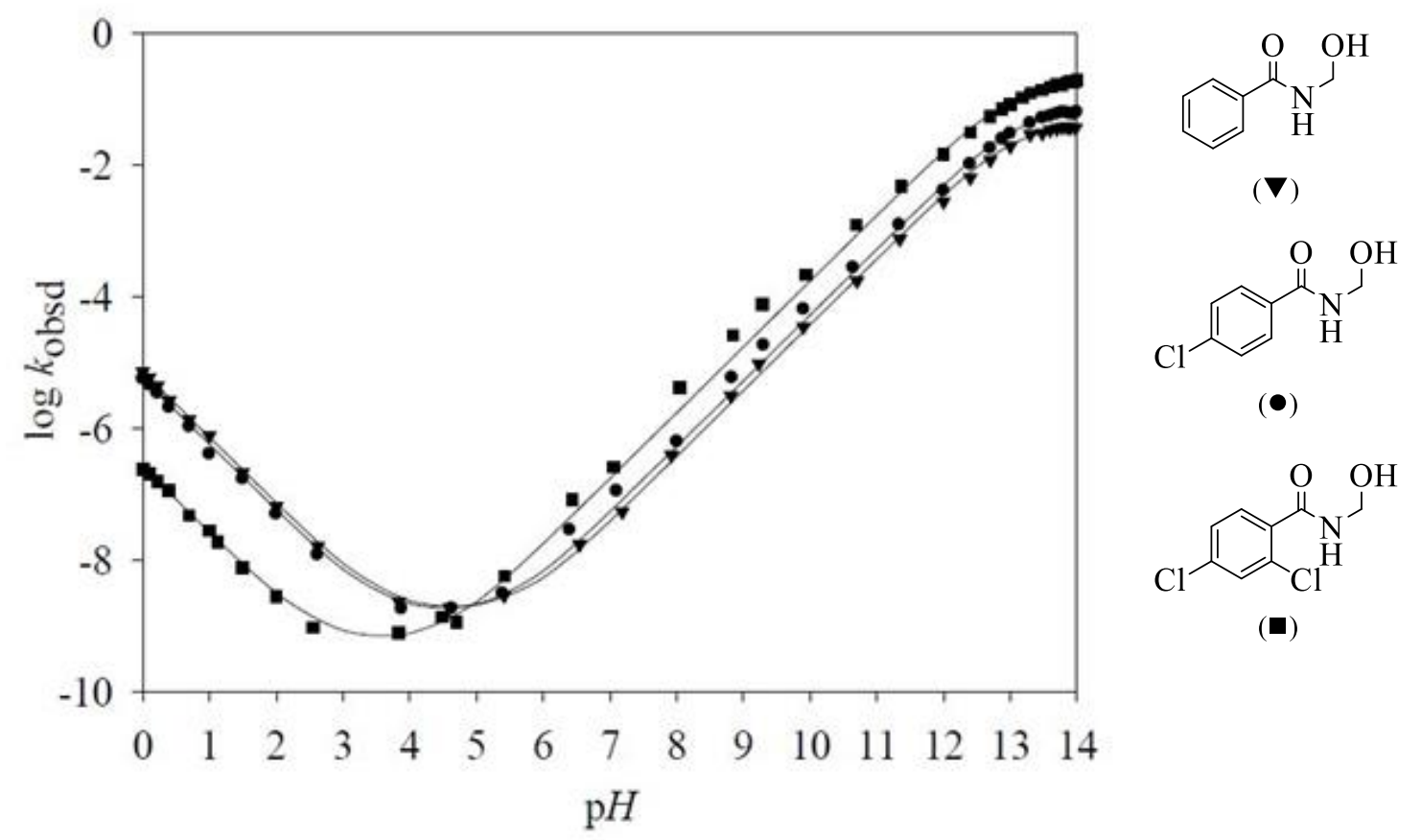


In the hydroxide region, all the compounds studied have shown a change from first-order dependence to zero-order dependence on [hydroxide], which can be seen in Figure 4. The kinetic data in Figure 4 support a specific-base catalyzed reaction (see Schemes $8 \& 10$ ) where there would be an initial deprotonation/ionization of the carbinolamide (15) to form the conjugate base (16). As shown in Scheme 10, this loss of a proton from the hydroxyl group of $\mathbf{1 5}$ is indicated as an ionization constant $\left(K_{\mathrm{a}}\right)$. Once $\mathbf{1 6}$ is formed, it undergoes rate-limiting breakdown $\left(k_{1}\right)$ to form the aldehyde and the resonance stabilized amidate leaving group. The rate expression for the reaction shown in Scheme 10 is shown in equation 1 . Plots of $\left[\mathrm{HO}^{-}\right] v s . k_{\mathrm{obsd}}$ are fit to equation 1 and such fits provide the limiting rate $\left(k_{1}\right)$ and the $K_{\mathrm{a}}$ of the hydroxyl group of the carbinolamide. Further support for the mechanism shown in Scheme 10 was provided by the lack of buffercatalysis for any of the studies performed in the hydroxide region of the $\mathrm{pH}$-rate profile. ${ }^{1-8,46-50}$

Figure 4: Hydroxide independent $\mathrm{p} H$-rate profile of $N$-(hydroxymethyl)benzamide ( $\boldsymbol{\nabla}$ ), 4-chloro- $N$ -

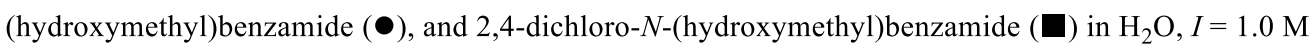
$(\mathrm{KCl})$, at $25^{\circ} \mathrm{C}^{7}$

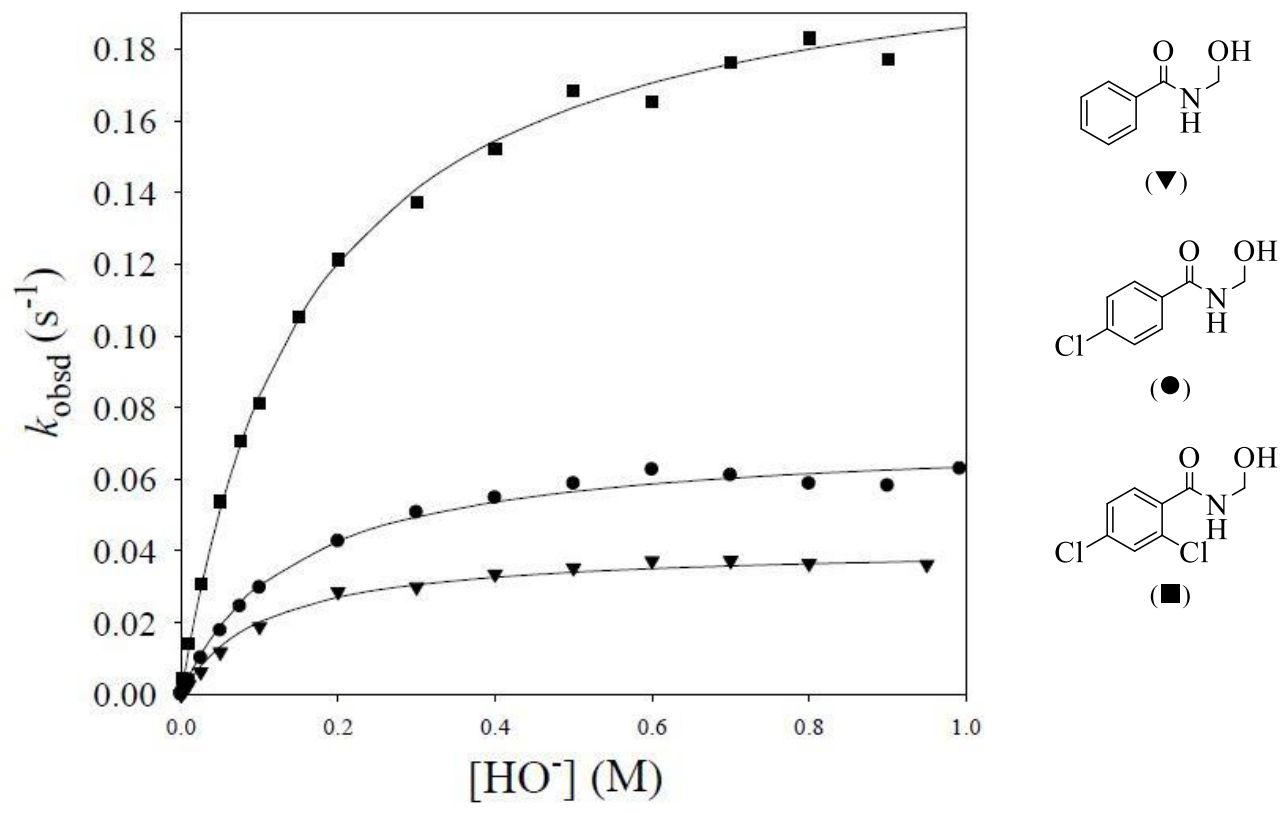


Scheme 10 - Specific-Base Catalyzed Mechanism.

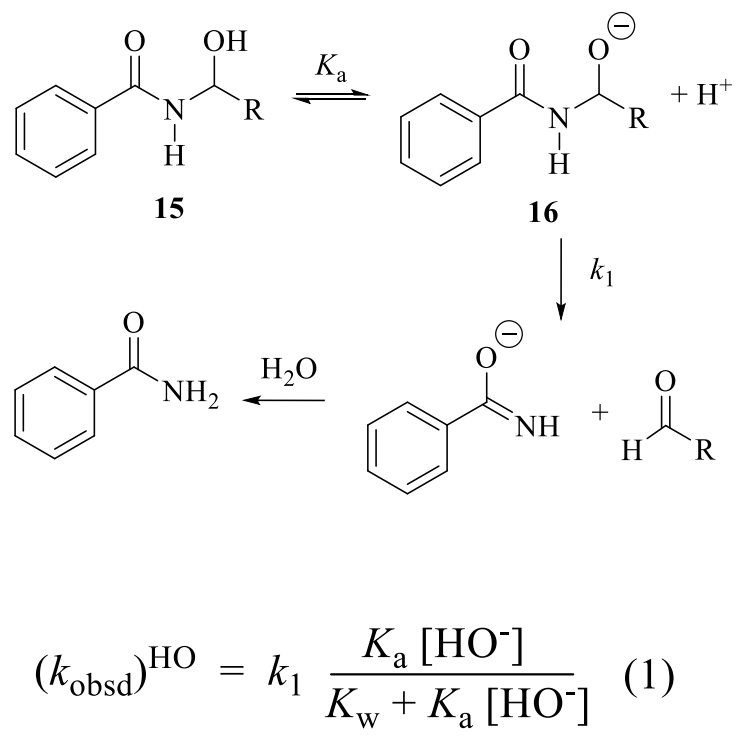

Much of the earlier works, from Bundgaard and coworkers, reported only the linear portion of the [hydroxide] dependence and only the apparent second-order rate constants for the hydroxide reaction were reported (see equation 2 , where $k^{\prime}{ }_{1}=\left(\left(k_{1} K_{\mathrm{a}}\right) / K_{\mathrm{w}}\right)$ and $k^{\prime}{ }_{1}$ is the apparent second-order rate for the hydroxide-catalyzed reaction). ${ }^{46-50}$ While the generation of the apparent second-order rates provide further knowledge of the reactivity of carbinolamides, it is difficult to assess the effects of structural changes to the molecule on the reactivity if the relative effects of such changes on $K_{\mathrm{a}}$ and $k_{1}$ cannot be evaluated. As a result of this observation, the studies performed within the Nagorski group have focused on kinetic testing on as broad a pH-range as possible. ${ }^{1-8}$ Shown in Figure 5 are the $k_{1}$ and $\mathrm{p} K_{\mathrm{a}}$ values for the compounds whose data are plotted in Figure $4 .^{7}$

$$
\left(k_{\mathrm{obsd}}\right)^{\mathrm{HO}}=\frac{k_{1} K_{\mathrm{a}}\left[\mathrm{HO}^{-}\right]}{K_{\mathrm{w}}}
$$


Figure 5: $\mathrm{p} K_{\mathrm{a}}$ and $k_{1}$ values of 4-chloro-, 2,4-dichloro-, and $N$-(hydroxymethyl)benzamide. ${ }^{7}$

17<smiles>O=C(NCO)c1ccccc1</smiles>

18<smiles>O=C(NCO)c1ccc(Cl)cc1</smiles>

19<smiles>O=C(NCO)c1ccc(Cl)cc1Cl</smiles>

$\mathrm{p} K_{\mathrm{a}} \quad k_{1}\left(\mathrm{~s}^{-1}\right)$

$13.05 \quad 0.042$

$13.04 \quad 0.068$

$13.04 \quad 0.19$

Data reported by Tenn et al. in Figure 5 with different substituted amide portions of the carbinolamide show little to no variance in $\mathrm{p} K_{\mathrm{a}}$ values of the hydroxyl group of the carbinolamide. ${ }^{7}$ This result was somewhat unexpected as it is known that substituents in the ortho-position often lead to large changes due to steric and hydrogen bonding possibilities. ${ }^{68}$ It is evident from the data in Figure 5, that the greatest effect of the substituents on the amidic portion of the carbinolamide was in the departure of the benzamidate leaving group with very little effect of the substituents on the acidity of the hydroxyl group. These observations were further supported by other $N$-(hydroxymethyl)benzamide derivatives studied. ${ }^{8}$ Marginally larger substituent effects on the $\mathrm{p} K_{\mathrm{a}}$ of the hydroxyl group of the carbinolamide were noted with the $N$ (hydroxybenzyl)benzamide derivatives with similar, in magnitude, effects on $k_{1} \cdot{ }^{3}$ However, as noted earlier, all current available data support a specific-base catalyzed reaction of the type shown in Scheme 10.

Due to rather narrow range of the $\mathrm{pH}$-rate profile where the acid-catalyzed reaction dominates, it has not received as much attention as the hydroxide catalyzed mechanism. The 
studies by Bundgaard and associates that led to the proposed specific-acid catalyzed mechanism was largely based upon the observation of no buffer catalysis for the reaction of carbinolamides under acidic conditions (see Scheme 9). ${ }^{46-50}$

More recent studies by the Nagorski group ${ }^{3,4,8}$ have shown that the acid-catalyzed reaction of $N$-(hydroxymethyl)benzamide derivatives and $N$-(hydroxybenzyl)benzamide do not react via a specific acid catalyzed mechanism, as proposed by Bundgaard et al. ${ }^{46-50}$ Buffer catalysis has been noted with all carbinolamide derivatives where buffer-catalysis studies in acidcatalyzed region have been performed. ${ }^{3,4,8}$ The involvement of buffer in the rate of the reaction indicates that the rate determining step of the acid-catalyzed reaction involves proton transfer which would not occur if the mechanism of the reaction was as shown in Scheme 9.

With the knowledge that the acid-catalyzed reaction requires proton transfer in the ratelimiting step, two kinetically equivalent mechanisms could be proposed..$^{3,4}$ Shown in Scheme 11 is a proposed general-acid catalyzed mechanism, where proton transfer, from an acid in solution, to the amide portion of the carbinolamide occurs as the carbinolamide decomposes into the amide and the protonated aldehyde. The kinetic expression is represented in equation 3 . The proton transfer is shown to add the proton to the amidic nitrogen in Scheme 11, however it is not possible to indicate exactly which position would be protonated. It is possible that the proton might be added to the lone pair electrons of nitrogen or could be added to the carbonyl oxygen to generate the tautomer of the amide. This argument aside, a reaction of the type shown in Scheme 11 would lead to every proton source in solution being capable of catalyzing the reaction. 
Scheme 11: General Acid Catalyzed Mechanism.

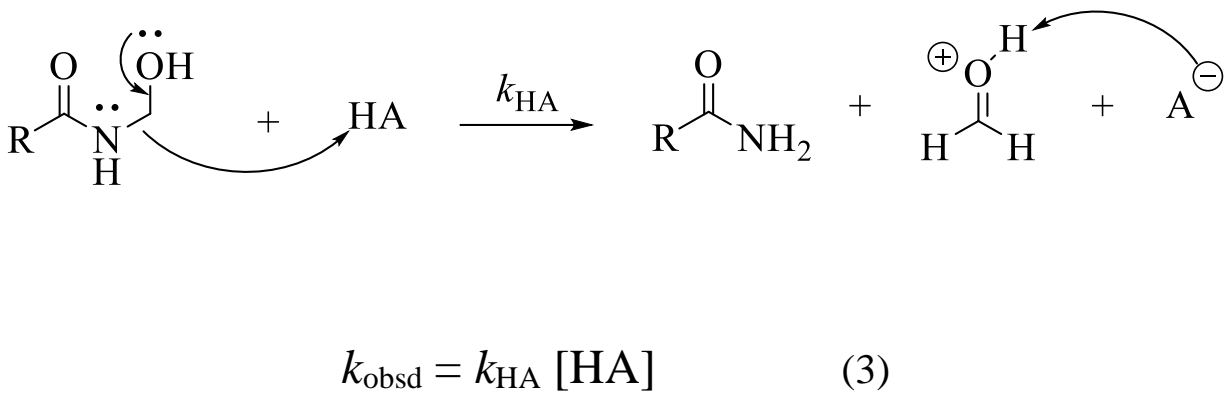

The second proposed mechanism, for the acid-catalyzed reaction of carbinolamides, is a specific-acid followed by general-base catalyzed mechanism (see Scheme 12). The first step is similar to the specific-acid catalyzed mechanism (see Scheme 9), proposed by Bundgaard and associates, ${ }^{46-50}$ and has equilibrium protonation of the amide carbonyl oxygen to generate intermediate 20. It is the breakdown of $\mathbf{2 0}$ that is the rate-determining step, which once again looks similar to mechanism illustrated in Scheme 9. Unlike the mechanism shown in Scheme 9, where the protonated species undergoes uncatalyzed breakdown, the rate-determining step of the reaction shown in Scheme 12 requires general base-catalyzed deprotonation of the hydroxyl group of the carbinolamide as the amide leaving group departs. The kinetic expression for this mechanism is shown in equation 4. The two mechanisms shown in Schemes $11 \& 12$ are kinetically identical and kinetics alone cannot provide an answer as to which mechanism is operationally correct. 
Scheme 12: Specific-Acid followed by General-Base Catalyzed Mechanism.

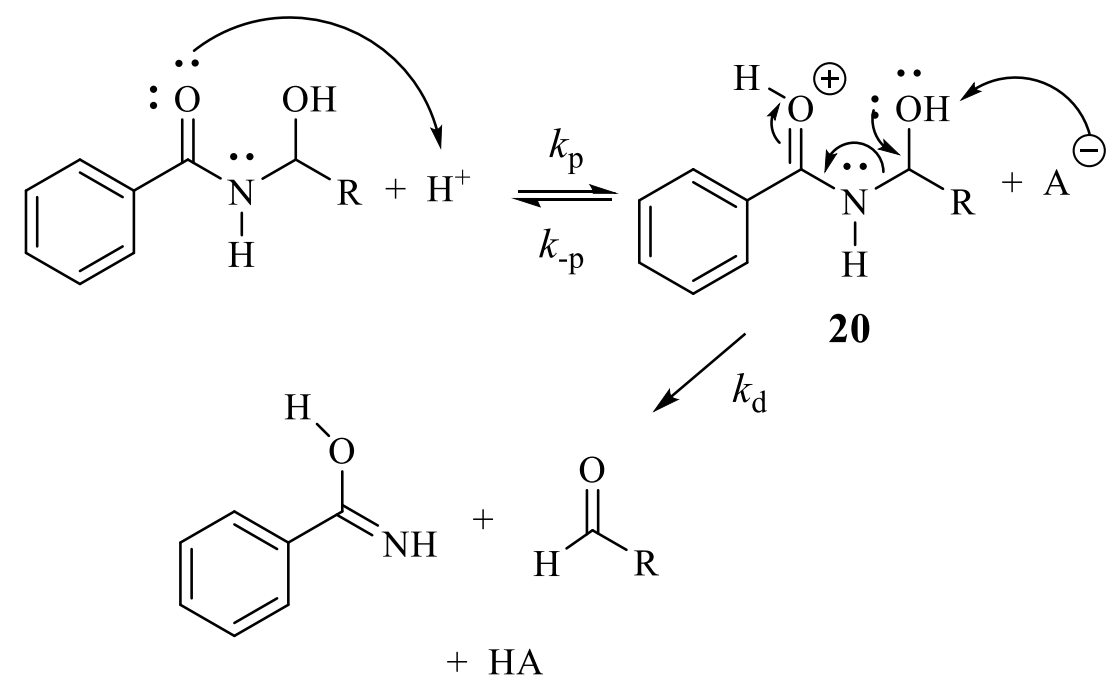

$$
\left(k_{\text {obsd }}\right)^{\mathrm{H}}=\frac{k_{\mathrm{p}} k_{\mathrm{d}}\left[\mathrm{H}^{+}\right]\left[\mathrm{A}^{-}\right]}{k_{-\mathrm{p}}+k_{\mathrm{d}}\left[\mathrm{A}^{-}\right]}=\frac{k_{\mathrm{p}} k_{\mathrm{d}} K_{\mathrm{a}}^{\mathrm{HA}}[\mathrm{HA}]}{k_{-\mathrm{p}}}
$$

Of the two acid-catalyzed mechanisms, the mechanism shown in Scheme 12 would be a more appealing route as enzymes are often very effective at catalyzing proton transfer reactions. Conversely, the mechanism shown in Scheme 11, would require that the enzyme somehow catalyze the departure of the amidic leaving group. However, once again the question of which mechanism the PAL enzyme uses to catalyze the breakdown of the carbinolamide must be broached.

Looking at Figure 4, or any of the $\mathrm{pH}$-rate profiles that have been published, shows that the hydroxide-dependent reaction dominates 60 to $70 \%$ of the $\mathrm{pH}$ range. ${ }^{1-8,46-50}$ From an evolutionary perspective, it makes more sense that an organism would choose to evolve an enzyme that utilizes the lowest energy pathway at biological $\mathrm{p} H$ so as to realize an immediate 
rate enhancement of the reaction of interest. While this starts an interesting philosophical discussion, it really does not answer any questions concerning how PAL catalyzes the breakdown of carbinolamides. In addition, the compounds undergoing catalysis via the enzymatic reaction have more complexity than the molecules just discussed. The primary difference between the compounds discussed and the substrate for PAL is the presence of the carboxylate group (see Scheme 6). The question that then occurs is: does the presence of the carboxylate group alter the reaction of the carbinolamide functionality?

This question was probed previously within the Nagorski group by Kati Feken who studied a series of $\alpha$-hydroxyhippuric acid derivatives (2). ${ }^{69}$ Unfortunately, Feken's study was hindered by problems synthesizing derivatives of 2 bearing electron-withdrawing groups. ${ }^{69}$ This aside, it was found that the hydroxide-dependent reaction did occur via a specific-base catalyzed reaction and, as shown by Bundgaard and coworkers, there was a large water-catalyzed region. Feken did conclusively show that there was also an acid-catalyzed region between $\mathrm{p} H 0$ and $2 .{ }^{69}$ This result was interesting as it had not been noted in the Bundgaard study of $\mathbf{2}$ that such a mechanism was operational. ${ }^{47}$ However, the result also illustrated how unlikely it was that an enzyme would be evolved to catalyze the acid-catalyzed mechanism.

Feken's results provided much of what we know about the reactivity of the $\alpha$ hydroxyhippuric acid derivatives but as we had seen substituent dependent changes in mechanisms of reaction with other carbinolamide derivatives, ${ }^{5}$ it became important to synthesize and study these compounds. Presented herein are the syntheses and kinetic investigation of a series of $\alpha$-hydroxyhippuric acid derivatives (2) bearing electron-withdrawing groups. 


\section{CHAPTER II: SYNTHESIS OF $\alpha$-HYDROXYHIPPURIC ACID DERIVATIVES}

\section{Introduction}

As stated in the introduction, carbinolamides are intermediates in a variety of processes, ${ }^{9,10,12-15}$ possess interesting pharmaceutical properties, ${ }^{17-21,23-31,70}$ but, more specifically, carbinolamides are generated as intermediates in the formation of peptide hormones by peptidylglycine- $\alpha$-amidating monooxygenase (PAM, ED 1.14.17.3). ${ }^{9,11,16}$ While the lyase portion of the enzyme has not been as thoroughly studied as the oxidative portion of the enzyme, studies have been performed, however these studies have all suffered from the same fundamental problem. ${ }^{35,61,62,64,65,71}$ This problem was a lack of understanding of the intrinsic reactivity of carbinolamides themselves. The purpose of synthesizing $\alpha$-hydroxyhippuric acid derivatives (2) was to study another class of carbinolamides but also a set of compounds that have been shown to be substrate for the lyase portion of PAM. ${ }^{61}$ The aqueous kinetic study of these compounds will provide mechanistic information concerning the aqueous reactivity of these compounds which, in turn, may further elucidate the means of catalysis utilized by the lyase or provide evidence for the type of catalysis necessary for the reaction to be facilitated. The series of compounds proposed will have primarily electron-withdrawing groups attached to the aromatic ring and the effects of these groups on the aqueous reaction of the compounds, as a function of $\mathrm{pH}$, will be studied.<smiles>[X]c1ccc(C(=O)NC(O)C(=O)O)cc1</smiles> 
As discussed earlier, PAM takes the glycine extended peptide precursor and oxidizes the methylene unit of glycine, adding a hydroxy group and creating the carbinolamide (see Scheme 6). ${ }^{1,22,23}$ The carbinolamide intermediate would then be released and enter the catalytic site of the lyase portion of this bifunctional enzyme. ${ }^{1,22,23}$ The lyase subunit then catalyzed the breakdown of the carbinolamide into the glyoxylate and the $\alpha$-amidated peptide. ${ }^{61}$ It is this portion of the enzymatic studies that is the problem. The studies often assume that deprotonation of the hydroxyl group is rate-limiting and there have been no comprehensive studies to probe this flawed assumption. ${ }^{4,7,8,46-50,72}$ As discussed in the introduction, the rate-determining step of the hydroxide dependent reaction of carbinolamides is the breakdown of the conjugate base of the carbinolamide (see Scheme 10), ${ }^{4,7,846-50,72}$ This is not too unbelievable, as it would not be expected that the amidate would be a very good leaving group..$^{3,7,8}$ The study of these compounds should provide further support for the fundamental aqueous mechanism that the enzyme must catalyze. The investigation of $\alpha$-hydroxyhippuric acid and its derivatives will be performed as a function of $\mathrm{pH}$ in the presence of buffers. Derivatization with electron withdrawing groups should provide an understanding of the type of charge being generated in the transition state of the rate-determining step of the reaction.

Scheme 13: Synthetic Scheme for the Synthesis of $\alpha$-Hydroxyhippuric Acid Derivatives.<smiles>[X]c1ccc(C(=O)O)cc1</smiles>

21<smiles>[X]c1ccc(C(N)=O)cc1</smiles>

22<smiles>[X]c1ccc(C(=O)NC(O)C(=O)O)cc1</smiles>

2 
Shown in the Scheme 13 is the synthetic plan for the generation of the $\alpha$-hydroxyhippuric acid derivatives. When the amide precursors were not easily commercially available, the synthesis would start with the benzoic acid derivative. The benzoic acid derivative starting material would be converted into the amide derivative by the intermediacy of the acyl chloride. The amide would then be reacted with glyoxylic acid to generate the $\alpha$-hydroxy hippuric acid derivative (Scheme 13).

\section{Experimental}

\section{Material}

All melting points reported were obtained using a Digimelt apparatus and are uncorrected. The ${ }^{1} \mathrm{H}$ and ${ }^{13} \mathrm{C}-\mathrm{NMR}$ spectra reported were obtained by dissolving the compound in deuterated DMSO (2.50 ppm) at $25^{\circ} \mathrm{C}$ using a 400 or $500 \mathrm{MHz}$ NMR spectrometer. All the chemicals used in the syntheses below and for assessment were commercial reagent grade materials and used without any further purification unless stated otherwise.

\section{Synthesis}

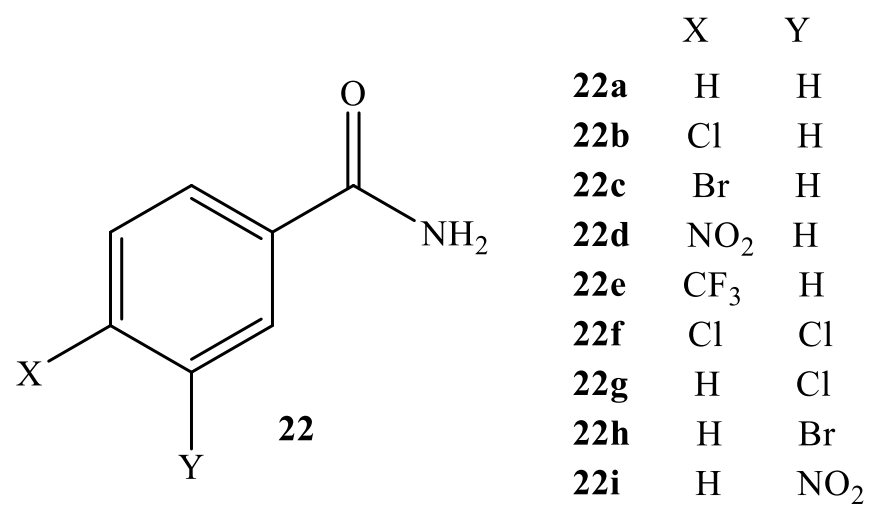




\section{Benzamide Derivatives}

The benzamide derivatives were all synthesized using the same general method. ${ }^{73}$ The experiment was scaled down version from the procedure outlined in Vogel's textbook of practical organic chemistry. ${ }^{73}$ Equimolar amounts of the benzoic acid derivative $(\mathbf{2 1})(\sim 10 \mathrm{~g}$, $\sim 0.060$ moles), and phosphorous pentachloride $\left(\mathrm{PCl}_{5}, 14 \mathrm{~g}, 0.060\right.$ moles) were added to a round bottom flask $(\mathrm{RBF})$. The contents of the RBF were heated gently in a warm water bath until the reaction commenced. As soon as the reaction was under way (evident by the formation of liquid and the evolution of gas), the RBF was attached to a condenser with a base trap. The formation of the acid chloride was allowed to proceed for thirty minutes, with heating toward the end of this time, to ensure complete reaction of the starting materials. In addition to the desired acid chloride, phosphoryl chloride $\left(\mathrm{POCl}_{3}\right)$, and hydrochloric acid $(\mathrm{HCl})$ gas were byproducts of this reaction. In order to purify the acid chloride, a vacuum distillation was required to remove the $\mathrm{POCl}_{3}$, leaving behind the desired acid chloride. Following the distillation, the acid chloride was reacted with two equivalents $(0.12$ moles $)$ of ammonium hydroxide. The ammonium hydroxide was administered dropwise to form the desired benzamide derivative, however, it was found in some cases that the ammonium hydroxide needed to be added more quickly to prevent reaction of the acyl chloride with the added water. Purification of the crude benzamide derivatives was performed via hot filtration in methanol. After purification, ${ }^{1} \mathrm{H} \&{ }^{13} \mathrm{C}-\mathrm{NMR}$, and melting points of the products were performed. 


\section{Benzamide (22a)}

The experimental melting point range was observed to be $124.0-127.0{ }^{\circ} \mathrm{C}$ (lit. mpt. 128 $\left.{ }^{\circ} \mathrm{C}\right) .{ }^{74} \mathrm{H}-\mathrm{NMR} 500 \mathrm{MHz}\left(\mathrm{DMSO}-d_{6}\right): \delta 7.34(1 \mathrm{H}, \mathrm{bs}), 7.45(2 \mathrm{H}, \mathrm{t}), 7.52(1 \mathrm{H}, \mathrm{t}), 7.88(1 \mathrm{H}, \mathrm{d})$, $7.95(1 \mathrm{H}, \mathrm{bs})$.

\section{4-Chlorobenzamide (22b)}

4-Chlorobenzamide was synthesized according to the general procedure detailed above. A $10.014 \mathrm{~g}$ (0.0640 moles) of 4-chlorobenzoic acid, was reacted with $13.307 \mathrm{~g}$ (0.0658 moles) of $\mathrm{PCl}_{5}$, followed by the addition of $\mathrm{NH}_{4} \mathrm{OH}$, yielding $7.533 \mathrm{~g}$ of product after isolation and purification $(75.75 \%$ yield). The experimental melting point range was observed to be 178.0 $180.0{ }^{\circ} \mathrm{C}$ (lit. mpt. $\left.178-180{ }^{\circ} \mathrm{C}\right) .{ }^{75}{ }^{1} \mathrm{H}-\mathrm{NMR} 500 \mathrm{MHz}$ (DMSO-d $): \delta 7.44$ (1H, bs), 7.53 (2H, d), $7.89(2 \mathrm{H}, \mathrm{d}), 8.03(1 \mathrm{H}, \mathrm{bs})$.

\section{4-Bromobenzamide (22c)}

4-Bromobenzamide was provided by a previous group member (KLB). The melting point was found to be $182-183{ }^{\circ} \mathrm{C}$ (lit. mpt. $\left.185-187{ }^{\circ} \mathrm{C}\right) .{ }^{76} \mathrm{H}-\mathrm{NMR} 500 \mathrm{MHz}$ (DMSO-d $)$; $\delta 8.3(2 \mathrm{H}$, d), $8.25(1 \mathrm{H}, \mathrm{bs}), 8.1(2 \mathrm{H}, \mathrm{d}), 7.7(1 \mathrm{H}, \mathrm{bs})$.

\section{4-Nitrobenzamide (22d)}

4-Nitrobenzamide was synthesized according to the general procedure detailed above. A $7.053 \mathrm{~g}$ (0.0422 moles) of 4-nitrobenzoic acid, was reacted with $9.045 \mathrm{~g}$ (0.0434 moles) of $\mathrm{PCl}_{5}$, followed by the addition to $2 \mathrm{eq}$. $\mathrm{NH}_{4} \mathrm{OH}$, yielding $3.11 \mathrm{~g}$ of product after isolation and purification (44.35\% yield). The experimental melting point range was observed to be 198.0- 
$199.0{ }^{\circ} \mathrm{C}$ (lit. mpt. $\left.198-200{ }^{\circ} \mathrm{C}\right) .{ }^{75,77}{ }^{1} \mathrm{H}-\mathrm{NMR} 500 \mathrm{MHz}$ (DMSO- $\left.d_{6}\right): \delta 7.70(1 \mathrm{H}, \mathrm{bs}), 8.10(2 \mathrm{H}$, d), $8.27(1 \mathrm{H}, \mathrm{bs}), 8.30(2 \mathrm{H}, \mathrm{d})$.

\section{4-(Trifluoromethyl)benzamide (22e)}

This material was obtained from commercial sources and had an experimental melting point range was determined to be $182.0-183.0{ }^{\circ} \mathrm{C}$ (lit. mpt. $182-183{ }^{\circ} \mathrm{C}$ ) ${ }^{75}{ }^{1} \mathrm{H}-\mathrm{NMR} 500 \mathrm{MHz}$ (DMSO-d 6$): \delta 7.60$ (1H, bs), 7.84 (2H, d). 8.07 (2H, d), 8.18 (1H, bs).

\section{3,4-Dichlorobenzamide (22f)}

3,4-Dichlorobenzamide was provided by a previous group member (KLB). The experimental melting point range was determined to be $138-139{ }^{\circ} \mathrm{C}$ (lit. mpt. $138-140{ }^{\circ} \mathrm{C}$ ) ${ }^{76}{ }^{1} \mathrm{H}-$ NMR $500 \mathrm{MHz}\left(\mathrm{DMSO}-d_{6}\right)$; d $7.58(1 \mathrm{H}, \mathrm{bs}), 7.78(1 \mathrm{H}, \mathrm{d}), 7.89(1 \mathrm{H}, \mathrm{d}), 8.10(1 \mathrm{H}, \mathrm{s}), 8.14(1 \mathrm{H}$, bs).

\section{3-Chlorobenzamide (22g)}

3-Chlorobenzamide was provided by a previous group member (KLB). The experimental melting point range was observed to be $123.0-125.0{ }^{\circ} \mathrm{C}$ (lit. mpt. $125-127{ }^{\circ} \mathrm{C}$ ) ${ }^{78}{ }^{1} \mathrm{H}-\mathrm{NMR} 500$ MHz (DMSO- $\left.d_{6}\right): \delta 7.50(1 \mathrm{H}, \mathrm{t}), 7.51(1 \mathrm{H}, \mathrm{bs}), 7.60(1 \mathrm{H}, \mathrm{d}), 7.84(1 \mathrm{H}, \mathrm{d}), 7.91(1 \mathrm{H}, \mathrm{s}), 8.08$ $(1 \mathrm{H}, \mathrm{bs})$.

\section{3-Bromobenzamide (22h)}

3-Bromobenzamide was provided by a pervious group member (EAG). The experimental melting point range was observed to be $149.5-152.2{ }^{\circ} \mathrm{C}$ (lit. mpt., $153-155{ }^{\circ} \mathrm{C}$ ) $.{ }^{79} \mathrm{H}-\mathrm{NMR} 500$ 
MHz (DMSO- $\left.d_{6}\right): \delta 7.43(1 \mathrm{H}, \mathrm{t}), 7.49(1 \mathrm{H}, \mathrm{bs}), 7.73(1 \mathrm{H}, \mathrm{d}), 7.88(1 \mathrm{H}, \mathrm{d}), 8.05(1 \mathrm{H}, \mathrm{s}), 8.07$

$(1 \mathrm{H}, \mathrm{bs})$.

3-Nitrobenzamide (22i)

3-Nitrobenzamide was provided by a previous group member (EAG). The experimental melting point range was observed to be $141-142{ }^{\circ} \mathrm{C}$ (lit. mpt., $138-140{ }^{\circ} \mathrm{C}$ ) ${ }^{79}{ }^{1} \mathrm{H}-\mathrm{NMR} 400 \mathrm{MHz}$ (DMSO- $\left.d_{6}\right): \delta 7.65(1 \mathrm{H}, \mathrm{s}), 7.75(1 \mathrm{H}, \mathrm{t}), 8.25-8.40(3 \mathrm{H}, \mathrm{m}), 8.65(1 \mathrm{H}, \mathrm{s})$.

\section{$\alpha$-Hydroxyhippuric Acid Derivatives.}

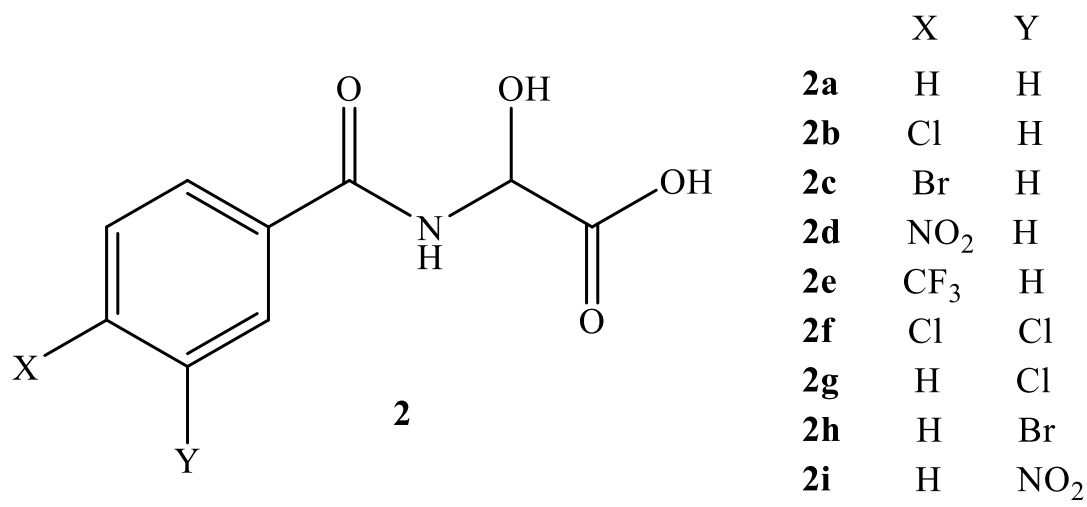

\section{a-Hydroxyhippuric Acid (2a)}

The synthesis of $\alpha$-hydroxyhippuric acid was accomplished by dissolving $2.011 \mathrm{~g}(0.0166$ mol) of benzamide in $30 \mathrm{~mL}$ of reagent grade acetone with $1.534 \mathrm{~g}(0.0166 \mathrm{~mol})$ of glyoxylic acid monohydrate in a round bottom flask. ${ }^{47}$ The round bottom flask was connected to a heating mantle and heated to reflux for 24 hours. ${ }^{47}$ Recrystallization of the $\alpha$-hydroxyhippuric acid can be performed by dissolving the acid in warm reagent grade ethyl acetate, cooling to room temperature, and then adding a nonpolar solvent to alter the polarity of the mixture allowing the acid to precipitate out of solution. The most effective nonpolar solvent for this recrystallization 
process was found to be hexanes. After recrystallization, filtration, and drying for 24 hours, under vacuum, the product was collected yielding $0.859 \mathrm{~g}(0.0044 \mathrm{~mol} 26.5 \%)$. The melting point was found to be $212-214{ }^{\circ} \mathrm{C}$ (lit. mpt. $208-213{ }^{\circ} \mathrm{C}$ ) ${ }^{80}{ }^{1} \mathrm{H}-\mathrm{NMR} 500 \mathrm{MHz}$ (DMSO- $d_{6}$ ): $\delta$ $5.61(1 \mathrm{H}, \mathrm{d}), 6.34(1 \mathrm{H} . \mathrm{bs}), 7.48(2 \mathrm{H}, \mathrm{t}), 7.56(1 \mathrm{H}, \mathrm{t}), 7.91(2 \mathrm{H}, \mathrm{d}), 9.21(1 \mathrm{H}, \mathrm{d}), 12.70(1 \mathrm{H} . \mathrm{bs})$. ${ }^{13} \mathrm{C}-\mathrm{NMR} 125 \mathrm{MHz}$ (DMSO- $\left.d_{6}\right): \delta 72.17,127.96,128.77,132.07,134.13,166.45,171.88$. HRMS (ESI-TOF) m/z: Calcd for $\mathrm{C}_{9} \mathrm{H}_{9} \mathrm{NO}_{4} \mathrm{Na}[\mathrm{M}+\mathrm{Na}]^{+} 218.0429$, Found 218.0427.

\section{4-Chloro- $\alpha$-hydroxyhippuric Acid (2b)}

4-Chloro- $\alpha$-hydroxyhippuric acid was synthesized utilizing a similar method to $\alpha$ hydroxyhippuric acid ${ }^{47}$ where $2.019 \mathrm{~g}(0.0129 \mathrm{~mol})$ of 4-chlorobenzamide was reacted with $1.192 \mathrm{~g}(0.0129 \mathrm{~mol})$ of glyoxylic acid monohydrate and were heated at reflux in $10 \mathrm{~mL}$ of reagent grade acetone for 24 hours. After recrystallization from acetone and hexanes, the product was filtered and dried for 24 hours in a desiccator, under vacuum. The dried, recrystallized product weighed $0.573 \mathrm{~g}(0.0025 \mathrm{~mol}, 19.3 \%)$. The melting point range was found to be $234-238$ ${ }^{\circ} \mathrm{C} .{ }^{1} \mathrm{H}-\mathrm{NMR} 500 \mathrm{MHz}$ (DMSO- $\left.d_{6}\right): \delta 7.51(1 \mathrm{H}, \mathrm{d}), 7.42(1 \mathrm{H}, \mathrm{bs}), 7.55(2 \mathrm{H}, \mathrm{d}), 7.92(2 \mathrm{H}, \mathrm{d})$, $9.33(1 \mathrm{H}, \mathrm{d}), 12.73$ (1H, bs). ${ }^{13} \mathrm{C}-\mathrm{NMR} 125 \mathrm{MHz}$ (DMSO- $\left.d_{6}\right): \delta 72.23,128.89,129.94,132.91$, 136.93, 165.46, 171.75. HRMS (ESI-TOF) m/z: Calcd for $\mathrm{C}_{9} \mathrm{H}_{8} \mathrm{ClNO}_{4} \mathrm{Na}[\mathrm{M}+\mathrm{Na}]^{+} 252.0040$, Found 252.0039.

\section{4-Bromo- $\alpha$-hydroxyhippuric Acid (2c)}

4-Bromo- $\alpha$-hydroxyhippuric acid was provided by a previous group member (RJS). The experimental melting point range was found to be $230-231{ }^{\circ} \mathrm{C} .{ }^{1} \mathrm{H}-\mathrm{NMR} 500 \mathrm{MHz}$ (DMSO- $d_{6}$ ): $\delta 5.60(1 \mathrm{H}, \mathrm{d}), 6.41(1 \mathrm{H}, \mathrm{bs}), 7.69(2 \mathrm{H}, \mathrm{d}), 7.85(2 \mathrm{H}, \mathrm{d}), 9.33(1 \mathrm{H}, \mathrm{s}), 12.68(1 \mathrm{H}, \mathrm{bs}) .{ }^{13} \mathrm{C}-\mathrm{NMR}$ 
$125 \mathrm{MHz}$ (DMSO- $\left.d_{6}\right): \delta 72.22,130.12,131.84,133.28,133.89,165.60,171.73$. HRMS (ESI-

TOF) m/z: Calcd for $\mathrm{C}_{9} \mathrm{H}_{8} \mathrm{BrNO}_{4} \mathrm{Na}[\mathrm{M}+\mathrm{Na}]^{+}$295.9534, Found 295.9569.

\section{4-Nitro-a-hydroxyhippuric Acid (2d)}

4-Nitro- $\alpha$-hydroxyhippuric acid was synthesized utilizing acetone as the solvent system and a procedurally similar method to that used for $\alpha$-hydroxyhippuric acid. Using $1.788 \mathrm{~g}$ (0.0108 mol) of 4-nitrobenzamide dissolved in $10 \mathrm{~mL}$ of acetone then $1.025 \mathrm{~g}(0.0111 \mathrm{~mol})$ of glyoxylic acid was added to the mixture. The round bottom flask containing the reactants was heated under reflux for 24 hours. After purification from ethyl acetate and hexanes, the product collected weighed at $1.018 \mathrm{~g}(0.0049 \mathrm{~mol}, 45.4 \%)$. The experimental melting point range was found to be $141-142{ }^{\circ} \mathrm{C} .{ }^{1} \mathrm{H}-\mathrm{NMR} 500 \mathrm{MHz}$ (DMSO- $\left.d_{6}\right): \delta 5.63(1 \mathrm{H}, \mathrm{d}), 6.51(1 \mathrm{H}, \mathrm{bs}), 8.13(2 \mathrm{H}$, d), $8.32(2 \mathrm{H}, \mathrm{d}), 9.61(1 \mathrm{H}, \mathrm{d}), 12.86(1 \mathrm{H}, \mathrm{bs}) .{ }^{13} \mathrm{C}-\mathrm{NMR} 125 \mathrm{MHz}$ (DMSO- $\left.d_{6}\right): \delta 72.35,123.99$, 129.52, 140.49, 149.73, 166.69, 171.55. HRMS (ESI-TOF) m/z: Calcd for $\mathrm{C}_{9} \mathrm{H}_{8} \mathrm{~N}_{2} \mathrm{O}_{6} \mathrm{Na}[\mathrm{M}+$ $\mathrm{Na}]^{+}$263.0280, Found 263.0300.

\section{4-(Trifluoromethyl)-a-hydroxyhippuric Acid (2e)}

4-(Trifluoromethyl)- $\alpha$-hydroxyhippuric acid utilizing a method similar to that used for $\alpha$ hydroxyhippuric acid. In a 50mL round bottom flask, $0.373 \mathrm{~g}(0.00197 \mathrm{~mol})$ of $4-$ (trifluoromethyl)benzamide and $0.183 \mathrm{~g}(0.00199 \mathrm{~mol})$ of glyoxylic acid monohydrate were dissolved in $20 \mathrm{~mL}$ of acetonitrile. This mixture was heated at reflux for 24 hours, then purified via recrystallization, and dried under vacuum for another 24 hours. The final product yield was $0.127 \mathrm{~g}(0.00048 \mathrm{~mol}, 24.5 \%)$. The experimental melting point range was found to be $251-252$ ${ }^{\circ} \mathrm{C} .{ }^{1} \mathrm{H}-\mathrm{NMR} 500 \mathrm{MHz}$ (DMSO- $\left.d_{6}\right): \delta 5.61(1 \mathrm{H}, \mathrm{d}), 6.50(1 \mathrm{H}, \mathrm{bs}), 7.86(2 \mathrm{H}, \mathrm{d}), 8.07$ (2H, d), 
$9.48(1 \mathrm{H}, \mathrm{d}) .{ }^{13} \mathrm{C}-\mathrm{NMR} 125 \mathrm{MHz}\left(\mathrm{DMSO}-d_{6}\right): \delta 72.28,124.35\left(\mathrm{q},{ }^{1} \mathrm{~J}_{\mathrm{CF}}=272.36 \mathrm{~Hz}, \mathrm{CF}_{3}\right)$,

$125.83,125.86,125.89,128.88,131.96\left(\mathrm{q},{ }^{2} \mathrm{~J}_{\mathrm{CF}}=32.10 \mathrm{~Hz}, \mathrm{C}-\mathrm{CF}_{3}\right), 137.90,165.55,171.62$.

HRMS (ESI-TOF) m/z: Calcd for $\mathrm{C}_{10} \mathrm{H}_{8} \mathrm{~F}_{3} \mathrm{NO}_{4} \mathrm{Na}[\mathrm{M}+\mathrm{Na}]^{+}$286.0303, Found 286.0303.

\section{3,4-Dichloro- $\alpha$-hydroxyhippuric Acid (2f)}

The synthesis of 3,4-dichloro- $\alpha$-hydroxyhippuric acid was accomplished in a similar fashion to the previous derivatives. Using $0.541 \mathrm{~g}(0.00285 \mathrm{~mol})$ of 3,4-dichlorobenzamide and $0.270 \mathrm{~g}(0.00293 \mathrm{~mol})$ of glyoxylic acid monohydrate dissolved in $10 \mathrm{~mL}$ of reagent grade acetone and heated at reflux for 24 hours. The mixture was cooled to room temperature, product collected by vacuum filtration, and purified through recrystallization from ethyl acetate and hexanes. After filtration and drying of the product, $0.241 \mathrm{~g}(0.000912 \mathrm{~mol}, 32.0 \%)$ was collected. The melting point range was observed to be $209-211{ }^{\circ} \mathrm{C} .{ }^{1} \mathrm{H}-\mathrm{NMR} 500 \mathrm{MHz}$ (DMSO- $d_{6}$ ): $\delta 5.61$ $(1 \mathrm{H}, \mathrm{d}), 6.46(1 \mathrm{H}, \mathrm{bs}), 7.77(1 \mathrm{H}, \mathrm{d}), 7.89(1 \mathrm{H}, \mathrm{d}), 8.16(1 \mathrm{H}, \mathrm{s}), 9.47(1 \mathrm{H}, \mathrm{d}), 12.84(1 \mathrm{H}, \mathrm{bs}) .{ }^{13} \mathrm{C}-$ NMR $125 \mathrm{MHz}$ (DMSO-d6): $\delta 72.33,128.33,129.98,131.23,131.79,134.47,134.93,164.26$, 171.58. HRMS (ESI-TOF) m/z: Calcd for $\mathrm{C}_{9} \mathrm{H}_{7} \mathrm{Cl}_{2} \mathrm{NO}_{4} \mathrm{Na}[\mathrm{M}+\mathrm{Na}]^{+}$285.9650, Found 285.9648.

\section{3-Chloro- $\alpha$-hydroxyhippuric Acid (2g)}

3-Chloro- $\alpha$-hydroxyhippuric acid was synthesized in the same manner of the previous derivatives, by dissolving $0.520 \mathrm{~g}(0.00362 \mathrm{~mol})$ of 3 -chlorobenzamide and $0.356 \mathrm{~g}(0.00387$ mol) of glyoxylic acid monohydrate in $15 \mathrm{~mL}$ of reagent grade acetone. The mixture was heated at reflux for 24 hours. After the heating was discontinued, the mixture was brought to room temperature, the product was collected by vacuum filtration, and recrystallized from ethyl acetate and hexane. After isolation of the recrystallized product, it was dried for 24 hours under vacuum, 
and $0.579 \mathrm{~g}(0.00211 \mathrm{~mol}, 52.9 \%)$ of $\mathbf{2 g}$ were isolated. The observed melting point range was 212-213 ${ }^{\circ} \mathrm{C} .{ }^{1} \mathrm{H}-\mathrm{NMR} 500 \mathrm{MHz}\left(\mathrm{DMSO}-d_{6}\right): \delta 5.61(1 \mathrm{H}, \mathrm{d}), 6.42(1 \mathrm{H}, \mathrm{bs}), 7.52(1 \mathrm{H}, \mathrm{t}), 7.63$ $(1 \mathrm{H}, \mathrm{d}), 7.87(1 \mathrm{H}, \mathrm{d}), 7.96(1 \mathrm{H}, \mathrm{s}), 9.40(1 \mathrm{H}, \mathrm{d}), 12.86(1 \mathrm{H}, \mathrm{bs}) .{ }^{13} \mathrm{C}-\mathrm{NMR} 125 \mathrm{MHz}\left(\mathrm{DMSO}-d_{6}\right)$ : $\delta 72.25,126.75,127.82,130.82,131.92,133.68,136.13,165.07,171.67$. HRMS (ESI-TOF) m/z: Calcd for $\mathrm{C}_{9} \mathrm{H}_{8} \mathrm{ClNO}_{4} \mathrm{Na}[\mathrm{M}+\mathrm{Na}]^{+} 252.0040$, Found 252.0038.

\section{3-Bromo- $\alpha$-hydroxyhippuric Acid (2h)}

3-Bromo- $\alpha$-hydroxyhippuric acid was synthesized in the same manner of the previous derivatives, by dissolving $0.751 \mathrm{~g}(0.0048 \mathrm{~mol})$ of 3-bromobenzamide and $0.370 \mathrm{~g}(0.00402 \mathrm{~mol})$ of glyoxylic acid monohydrate in $15 \mathrm{~mL}$ of reagent grade acetone. The mixture was heated at reflux for 24 hours. Subsequently, the mixture was cooled to room temperature, the product was isolated by vacuum filtration, and recrystallized from ethyl acetate and hexane. After isolation of the recrystallized product, it was dried for 24 hours under vacuum. Product isolation led to 0.542 $\mathrm{g}(0.00236 \mathrm{~mol}, 65.1 \%)$. The observed melting point range was $217-219{ }^{\circ} \mathrm{C} .{ }^{1} \mathrm{H}-\mathrm{NMR} 500 \mathrm{MHz}$ (DMSO- $\left.d_{6}\right): \delta 5.60(1 \mathrm{H}, \mathrm{d}), 6.40(1 \mathrm{H}, \mathrm{bs}), 7.46(1 \mathrm{H}, \mathrm{t}), 7.77(1 \mathrm{H}, \mathrm{d}), 7.91(1 \mathrm{H}, \mathrm{d}), 8.10(1 \mathrm{H}, \mathrm{s})$, $9.40(1 \mathrm{H}, \mathrm{d}), 12.82(1 \mathrm{H}, \mathrm{bs}) .{ }^{13} \mathrm{C}-\mathrm{NMR} 125 \mathrm{MHz}$ (DMSO- $\left.d_{6}\right): \delta 72.24,122.12,127.14,130.69$, 131.09, 134.82, 136.31, 164.99, 171.70. HRMS (ESI-TOF) m/z: Calcd for $\mathrm{C}_{9} \mathrm{H}_{8} \mathrm{BrNO}_{4} \mathrm{Na}[\mathrm{M}+$ $\mathrm{Na}]^{+}$295.9534, Found 295.9567.

\section{3-Nitro- $\alpha$-hydroxyhippuric Acid (2i)}

3-Nitro- $\alpha$-hydroxyhippuric acid was synthesized by dissolving $0.618 \mathrm{~g}(0.00329 \mathrm{~mol})$ of 3-nitrobenzamide, and $0.364 \mathrm{~g}(0.00395 \mathrm{~mol})$ of glyoxylic acid monohydrate in $15 \mathrm{~mL}$ of reagent grade acetone. The mixture was heated at reflux for 24 hours, after which it was cooled to room 
temperature and the product was collected via vacuum filtration. The product was recrystallized from ethyl acetate and hexanes, filtered, and dried for 24 hours under vacuum. The observed melting point range was $116-118{ }^{\circ} \mathrm{C} .{ }^{1} \mathrm{H}-\mathrm{NMR} 500 \mathrm{MHz}$ (DMSO- $\left.d_{6}\right): \delta 5.65(1 \mathrm{H}, \mathrm{d}), 6.49(1 \mathrm{H}$, bs), $7.80(1 \mathrm{H}, \mathrm{t}), 8.34(1 \mathrm{H}, \mathrm{d}), 8.41(1 \mathrm{H}, \mathrm{d}), 8.74(1 \mathrm{H}, \mathrm{s}), 9.70(1 \mathrm{H}, \mathrm{d}), 12.82(1 \mathrm{H}, \mathrm{bs}) .{ }^{13} \mathrm{C}-\mathrm{NMR}$ $125 \mathrm{MHz}$ (DMSO- $\left.d_{6}\right): \delta$ 72.37, 122.81, 126.70, 130.67, 134.43, 135.62, 148.28, 164.51, 171.58. HRMS (ESI-TOF) m/z: Calcd for $\mathrm{C}_{9} \mathrm{H}_{8} \mathrm{~N}_{2} \mathrm{O}_{6} \mathrm{Na}[\mathrm{M}+\mathrm{Na}]^{+}$263.0280, Found 263.0281.

\section{2-Ethanamido-(4-nitrobenzamido)acetic Acid (23)}

2-Ethanamido-(4-nitrobenzamido)acetic acid was synthesized by dissolving $1.788 \mathrm{~g}$ (0.0108 mol) of 4-nitrobenzamide, and $1.025 \mathrm{~g}(0.0111 \mathrm{~mol})$ of glyoxylic acid monohydrate in $20 \mathrm{~mL}$ of reagent grade acetonitrile. The mixture was heated at reflux for 24 hours, after which it was cooled to room temperature and the product was collected via vacuum filtration. The product was recrystallized from ethyl acetate and hexanes, filtered, and dried for 24 hours under vacuum. Product isolation led to $1.018 \mathrm{~g}(0.00489 \mathrm{~mol}, 45.4 \%) .{ }^{1} \mathrm{H}-\mathrm{NMR} 500 \mathrm{MHz}$ (DMSO- $d_{6}$ ): $\delta 1.91(3 \mathrm{H}, \mathrm{s}), 5.80(1 \mathrm{H}, \mathrm{t}), 8.11(2 \mathrm{H}, \mathrm{d}), 8.34(2 \mathrm{H}, \mathrm{d}), 8.69(1 \mathrm{H}, \mathrm{d}), 9.61(1 \mathrm{H}, \mathrm{d}), 13.02(1 \mathrm{H}, \mathrm{bs})$.

${ }^{13} \mathrm{C}-\mathrm{NMR} 125 \mathrm{MHz}$ (DMSO- $d_{6}$ ): $\delta 22.76,57.14,124.08,129.47,139.39,149.77,165.00,169.96$, 169.99 .

\section{Results and Discussion}

\section{Synthesis of Benzamide Derivatives}

The synthesis of benzamide derivatives was the initial step in the synthesis of the $\alpha$ hydroxyhippuric acid derivatives. The general method used in making amide derivatives began 
with carboxylic acid precursors, where the carboxylate was transformed into an acyl chloride (see Scheme 14). Two general methods could be used to generate acyl chlorides, where the first involves the use of thionyl chloride, and the second method makes use of phosphorous pentachloride. ${ }^{73}$ Thionyl chloride is not typically used with aromatic carboxylic acid species, so the $\mathrm{PCl}_{5}$ method was used exclusively. It is worth noting that the $\mathrm{PCl}_{5}$ is a hazardous material and should be handled with care, the formation of the acyl chloride involves the evolution of $\mathrm{HCl}$ gas and the formation of phosphoryl chloride $\left(\mathrm{POCl}_{3}\right)$. In order to move forward with the formation of benzamide derivatives $\mathrm{POCl}_{3}$ must be removed from the reaction mixture, which is achieved by distilling off this species, under reduced pressure, and disposing of it appropriately. Following the formation and purification of the acid chloride, it was treated with ammonium hydroxide $\left(\mathrm{NH}_{4} \mathrm{OH}\right)$ to generate the amide product (see Scheme 14).

Scheme 14: Benzamide Derivative Synthesis.<smiles>[X]c1ccc(C(=O)O)cc1</smiles><smiles>[X]c1ccc(C(=O)Cl)cc1</smiles><smiles>NO</smiles><smiles>[X]c1ccc(C(N)=O)cc1</smiles>

At the ammonium hydroxide addition step, it was determined that when working with the 4-nitrobenzoyl chloride intermediate, reversing the addition order, that is adding the acid chloride to the ammonium chloride solution, provided higher yields of 4-nitrobenzamide to 4nitrobenzoic acid (2:1). If the reaction was performed in the same manner as the other amide formation reactions, a 1:1 or a 1:2 ratio of amide to acid was recovered, which was a detriment to yields and purity of the desired product. Recrystallization from either water or methanol proved to be adequate in purifying the amide. ${ }^{73}$ 


\section{Synthesis of $\alpha$-Hydroxyhippuric Acid Derivatives}

Previous synthetic approaches for $\alpha$-hydroxyhippuric acid derivatives were achieved through the reversible reaction between amide and aldehydic species as shown in Scheme 15. 4,7,8,18,50,72,81 The synthesis of $N$-(hydroxymethyl)benzamide and its derivatives were achieved with the use of catalytic potassium carbonate in methanol (see Scheme 16). The methods detailed in this chapter were similar to those used by Bundgaard et al. during their kinetic investigations of $\alpha$-hydroxyhippuric acid derivatives as pro-drugs. ${ }^{47}$ Equimolar amounts of benzamide and glyoxylic acid monohydrate were $(\sim 0.06 \mathrm{~mol})$ dissolved in approximately $20 \mathrm{~mL}$ of reagent grade acetone. ${ }^{47}$ The reaction mixture was setup under gentle reflux for 24 hours after which the heating was discontinued and the reaction mixture was allowed to cool to room temperature.

Once sufficiently cooled, the reaction mixture was concentrated to half volume, utilizing a rotary evaporator. See Figure 6 and 7 to see the ${ }^{1} \mathrm{H}$ and ${ }^{13} \mathrm{C}-\mathrm{NMR}$ spectra for 4 -chloro- $\alpha$ hydroxyhippuric acid. (Spectra for the other compounds are in the Appendix.)

Scheme 15: Generic Carbinolamide Synthesis.<smiles>[R]C(=O)N[Z17]([H])=C[R]C#CC=C</smiles>

Scheme 16: $N$-(hydroxymethyl)benzamide Derivative Synthesis.<smiles>[X]c1ccc(C(N)=O)cc1</smiles> 


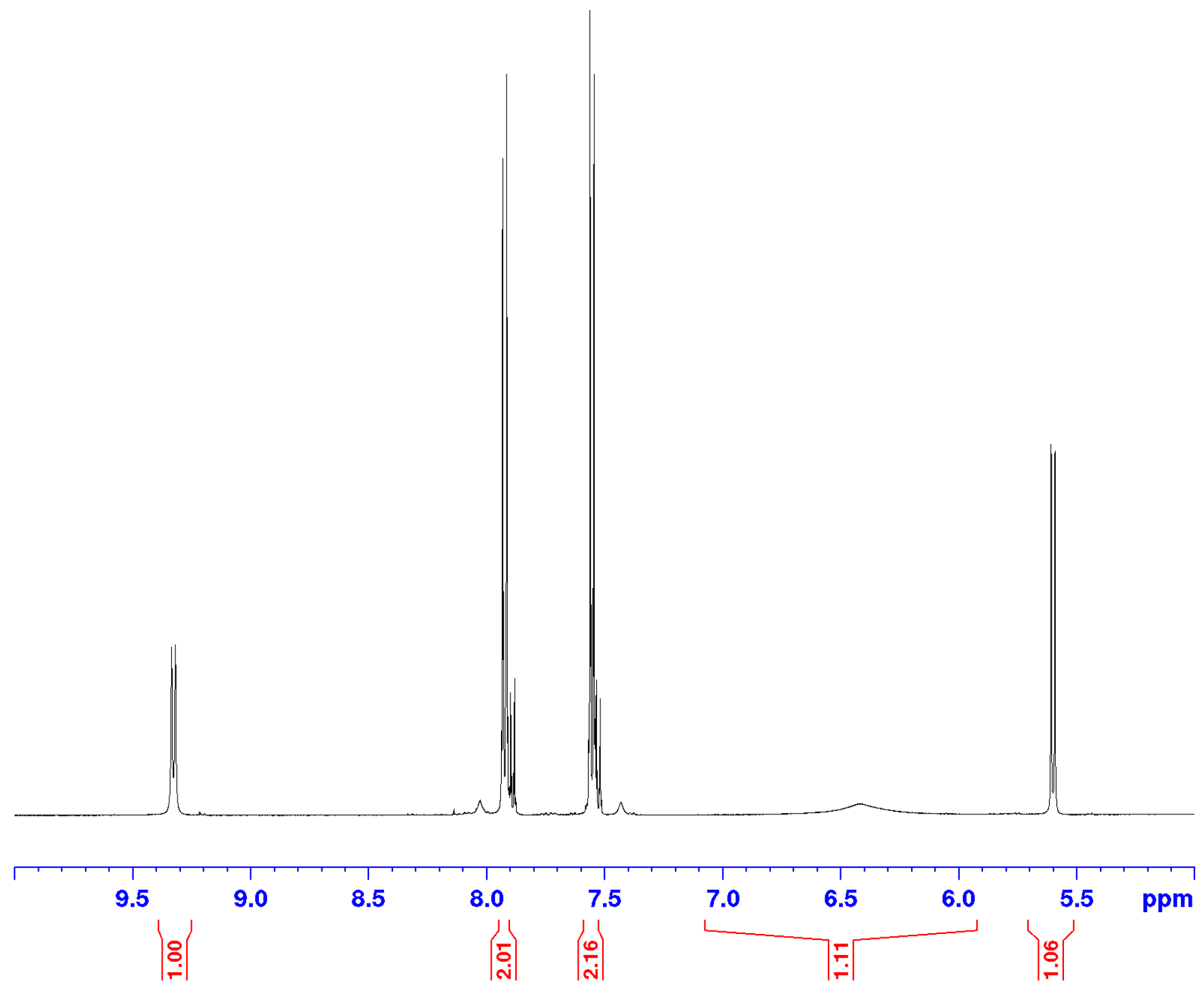

Figure 6: $500 \mathrm{MHz}{ }^{1} \mathrm{H}-\mathrm{NMR}$ Spectrum of 4-Chloro- $\alpha$-Hydroxyhippuric Acid (2b) in DMSO-d6. 


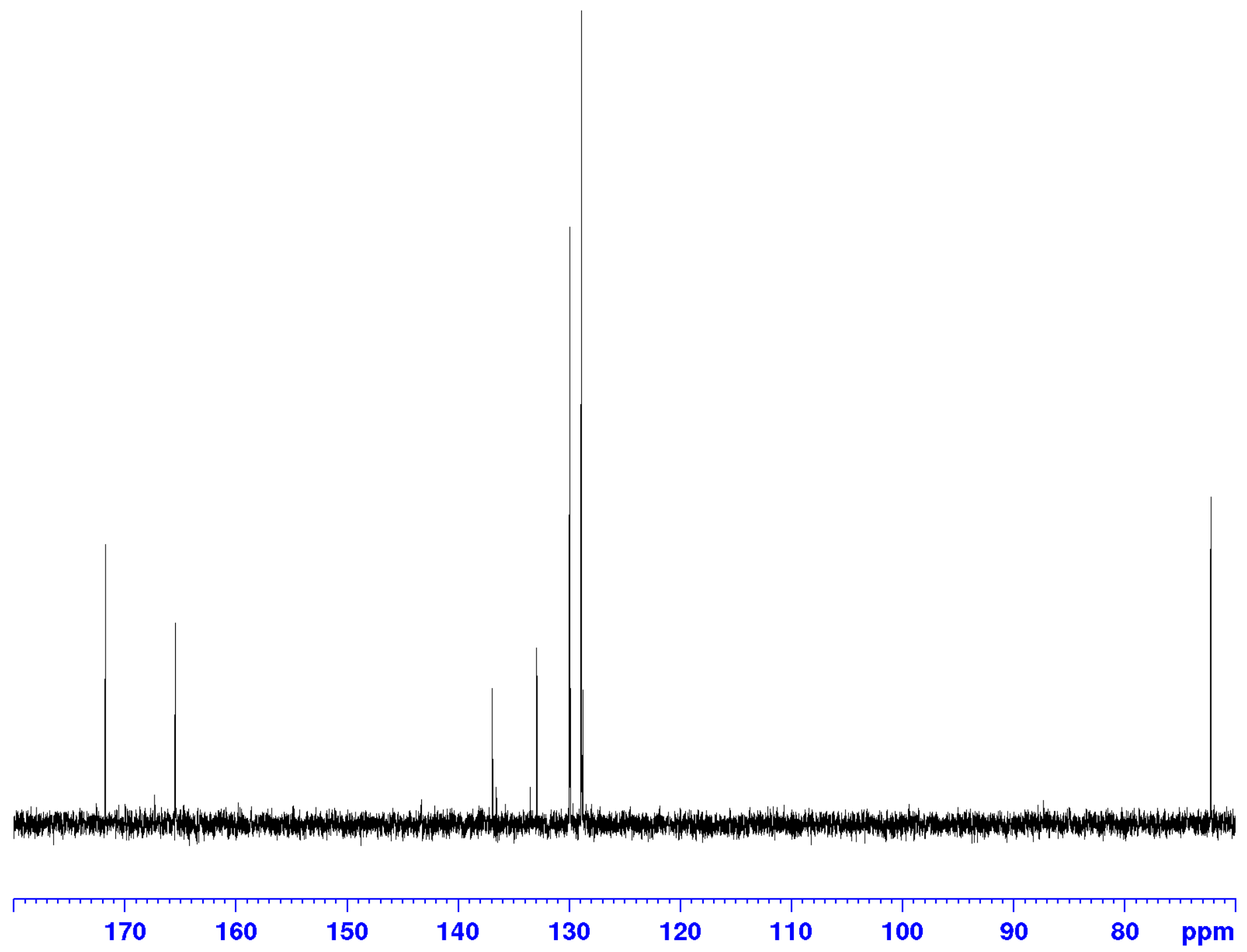

Figure 7: $125 \mathrm{MHz}{ }^{13} \mathrm{C}-\mathrm{NMR}$ of 4-Chloro- $\alpha$-Hydroxyhippuric Acid (2b) DMSO-d 6 . 
The initial synthesis of 4-nitro- $\alpha$-hydroxyhippuric acid, which was performed in acetonitrile rather than acetone as stated in the general method, proved to be challenging as a product resembling (by ${ }^{1} \mathrm{H}-\mathrm{NMR}$ ) the product that was expected was isolated. Shown in Figure 8 is the ${ }^{1} \mathrm{H}-\mathrm{NMR}$ for 2-ethanamido-(4-nitrobenzamido)acetic acid (23), whose spectrum only showed minor differences from that which would be expected (compare Figures 6 and 8). However, when $\mathbf{2 3}$ was used for initial kinetic studies, no changes were observed in the absorbance, indicating that no observable change was occurring on the time scale that was expected or that the reaction was occurring much more quickly than expected based upon the kinetic results of the other derivatives. The original syntheses of these compounds, by Feken, were all performed in acetonitrile as the solvent for the reaction.$^{69}$ The synthesis of $\mathbf{2 3}$ was performed once again, however the solvent used was acetone and the product isolated proved to be the desired compound. The ${ }^{1} \mathrm{H}-\mathrm{NMR}$ spectrum, shown in Figure 8, showed similarities to that shown in Figure 6 for $\mathbf{2 b}$ (4-chloro compound), but there are some apparent differences.

The most obvious difference was the movement of the hydroxyl proton resonance from approximately $6.5 \mathrm{ppm}$ for $\mathbf{2 b}$, to $8.8 \mathrm{ppm}$ for $\mathbf{2 3}$. In addition, there is a singlet at approximately 2 ppm that could not be accounted for. After the ${ }^{13} \mathrm{C}-\mathrm{NMR}$ was acquired, it became clear that there were more carbon peaks than would be expected based upon the structure of the desired product. The ${ }^{13} \mathrm{C}-\mathrm{NMR}$ of $\mathbf{2 3}$ has two peaks that are unexpected, an extra carbonyl peak and a methyl peak at $\sim 23 \mathrm{ppm}$ (see Figure 9). We have proposed the product to be $\mathbf{2 3}$, as shown in Scheme 17.

The proposed mechanism of the production of $\mathbf{2 3}$ is shown in Scheme 17. It was believed that the 4-nitro- $\alpha$-hydroxyhippuric acid derivative undergoes loss of the hydroxyl group to form an $N$-acylimminium ion (24). This loss of hydroxide is thought to occur for all the derivatives of 
2 but becomes a problem with those bearing electron-withdrawing groups as this decreases the stability of $\mathbf{2 4}$ making it susceptible to attack by weaker nucleophiles. It is proposed that $\mathbf{2 4}$ undergoes attack by acetonitrile (solvent for the reaction in this case) to form the cation $\mathbf{2 5}$. This would be subsequently attacked by water or hydroxide to generate the tautomer of $\mathbf{2 3}$ (see Scheme 17). The stability of these compounds under aqueous conditions is not known, however the studies performed here suggest that the reactivity of $\mathbf{2 3}$ was much less than any of the derivatives of $\mathbf{2}$. This conclusion was based upon a lack of observable change in the absorbance spectrum over an extended period of time under conditions which would have completed reacted the derivatives of $\mathbf{2}$ to the amide and glyoxylate products. No further experiments were performed upon 23.

Scheme 17: Potential Synthetic Route of 2-Ethenamido-(4-nitrobenzamido)acetic Acid (23).<smiles>CC#[N+]CCCC(C)C(=O)NC(=O)c1ccc([N+](=O)[O-])cc1</smiles>

24<smiles></smiles>

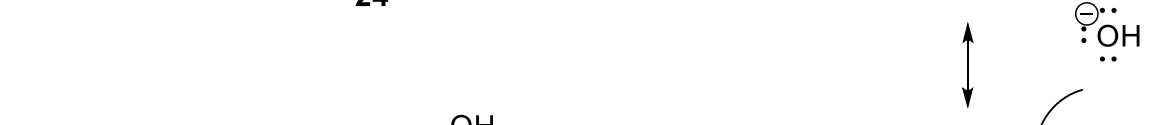<smiles>CCCC(C)=NC(NC(=O)c1ccc([N+](=O)[O-])cc1)C(=O)O</smiles> 


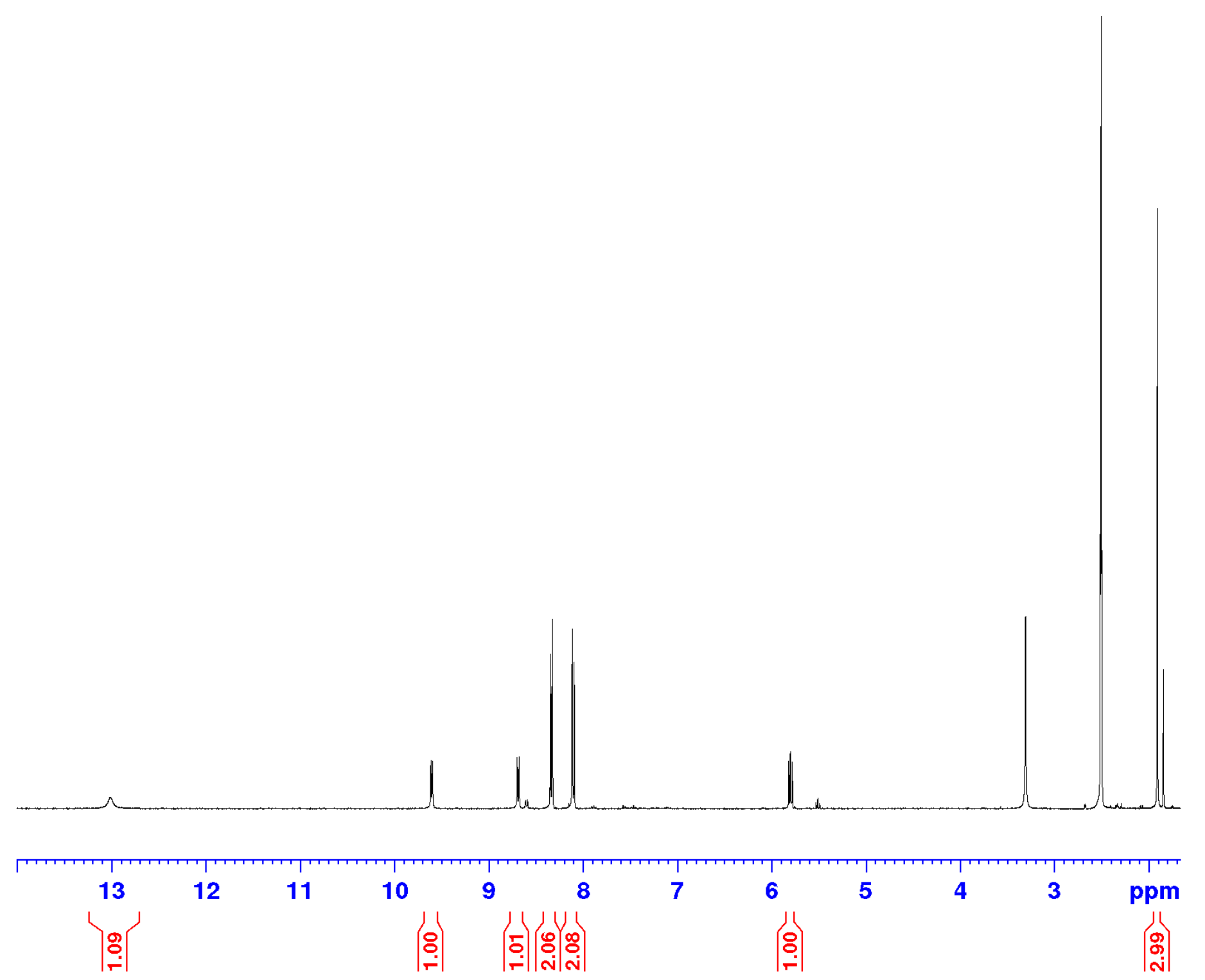

Figure 8: $400 \mathrm{MHz}{ }^{1} \mathrm{H}-\mathrm{NMR}$ of 2-Ethanamido-(4-nitrobenzamido)acetic Acid (23) in DMSO-d 6 . 


$$
\pm
$$


Purification of the crude $\alpha$-hydroxyhippuric acid derivatives was performed by recrystallization from an ethyl acetate and hexanes system. The recrystallization was initiated by taking the crude material and dissolving it in a minimal amount of ethyl acetate, gentle heating of this mixture allows for complete solvation in the small amount of solvent used. Once the crude $\alpha$-hydroxyhippuric acid material was dissolved and the mixture had cooled to room temperature, hexanes was added dropwise until cloudiness of the mixture persists for a brief moment. To induce recrystallization, the mixture of ethyl acetate and hexanes was put into the freezer overnight. Vacuum filtration was used to collect the recrystallized product, with subsequent characterization techniques utilized to identify the products.

Scheme 18: Synthesis of $\alpha$-Hydroxyhippuric Acid Derivatives.<smiles>[X]c1ccc(C(=O)NC(O)C(=O)O)cc1</smiles>

\section{Conclusions}

The synthesis of the benzamide derivatives and the $\alpha$-hydroxyhippuric acid derivatives was relatively straight forward. Optimizations were not the purpose of the work performed, rather having the compounds available and pure was much more important. As with any research being conducted there will be hurdles to overcome and, in this work, synthesizing the 4-nitro compounds, and purifying the carbinolamide derivatives did prove challenging. It was imperative to let the carbinolamide heat at reflux under as mild heating conditions, as possible, for a prolonged period to ensure the highest possible yield. The ethyl acetate and hexanes solvent recrystallization system was a simple solution to the problem of purity of compounds. Some 
carbinolamides required one recrystallization, while others needed multiple recrystallizations to achieve purity. Multiple recrystallizations come at the cost of yield, and most of these compounds at the crude product step provided modest amounts of product. Future work could be geared to optimizing the synthesis at the benzamide, and the carbinolamide steps. 


\section{CHAPTER III: KINTETICS OF $\alpha$-HYDROXYHIPPURIC ACID DERIVATIVES}

\section{Introduction}

This chapter will detail the kinetic studies performed with $\alpha$-hydroxyhippuric acid derivatives bearing electron withdrawing groups substituted on to the aromatic ring. Previous studies on the $\alpha$-hydroxyhippuric acid derivatives focused primarily on electron-donating substituents and included only a single electron withdrawing derivative. ${ }^{69}$ Part of the reason that these derivatives of $\mathbf{2}$ are so interesting was that it is known that $\alpha$-hydroxyhippuric acid is a substrate for PAL. ${ }^{61}$ Another reason that the derivatives of $\mathbf{2}$ are of interest is the presence of the carboxylate group on the aldehyde side of the carbinolamide. The carboxylate group is very interesting as at $\mathrm{pH}$ values greater than $\sim 5$ since the carboxylate group will be ionized.

Past work performed in the Nagorski group related to understanding the relevant mechanistic steps involved in the breakdown of carbinolamides over a full $\mathrm{pH}$ rate profile $(0-14$ $\mathrm{pH}$ units), exploring the acid-catalyzed, water-catalyzed, hydroxide-dependent, and the hydroxide-independent regions. ${ }^{1,3-8}$ In addition to exploring the mechanism of reaction of these molecules, investigations into the effect of structural changes on the reactivity of these compounds will lead to a better universal understanding of the reactivity of carbinolamides. Compared to the previously studied $N$-(hydroxymethyl)benzamide and $N$ (hydroxybenzyl)benzamide derivatives, the $\alpha$-hydroxyhippuric acid derivatives have a carboxylate group that could result in different forms of reactivity due to the ionized carboxylate group ( $\mathrm{pH}$ values above 5). Studies performed on $\mathrm{N}$-(hydroxymethyl)benzamide $(\mathbf{1 7} \&$ derivatives) with electron donating, and electron withdrawing groups substituted on to the aromatic ring portion showcased the fundamental reactivity of carbinolamides, but how broadly can the observations from these studies be applied to the larger population of carbinolamide 
compounds? $?^{1,4,5,7,8}$ The reason for a question of this type lies in the fact that formaldehyde is not a typical aldehyde and, in fact, could be classified as a functional group but a functionality in which the entire population is a single compound.

Formaldehyde is a unique compound as it has two hydrogens attached to the carbonyl group and this structural feature has profound effects upon its reactivity. Aldehydes tend to be relatively electrophilic as measured by their degree of hydration in water ${ }^{82-84}$ Substitution patterns can have a significant effect on the degree of hydration but very few true aldehydes are as highly hydrated as formaldehyde $\left(K_{\text {hyd }}=2420\right) .{ }^{85}$ As a result of this analysis, are the $N$ (hydroxymethyl)benzamide compounds a typical carbinolamide? Other work would suggest that while $\mathbf{1 7}$ and its derivatives are somewhat less reactive than other carbinolamides but, in general, their reactivity mirrors that of other carbinolamides. ${ }^{3,46-50}$ Albeit, with some unique forms of reactivity. ${ }^{5}$

Some general observations that have resulted from these studies are that electron withdrawing groups, added to the amide portion of the carbinolamide, lead to an increase in the rate of reaction in the hydroxide-dependent region, and slowed the rate of reaction in the acidcatalyzed region. ${ }^{3,4,7,8}$ In accord with this observation, the addition of electron-donating groups to the amide portion of the carbinolamide slows the hydroxide-dependent reaction and increases the rate of the acid-catalyzed reaction. Another important observation was the presence of buffer catalysis in the acid-catalyzed region, indicating that proton transfer was occurring in the ratedetermining step of the reaction which was contrary to prior studies. ${ }^{3,4}$

Initial work performed by Feken on $\alpha$-hydroxyhippuric acid and some of its derivatives focused on the rates of reaction of these compounds as a function of $\mathrm{pH}$ and the presence of buffer. The derivatives of $\mathbf{2}$ have an increased reactivity when compared against similarly 
substituted $N$-(hydroxymethyl)benzamide derivatives. As mentioned above, in the hydroxidedependent reaction, electron withdrawing groups could stabilize developing negative charge on the nitrogen during the cleavage of the $\mathrm{N}-\mathrm{C}$ bond. However, the benzamidate leaving group would be the same, with similarly substituted derivatives, so the difference in the reactivity of 2 $v s . N$-(hydroxymethyl)benzamide compounds must be due to the glyoxylate $v s$. formaldehyde providing a push to the departure of the benzamidate leaving group.

As was discussed in the introduction, the hydroxide-dependent mechanism is thought to be a specific-base catalyzed reaction, where the deprotonation of the hydroxyl group occurs prior to the rate-determining step. Under such basic conditions, the $\alpha$-hydroxyhippuric acid derivative would be already deprotonated at the carboxylate portion due to the low $\mathrm{p} K_{\mathrm{a}}$ of the carboxylate group. Shown in Scheme 19 is the initial deprotonation of the $\alpha$-hydroxyl group which would be followed by rate determining breakdown into glyoxylate and the amidate anion. Protonation of the amidate should occur relatively easily by the solvent as the $\mathrm{p} K_{\mathrm{a}}$ of benzamides are thought to be $\sim 18 .{ }^{86,87}$ The mechanism shown in Scheme 19 has been supported by various observations, but most importantly by the lack of buffer catalysis. ${ }^{3,5,7,8}$ 
Scheme 19: Accepted Mechanism for the Hydroxide-Catalyzed Reaction of $\alpha$-Hydroxyhippuric Acid.

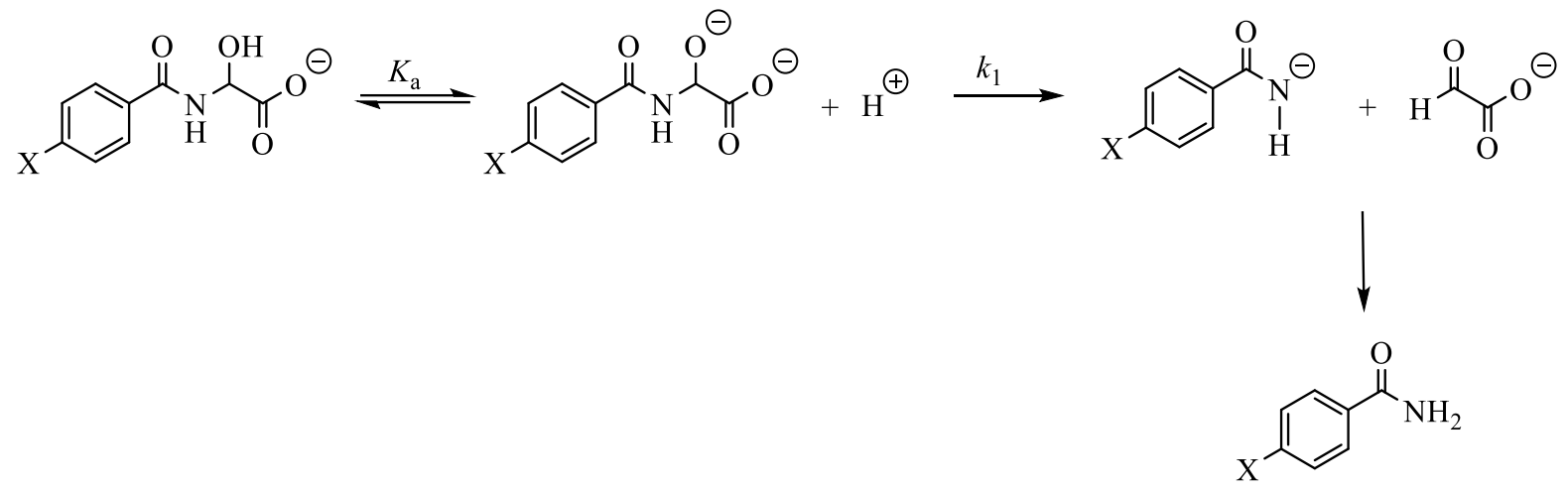

The purpose of investigating the derivatives of $\mathbf{2}$ studied here was to probe their aqueous kinetic tendencies, compare mechanistic results from previous studies performed, and to report any new forms of reactivity observed. Another factor that placed some importance on these studies was the fact that Kati Feken, who originally studied derivatives of $\mathbf{2}$ encountered difficulties synthesizing derivatives with electron-withdrawing groups. ${ }^{69}$ Feken apparently synthesized several derivatives of $\mathbf{2}$ bearing electron-withdrawing groups; however, the compounds did not react in accord with those bearing electron-donating groups ${ }^{69}$ More recently it was determined that the compounds that Feken made were not the derivatives of $\mathbf{2}$ that they were thought to be. The work presented here produced the targeted compounds after having determined what had occurred in the Feken syntheses.

The scope of the work presented here focused on expanding our knowledge of derivatives of $\mathbf{2}$ having electron withdrawing groups substituted onto the amide side of $\alpha$-hydroxyhippuric acid, studying their aqueous kinetics. Knowing that $\alpha$-hydroxyhippuric acid is a substrate for the enzymatic system PAM, understanding the kinetic tendencies of the derivatives of $\mathbf{2}$ could provide us with potentially relevant information on the mechanism utilized by this enzymatic 
system. ${ }^{61}$ Previous kinetic work on carbinolamide containing compounds focused on aromatic amides with aromatic aldehydes, ${ }^{3}$ aromatic amides with formaldehyde, ${ }^{7,8,81}$ aliphatic amides with aromatic aldehydes ${ }^{6}$ and aromatic amides with glyoxylic acid for the aldehyde portion. ${ }^{69}$ Detailed in Table 1 are the derived kinetic data, using equations 1 and 2, from Feken's' work performed on $\alpha$-hydroxyhippuric acid and its derivatives all in the para-position. ${ }^{69}$ The apparent second-order rate constants $\left(k_{1}^{\prime}\right)$, increases as the substituent gets increasingly electron withdrawing. This pattern should continue increasing as stronger electron withdrawing groups are added to the aromatic portion of the carbinolamide. The dissociation constant $\left(K_{\mathrm{a}}\right)$ for the hydroxyl group is also reported in Table 1, providing us with information relating to the acidity of the hydroxyl proton with different substituents. ${ }^{69}$

Table 1: Rate Constants for the Hydroxide-Independent and Dependent Reactions of $\alpha$ Hydroxyhippuric Acid and Derivatives Under Aqueous Conditions at $25{ }^{\circ} \mathrm{C}, I=1.0 \mathrm{M}(\mathrm{KCl}){ }^{\text {a }}$

\begin{tabular}{ccccc}
\hline Compound & $k_{1}\left(\mathrm{~s}^{-1}\right)$ & $K_{\mathrm{a}}(\mathrm{M})$ & $\mathrm{p} K_{\mathrm{a}}$ & $k_{1}\left(\mathrm{M}^{-1} \mathrm{~s}^{-1}\right)$ \\
\hline $4-\mathrm{N}\left(\mathrm{CH}_{3}\right)_{2}$ & 0.650 & $5.14 \times 10^{-14}$ & 13.27 & 2.57 \\
$4-\mathrm{OCH}_{3}$ & 0.664 & $8.55 \times 10^{-14}$ & 13.07 & 3.43 \\
$4-\mathrm{CH}_{3}$ & 0.773 & $5.31 \times 10^{-14}$ & 13.27 & 3.93 \\
$4-\mathrm{H}$ & 0.986 & $4.96 \times 10^{-14}$ & 13.30 & \\
$4-\mathrm{Cl}$ & 1.361 & $5.55 \times 10^{-14}$ & 13.25 & 5.09 \\
\hline
\end{tabular}

a) Feken, K. $\alpha$-Hydroxyhippuric Acid Derivatives: $\mathrm{pH}$-Dependent Aqueous Kinetics and Buffer Catalysis. Master of Science Thesis, Illinois State University, 2013. 


\section{Experimental}

\section{Materials}

All chemicals used were reagent grade unless specified otherwise. The $\alpha-$ hydroxyhippuric acid derivatives were purified as previously mentioned in chapter II and were dissolved in DMSO to generate 0.1 M concentrated solutions of carbinolamide. Potassium carbonate, potassium pyrophosphate, potassium phosphate, and potassium chloride salts were used to make buffer solutions at specific $\mathrm{p} H$ values. Any mention of water used refers to house DI water that was further purified by a Nanopure Water Filtration System. A stock solution of $\sim 2.5 \mathrm{M}$ potassium hydroxide $(\mathrm{KOH})$ was prepared and standardized, so that 2.0 and $1.0 \mathrm{M}$ solutions of $\mathrm{KOH}$ could be prepared and standardized. Titrations were performed on these $\mathrm{KOH}$ solutions in triplicate with a standard $0.100 \mathrm{M} \mathrm{HCl}$ solution, and phenolphthalein was used as an end point indicator. Solutions ranging from $0.03 \mathrm{M}$ to $2.0 \mathrm{M} \mathrm{KOH}$ with $I=2.0 \mathrm{M}(\mathrm{KCl})$ were prepared for stopped-flow kinetic experiments.

\section{Kinetics}

Prior to the initiation of kinetic studies, each derivative of $\mathbf{2}$ had to undergo three steps: 1) solubility testing, 2) initial kinetics, and 3) rate determination as a function of $\mathrm{pH}$. Solubility studies of the substrate were performed by adding small increments of a stock solution of the substrate into a $1 \mathrm{M} \mathrm{KCl}$ solution with the absorbance spectrum acquired between substrate additions. In general, the additions were continued until the total substrate concentration was $\sim 8$ $\mathrm{x} 10^{-4} \mathrm{M}$. After the addition of substrate was completed, at least two wavelengths were chosen where the concentration of substrate $v s$. absorbance were plotted. Plots of all derivatives of $\mathbf{2}$ were linear up to, at least, $5 \times 10^{-4} \mathrm{M}$ indicating sufficient solubility for the types of kinetic studies that were planned. 
The second step involved the initial kinetic experiments which were performed to determine the wavelength to best follow the reaction of a particular derivative of $\mathbf{2}$ and to provide an approximate rate of reaction. The experiment was initiated by dilution of a derivative of $\mathbf{2}$, in DMSO, to yield a final concentration of $\sim 1 \times 10^{-4} \mathrm{M}$. The absorbance of the sample was then acquired at timed intervals. Using this procedure, the wavelength of maximum absorbance change could be determined as well as the approximate of reaction. Shown in Table 2 are the wavelengths at which each of the derivatives of $\mathbf{2}$ were followed.

Table 2: Wavelengths Determined for $\alpha$-Hydroxyhippuric Acid Derivatives Using Initial Kinetics Method, at $25^{\circ} \mathrm{C}$ and $I=1.0 \mathrm{M}(\mathrm{KCl})$.

\begin{tabular}{ccc}
\hline Compound & Label & $\lambda_{\max }(\mathrm{nm})$ \\
\hline -hydroxyhippuric acid & $\mathbf{2 a}$ & 240 \\
4-chloro- $\alpha$-hydroxyhippuric acid & $\mathbf{2 b}$ & 255 \\
4-bromo- $\alpha$-hydroxyhippuric acid & $\mathbf{2 c}$ & 255 \\
4-(trifluoromethyl)- $\alpha$-hydroxyhippuric acid & $\mathbf{2 e}$ & 245 \\
4-nitro- $\alpha$-hydroxyhippuric acid & $\mathbf{2 d}$ & 280 \\
3,4-dichloro- $\alpha$-hydroxyhippuric acid & $\mathbf{2 f}$ & 250 \\
3-chloro- $\alpha$-hydroxyhippuric acid & $\mathbf{2 g}$ & 245 \\
3-bromo- $\alpha$-hydroxyhippuric acid & $\mathbf{2 h}$ & 245 \\
3-nitro- $\alpha$-hydroxyhippuric acid & $\mathbf{2 i}$ & 240 \\
\hline
\end{tabular}


Stopped-Flow Spectroscopy. High hydroxide (pH 12-14) kinetics were followed utilizing a stopped-flow apparatus due to the rapid rates of reaction exhibited at these $\mathrm{pH}$ values. The instrument used was an Olis-Cary 14 spectrophotometer, along with the Olis-GlobalWorks, this software operated the instrument and was used for the analysis of the data collected. The temperature of the syringe chamber was maintained at $25^{\circ} \mathrm{C}$. Two syringes, that contained $\mathrm{KOH}$ solution in one and water in the other, with substrate dissolved in the water syringe, are a part of the instrument. The final substrate concentration in the water solution was $3.5 \times 10^{-5} \mathrm{M}$ which was halved when the hydroxide and water solutions were mixed, to yield a solution at the desired $\left[\mathrm{HO}^{-}\right]$and $I=1.0 \mathrm{M}(\mathrm{KCl})$. The kinetics of the reaction of the derivatives of $\mathbf{2}$ were investigated from $0.03 \mathrm{M}$ to $1.0 \mathrm{M} \mathrm{KOH}$. No less than five kinetic experiments were acquired for each derivative of $\mathbf{2}$ at each [HO-].

UV-Vis Spectroscopy. For kinetic studies between $\mathrm{p} H$ values of 8.5 and 11.5 , the instrument used was a UV-Vis spectrophotometer. The reaction times observed for these experiments ranged from minutes to days. The Varian Cary 100-Bio, and 1G UV-Vis spectrophotometers were equipped with a temperature-controlled sample holder that could hold up to 6 cuvettes at once, but no more than 3 cuvettes were sampled at a time. The solution was allowed to equilibrate at $25{ }^{\circ} \mathrm{C}$ for 10 to 15 minutes prior to the initiation of the experiment by the injection of 1.0-1.4 $\mu \mathrm{L}$ of $0.1 \mathrm{M}$ substrate solution, in DMSO, into a $3 \mathrm{~mL}$ total volume. The final substrate concentrations in the cuvettes ranged from $1.4 \times 10^{-4} \mathrm{M}$ to $4.67 \times 10^{-5} \mathrm{M}$. Kinetic studies were run in triplicate at each [HO-] or buffer concentration. For those experiments where buffers were used, kinetic experiments were performed at three total [buffer], to probe whether buffer catalysis was being observed. The $\mathrm{pH}$ of the kinetic solutions were measured after kinetics acquisition using a standardized combination glass electrode attached to Accumet Model $15 \mathrm{pH}$ - 
meter. The wavelength where the kinetics were determined for each derivative of $\mathbf{2}$ are shown in Table 2.

\section{Results and Discussion}

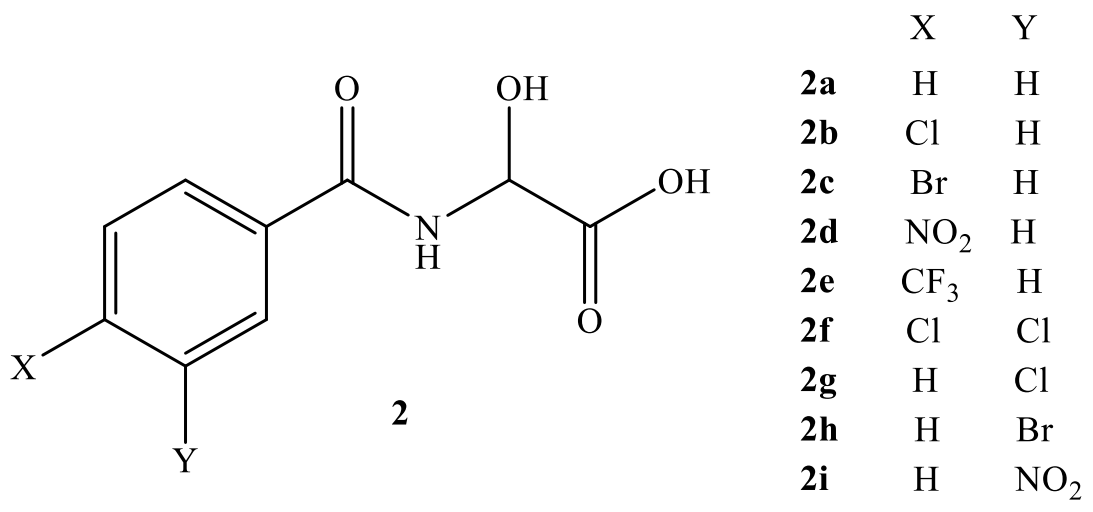

\section{Kinetics}

$\alpha$-Hydroxyhippuric acid derivatives studied in this project were primarily monosubstituted with electron withdrawing groups at the meta or para-position, except for the disubstituted 3,4-dichloro- $\alpha$-hydroxyhippuric acid. The kinetic data for $\mathbf{2} \mathbf{i}$ was not acquired due to difficulties with the substrate and 2a had been previously studied. As a result, the data presented will focus on seven out of the nine derivatives synthesized. Previously performed studies showed that electron donating groups substituted on the amide portion of the carbinolamide slowed the rate of reaction in the hydroxide region while increasing the rate of reaction in the acid catalyzed region. ${ }^{1,3-8}$ With electron withdrawing groups substituted on the amide portion, they observed an increase of rate of reaction in the hydroxide region with a decrease in the rate of reaction in the acid catalyzed region. ${ }^{1,3-8}$

The kinetics of the derivatives of 2 were performed at $25^{\circ} \mathrm{C}$ and at $I=1.0 \mathrm{M}(\mathrm{KCl})$. Stopped-flow, and UV-Vis spectroscopy were used to determine the rate of carbinolamide 


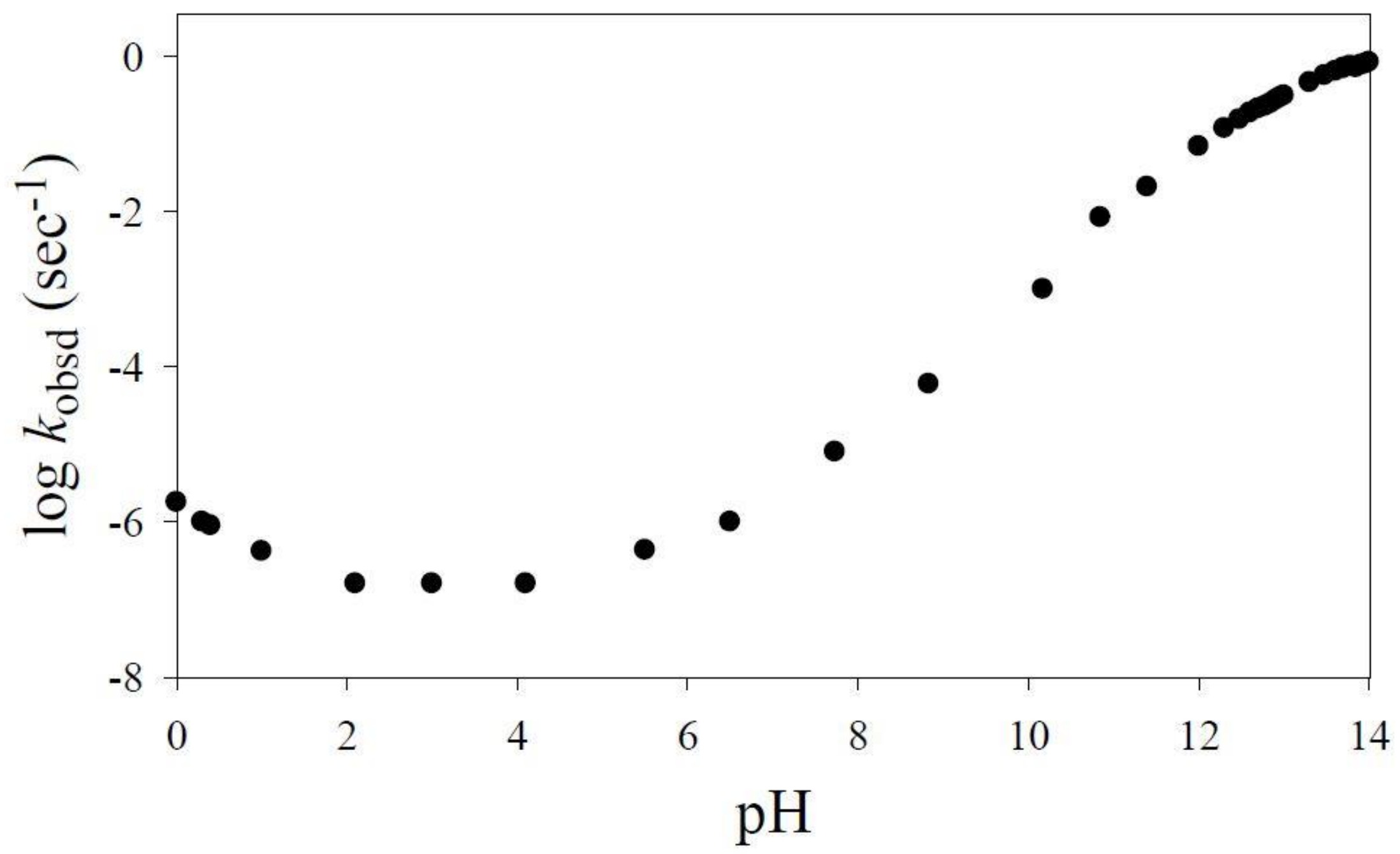

Figure 10: $\mathrm{p} H$ Rate Profile for the Aqueous Reaction of 4-Chloro- $\alpha$-hydroxyhippuric Acid $(\mathbf{2 b})$ at $25^{\circ} \mathrm{C}$, and $I=1.0 \mathrm{M}(\mathrm{KCl}) .{ }^{69}$ 
breakdown to amide and glyoxylic acid. The rates were determined by following their absorbance change as a function of time. Figure 10 shows the dependence of the $\log k_{\mathrm{obsd}} v s . \mathrm{p} H$ for the reaction of $\mathbf{2 b}$ in $\mathrm{H}_{2} \mathrm{O}, I=1.0 \mathrm{M}(\mathrm{KCl})$, at $25^{\circ} \mathrm{C}$.

As mentioned previously, the $\mathrm{p} H$-rate profiles of the $\alpha$-hydroxyhippuric acid derivatives probed are similar to previously studied carbinolamides. ${ }^{3,7}$ The $\mathrm{pH}$-rate profile, shown in Figure 10, has four distinct regions of reactivity: 1) a hydroxide-independent, 2) hydroxide-dependent, 3) water-catalyzed (or the chemical equivalent), and 4) acid-catalyzed region. Studies performed on 2a, by Bundgaard et al., did not show the presence of an acid-catalyzed mechanism in the $\mathrm{pH}$ range of 0 to $2 .{ }^{47}$ Similar studies performed by Feken on $\alpha$-hydroxyhippuric acid derivatives did note the observation of an acid-catalyzed reaction. ${ }^{69}$ The focus of the work presented here will be on the hydroxide portion of the $\mathrm{p} H$ rate profile.

Studies performed on derivatives of $\mathbf{2}$ showed good pseudo-first order kinetics over the $\mathrm{pH}$ range that was probed. Furthering the scope of this project would entail kinetic testing in the water-catalyzed region and the acid-catalyzed region, to give an idea about each mechanism present in each region. Stopped-flow and UV-Vis spectroscopic techniques were used to study the hydroxide region of these compounds. 
Scheme 20: Accepted Mechanism for the Hydroxide-Catalyzed Reaction of $\alpha$-Hydroxyhippuric Acid.
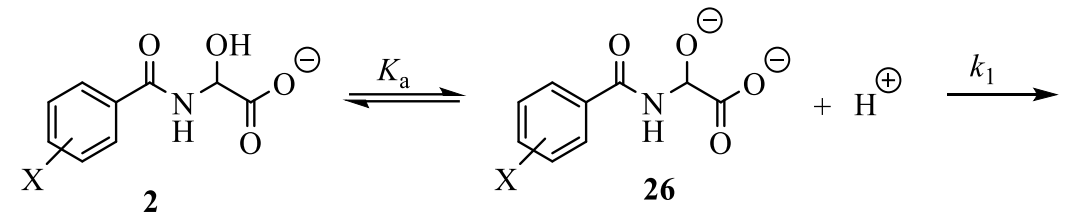<smiles>[X]c1ccc(C(=O)N[18OH])cc1</smiles><smiles>NC(=O)c1ccc(I)cc1</smiles>

\section{Hydroxide Dependent and Independent Region}

A unique characteristic of the $\alpha$-hydroxyhippuric acid derivatives, compared to previously studied carbinolamide compounds, was the presence of the carboxylate group. Although the $\mathrm{p} K_{\mathrm{a}}$ of the carboxylate group on the derivatives of $\mathbf{2}$ is not known, it is possible to draw some comparisons to other compounds with similar structure. For example, $\alpha$ hydroxyacetic acid has a $\mathrm{p} K_{\mathrm{a}}$ value of $3.83{ }^{88}$ It would be anticipated that the $\mathrm{p} K_{\mathrm{a}}$ of the derivatives of $\mathbf{2}$ would have similar or slightly lower $\mathrm{p} K_{\mathrm{a}}$ to $\alpha$-hydroxyacetic acid, due to the electron-withdrawing nature of the amide. In addition, the substituents on the aromatic ring of the amide would not be expected to have a significant effect on the $\mathrm{p} K_{\mathrm{a}}$ of the carboxylate, as Feken showed that they had little effect on the $\mathrm{p} K_{\mathrm{a}}$ of the hydroxyl group itself. ${ }^{69}$ While small variations of the $\mathrm{p} K_{\mathrm{a}}$ values of $\mathbf{2}$ may be expected, it is clear that at solution $\mathrm{p} H$ values above 5, the carboxylate will be fully deprotonated. With that in mind, what sort of effect would the carboxylate group have on the reactivity 2 ? The negative charge could affect the $\mathrm{p} K_{\mathrm{a}}$ of the hydroxyl group, but it could also provide electron density to assist in the departure of the benzamidate anion (see Scheme 20). 
Shown in Figure 11 is the $k_{\text {obsd }} v s$. [ $\left.\mathrm{OH}\right]$ for a number of the derivatives of $\mathbf{2}$ that were explored in this study. From the plots in Figure 11, at low [HO-] a first-order correlation between the hydroxide concentration and $k_{\text {obsd. }}$. As the hydroxide concentration was increased the correlation between $k_{\mathrm{obsd}}$ and $\left[\mathrm{HO}^{-}\right]$went from first-order to zero-order or the rate of the reaction became insensitive to changes in the [HO-]. This observation was in accord with the Feken studies and all the various carbinolamides studied to date. ${ }^{3,6-8,69}$ This observation suggests that the specific-base catalyzed reaction proposed in these other studies (see Scheme 20) was being used by the derivatives of $\mathbf{2}$ studied herein.

Further support for the mechanism shown in Scheme 20, comes from the studies below $\mathrm{p} H=12$ (see Figure 12). For the hydroxide-dependent rate studies performed below $\mathrm{p} H$ 12, various buffers were used to maintain the $\mathrm{pH}$ of the solution during kinetic testing. All kinetic studies were performed at varying [buffer] and no evidence for buffer catalysis was observed. This observation indicates that proton transfer is not occurring in the rate determining step of the reaction and provides support for a mechanism of the type shown in Scheme 20. 


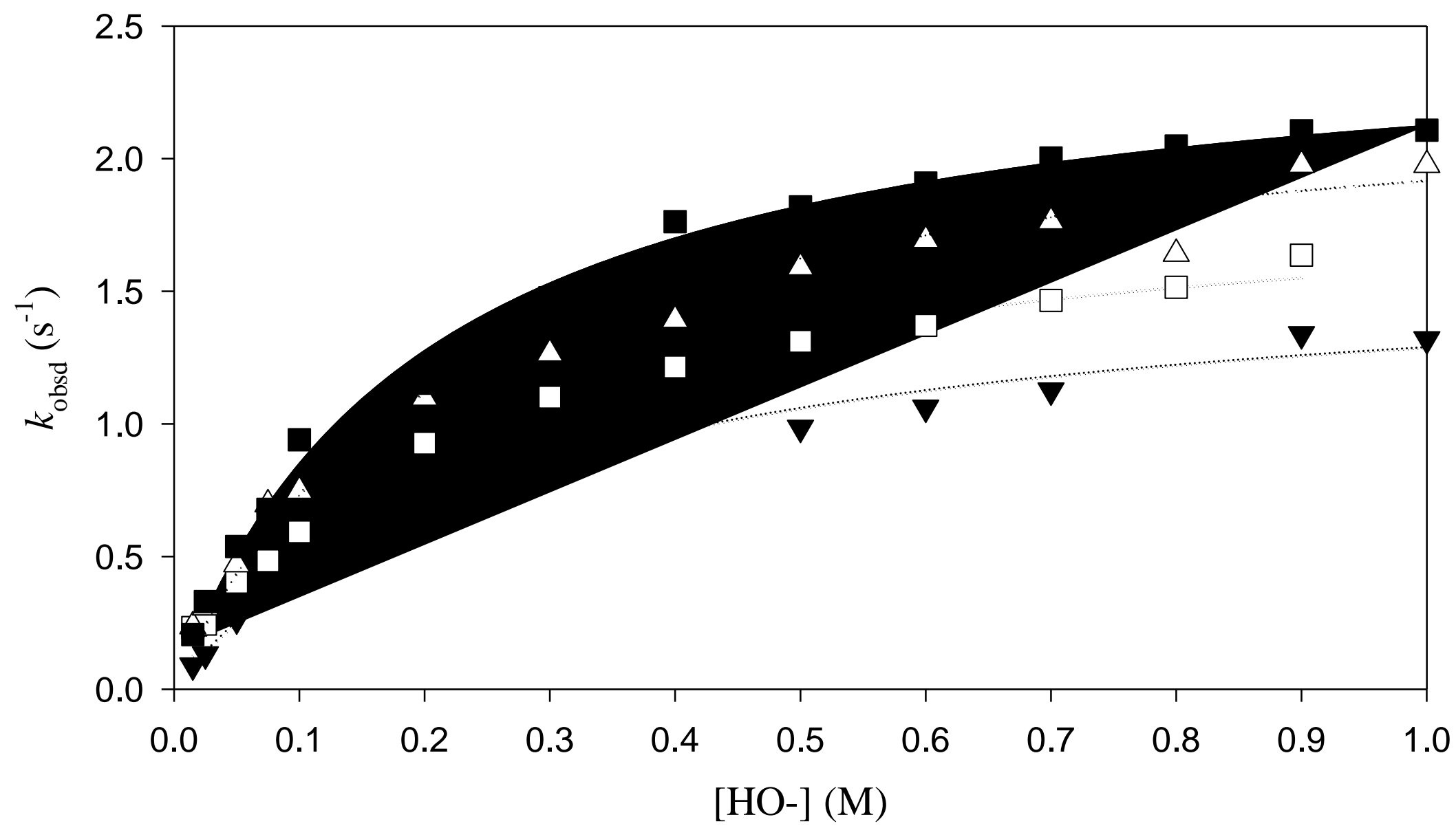

Figure 11: Effect of Increasing Hydroxide Concentration on the $k_{\text {obsd }}$ of $\alpha$-Hydroxyhippuric Acid Derivatives in Water, at $25{ }^{\circ} \mathrm{C}$ and $I$

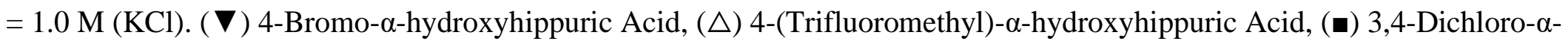
hydroxyhippuric Acid, ( $\square$ ) 3-Chloro- $\alpha$-hydroxyhippuric Acid. 


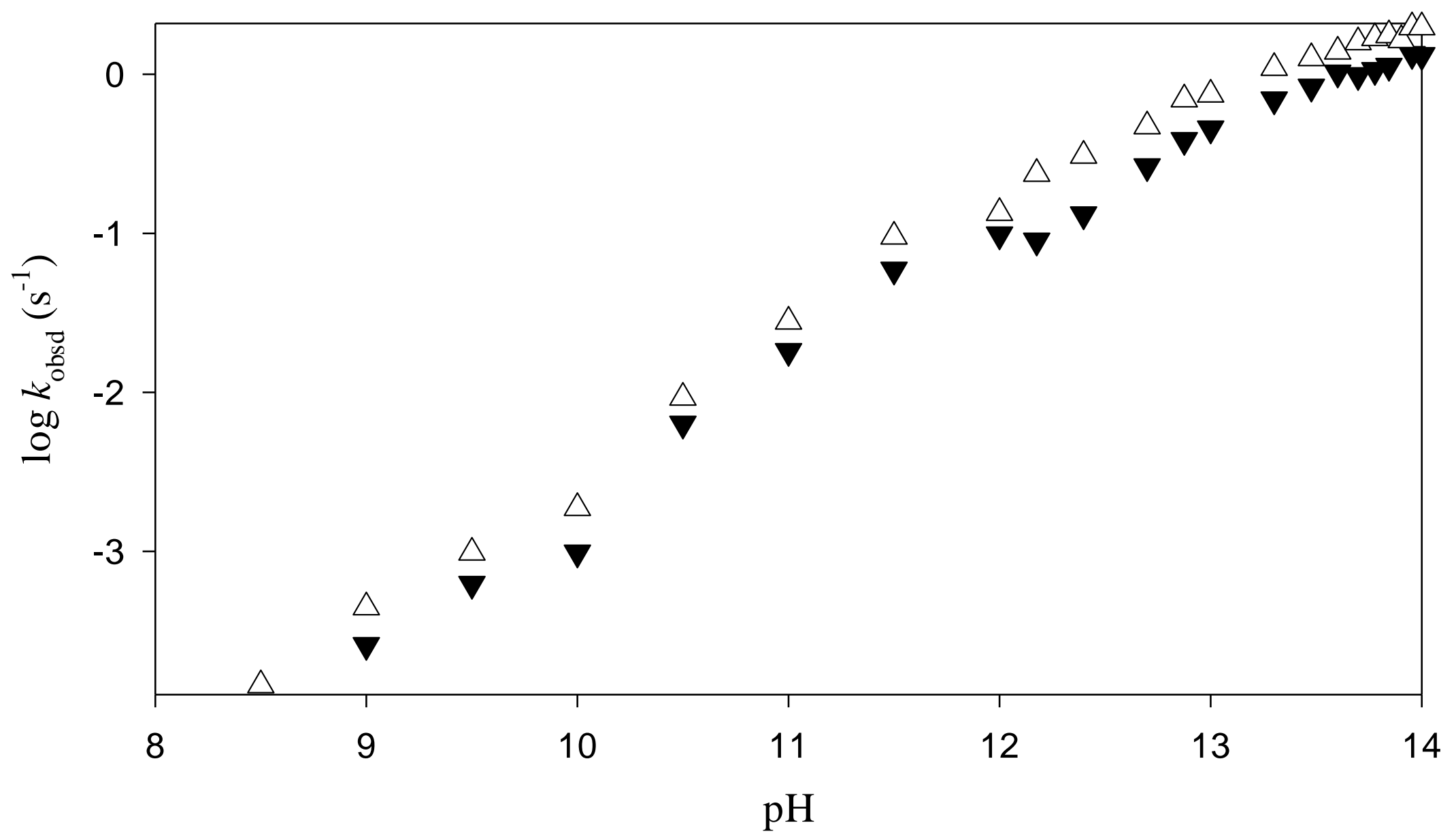

Figure 12: Effect of $\mathrm{p} H$ on the $k_{\mathrm{obsd}}$ of $\alpha$-Hydroxyhippuric Acid Derivatives in Water, at $25^{\circ} \mathrm{C}$ and $I=1.0 \mathrm{M}(\mathrm{KCl})$. ( $\left.\boldsymbol{\nabla}\right) 4$-Bromo- $\alpha$ hydroxyhippuric Acid, $(\triangle)$ 4-(Trifluoromethyl)- $\alpha$-hydroxyhippuric Acid. 
Based on the $\mathrm{pH}$-rate profile (Figure 10), the specific-base catalyzed mechanism seems to dominate at $\mathrm{p} H$ values above 6 . Keeping in mind the presumed $\mathrm{p} K_{\mathrm{a}}$ of the carboxylate group (about 3.8), ${ }^{88}$ the substrate carboxylate group should be fully deprotonated at $\mathrm{p} H$ values of 5 and above. In addition, Figure 11 exhibits saturation kinetics behavior with a first-order dependence switching to a zero-order dependence at higher $\left[\mathrm{HO}^{-}\right]$. Thus, we are proposing a specific-base catalyzed mechanism, as shown in Scheme 20, as the route by which the derivatives of 2 are reacting under hydroxide-dependent conditions. As shown in Scheme 20, there is an initial ionization of the hydroxyl group (assuming that the carboxylate has already been ionized at the $\mathrm{p} H$ under study), generating a dianion intermediate. Thus, an increase in the [hydroxide] would shift the equilibrium in the direction of the dianion (26), which is the species that undergoes ratelimiting breakdown.

Rate-determining breakdown of $\mathbf{2 6}$ involves the departure of a benzamidate anion and the formation of a glyoxylate anion, which will both be subsequently protonated to generate glyoxylate and benzamide. It is assumed that the large amount of negative charge on the glyoxylate portion of $\mathbf{2 6}$ provides an electronic push to assist the departure of the benzamidate leaving group. The rate expression for the mechanism shown in Scheme 20 is as shown in equation 5. The data from Figure 11 was fit to equation 5, and these fits are represented by the lines in Figure 11. From these fits both $k_{1}$ and $K_{\mathrm{a}}$ for the derivatives were determined and these values are listed in Table 3.

$$
\begin{aligned}
& \left(k_{\mathrm{obsd}}\right)^{\mathrm{OH}^{-}}=k_{1} \frac{K_{\mathrm{a}}[\mathrm{OH}]^{-}}{K_{W}+K_{\mathrm{a}}[\mathrm{OH}]^{-}} \\
& \left(k_{\mathrm{obsd}}\right)^{\mathrm{OH}^{-}}=k_{1} \frac{K_{\mathrm{a}}[\mathrm{OH}]^{-}}{K_{W}}=k_{1}^{\prime}[\mathrm{OH}]^{-}
\end{aligned}
$$


Table 3: Rate Constants for the Hydroxide-Dependent Reactions of $\alpha$-Hydroxyhippuric Acid Derivatives and their $\mathrm{p} K_{\mathrm{a}}$ 's in Water at $25^{\circ} \mathrm{C}$, and $I=1.0 \mathrm{M}(\mathrm{KCl})$.

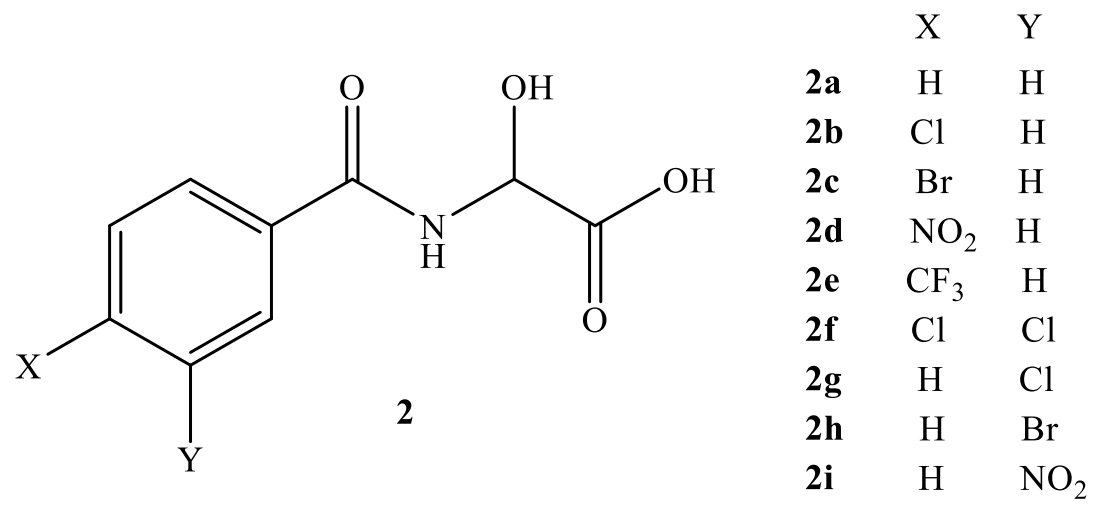

\begin{tabular}{cccccc}
\hline Compound & & $k_{1}\left(\mathrm{~s}^{-1}\right)$ & $K_{\mathrm{a}}(\mathrm{M})$ & $\mathrm{p} K_{\mathrm{a}}$ & $k_{1}^{\prime}\left(\mathrm{M}^{-1} \mathrm{~s}^{-1}\right)$ \\
\hline $3-\mathrm{Br}$ & $\mathbf{2 h}$ & 2.004 & $4.369 \times 10^{-14}$ & 13.35 & 5.921 \\
$3-\mathrm{Cl}$ & $\mathbf{2 g}$ & 1.958 & $4.333 \times 10^{-14}$ & 13.36 & 5.599 \\
$4-\mathrm{Br}$ & $\mathbf{2 c}$ & 1.643 & $3.604 \times 10^{-14}$ & 13.44 & 8.755 \\
$4-\mathrm{CF} 3$ & $\mathbf{2 e}$ & 2.336 & $4.556 \times 10^{-14}$ & 13.34 & 10.643 \\
$4-\mathrm{Cl}$ & $\mathbf{2 b}$ & 1.735 & $3.227 \times 10^{-14}$ & 13.49 & 8.484 \\
$4-\mathrm{NO}{ }_{2}$ & $\mathbf{2 d}$ & 4.411 & $3.848 \times 10^{-14}$ & 13.41 & 16.974 \\
$3,4-\mathrm{diCl}$ & $\mathbf{2 f}$ & 2.548 & $5.015 \times 10^{-14}$ & 13.30 & 12.778 \\
\hline
\end{tabular}




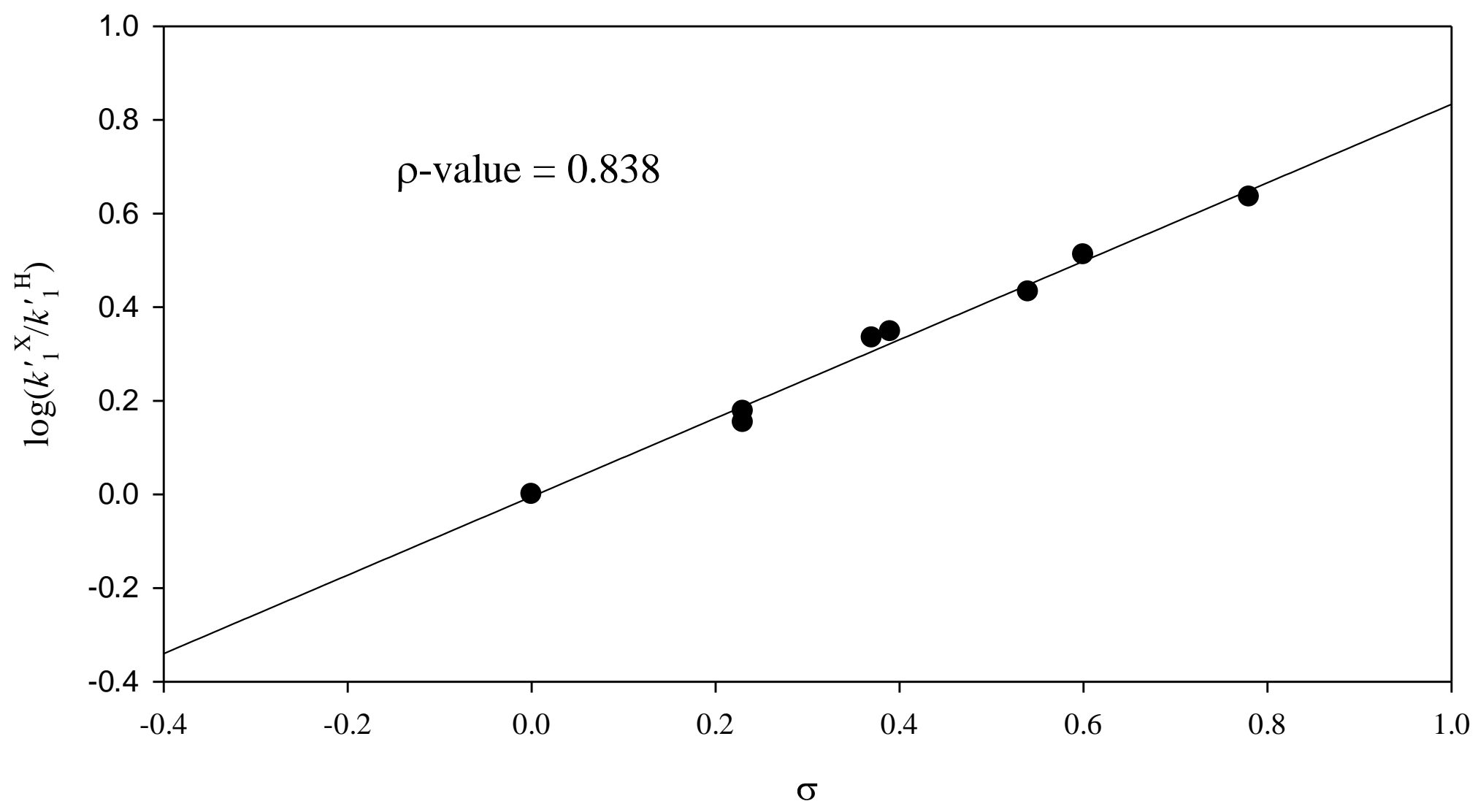

Figure 13: Hammett Plot of Apparent Second-Order Rate Constants $\left(k_{1}^{\prime}\right)$ for the Hydroxide Reaction of $\alpha$-Hydroxyhippuric Acid Derivatives with Electron Withdrawing Groups in Water, at $25^{\circ} \mathrm{C}$ and $I=1.0 \mathrm{M}(\mathrm{KCl})$. 


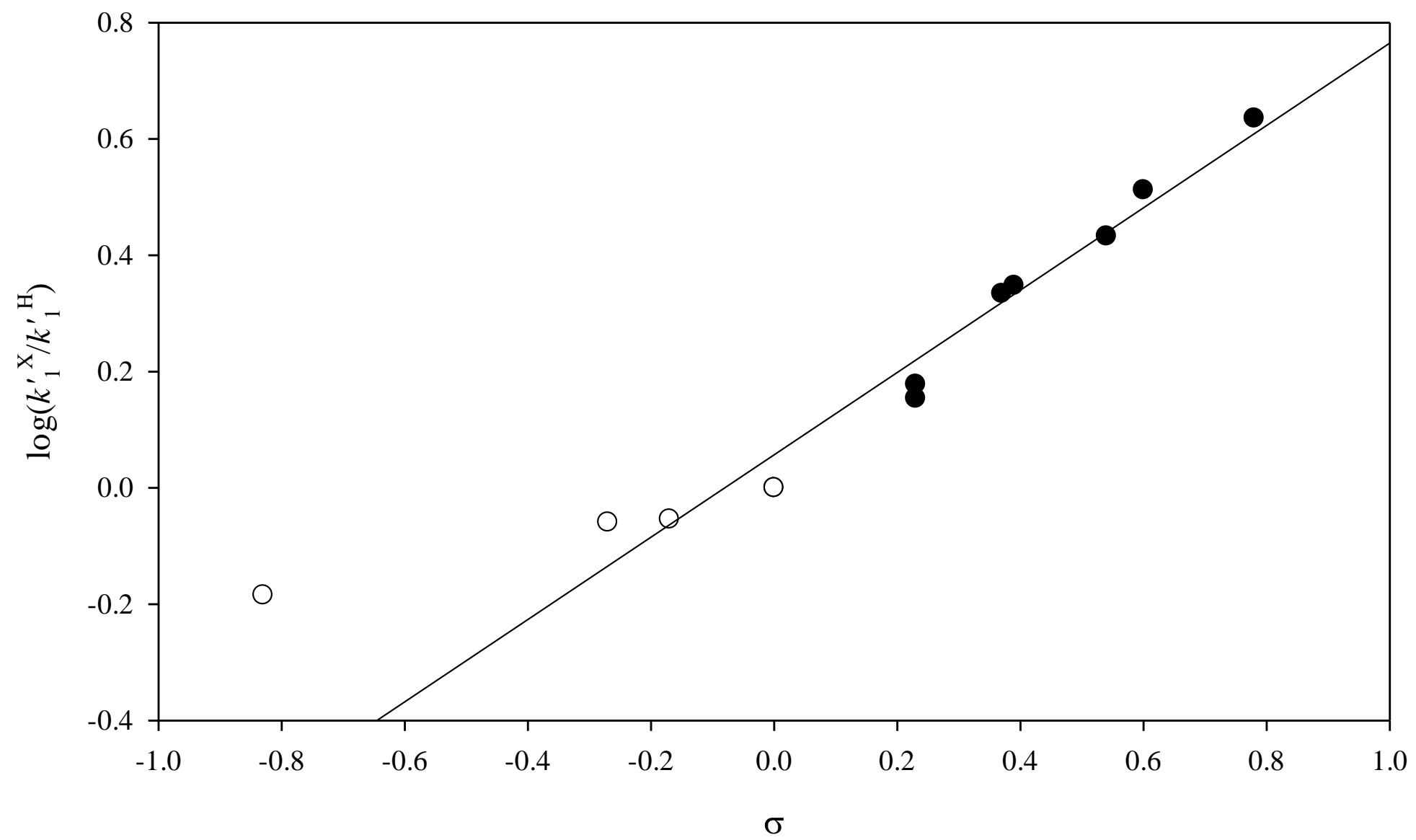

Figure 14: Hammett Plot of Apparent Second-Order Rate Constants $\left(k_{1}^{\prime}\right)$ for the Hydroxide Reaction of all $\alpha$-Hydroxyhippuric Acid Derivatives in Water, at $25^{\circ} \mathrm{C}$ and $I=1.0 \mathrm{M}(\mathrm{KCl})$. 
Apparent Second-Order Rate Constant ( $\left.\boldsymbol{k}_{1}^{\prime}\right)$ : From equation 5, if the $\left[\mathrm{HO}^{-}\right]$is low, then $K_{\mathrm{a}}\left[\mathrm{HO}^{-}\right]$will be small compared to the $K_{\mathrm{w}}$ and the rate expression simplifies to equation 6 . This equation would represent the linear portion of the hydroxide-dependent data shown in Figure 10 $\& 12$. This value has been referred to as the apparent second order rate constant $\left(k_{1}^{\prime}\right)$ for hydroxide-catalyzed breakdown of carbinolamides. The apparent second-order rate constant data for the derivatives of $\mathbf{2}$ studied herein are reported in Table 3, along with the other rate constants determined from the fit of the date to eq. 5 .

The $k_{1}^{\prime}$ data show that as the substituent group becomes increasingly electron withdrawing, the rate of the reaction increases. The Hammett plot of the $k_{1}^{\prime}$ data (Figure 13), shown in Table 3, was linear with a $\rho$-value of 0.84 . The linearity of the plot indicates that a similar mechanism has been utilized for the differently substituted carbinolamides studied. If the data from the previous study by Feken was included in the plot (see Figure 14) the plot was also linear, however the $\rho$-value $=0.71 .^{69}$ (The data point for the $N, N$-dimethylamine compound was not included in the plot.) This $\rho$-value includes both changes to the $K_{\mathrm{a}}$ and $k_{1}$, but its greatest value lies in its linearity as it indicates a similar mechanism for all of the compounds studied.

The reactivity of the derivatives of $\mathbf{2}$, with regard to the $k_{1}^{\prime}$ values fall in between those values reported for $N$-(hydroxymethyl)benzamide and $N$-(hydroxybenzyl)benzamide but with their reactivity being much more closely aligned with the $N$-(hydroxymethyl)benzamide compounds. ${ }^{3,78}$

Dissociation Constant of the Hydroxyl Group $\left(\boldsymbol{K}_{a}\right)$ : As stated above, when the data in Figure 11 was fitted to eq. 5 , the values of the $K_{\mathrm{a}}$ and the limiting rate $\left(k_{1}\right)$ could be determined. The data in Table 3 provides the $K_{\mathrm{a}}$ and associated $\mathrm{p} K_{\mathrm{a}}$ values for the hydroxyl group of the carbinolamide for the compounds studied herein. As with previous studies, there was no strong 
correlation between the substituent on the aromatic ring of the amide and the $\mathrm{p} K_{\mathrm{a}}$ of the hydroxyl group of the derivatives of $2^{3,7,8,69} \mathrm{In}$ fact, Feken reported that there was no effect of substitution on the $K_{\text {a }}$ of the hydroxyl group of the derivatives of $\mathbf{2}$ that were studied ${ }^{69}$

The average of the $\mathrm{p} K_{\mathrm{a}}$ values shown in Table 3 is 13.38 and the average of the values determine by Feken was 13.23, which does not represent a large difference between the two sets of data. ${ }^{69}$ This difference could be real or just the result of subtle differences in the experiments between the two studies. These values compare to values of $\sim 13.0$ for the $N$ (hydroxymethyl)benzamide derivatives and $\sim 12.8$ for the $N$-(hydroxybenzyl)benzamide derivatives. ${ }^{3,8}$ While these differences are all small, the derivatives of $\mathbf{2}$ are the least acidic of the carbinolamides studied and we propose that it is the charge on the carboxylate group that decreases the acidity of the hydroxyl group through inductive and field effects relative to other compounds that have been studied.

Shown in Figure 15 is the Hammett plot of the $K_{\mathrm{a}}$ values determined herein. While a correlation line can be fit to the data, it is obvious that the fit is not a strong one ( $\rho$-value $=$ $\left.0.057 ; r^{2}=0.043\right)$. Shown in Figure 16 is the plot of all the derivatives of 2 that have been investigated in this study and the previous study. ${ }^{69}$ From both Figure 15 and 16, it is clear that no strong correlation exists between the substituents on the aromatic ring of the amide and the ionization constant for the hydroxyl group. This is not too surprising as the carboxylate provides the dominant effect due to its proximity to the hydroxyl group. 


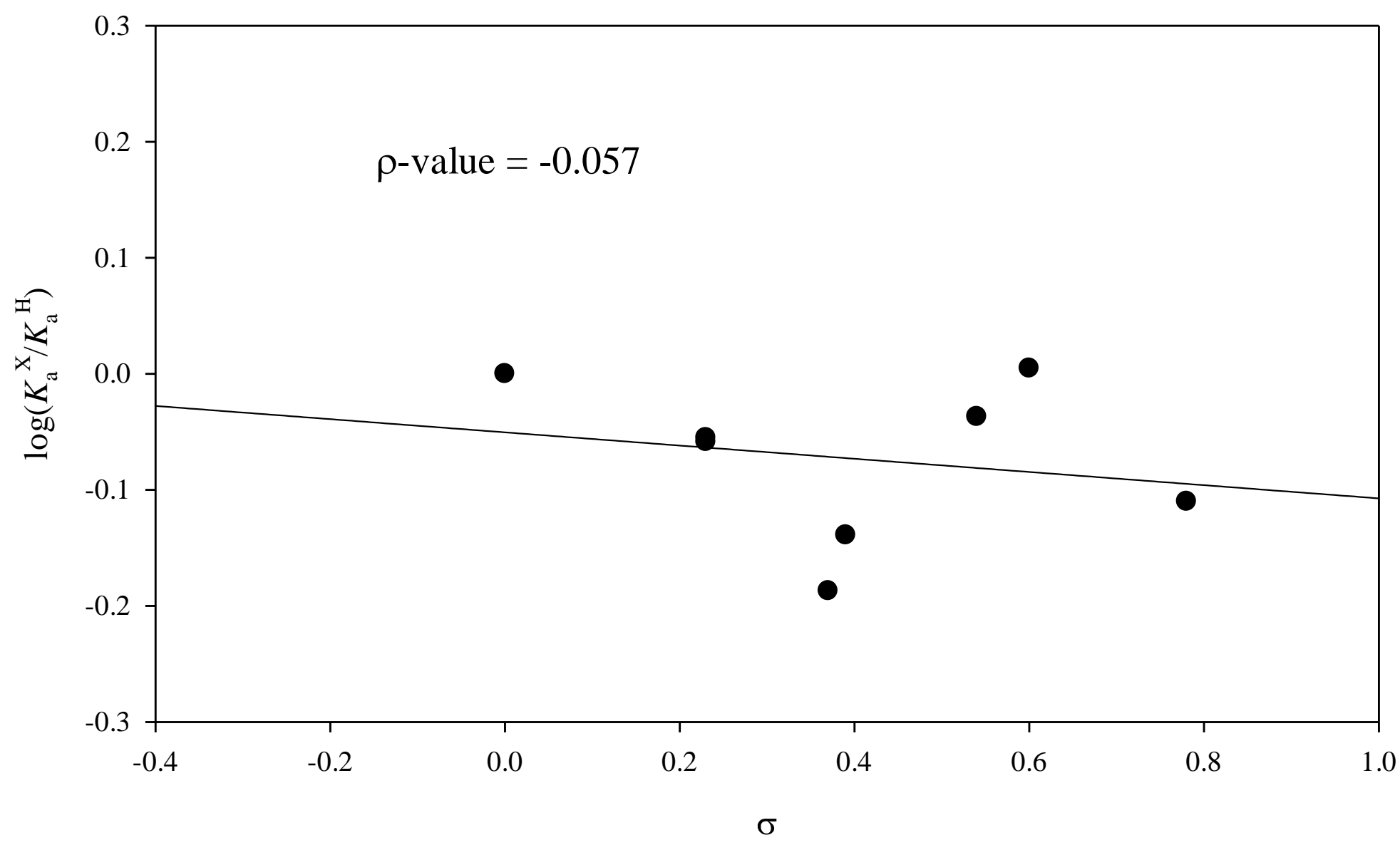

Figure 15: Hammett Plot of Dissociation Constants $\left(K_{\mathrm{a}}\right)$ of the Hydroxyl Group for the Hydroxide Reaction of $\alpha$-Hydroxyhippuric Acid Derivatives with Electron Withdrawing Groups in Water, at $25^{\circ} \mathrm{C}$ and $I=1.0 \mathrm{M}(\mathrm{KCl})$. 


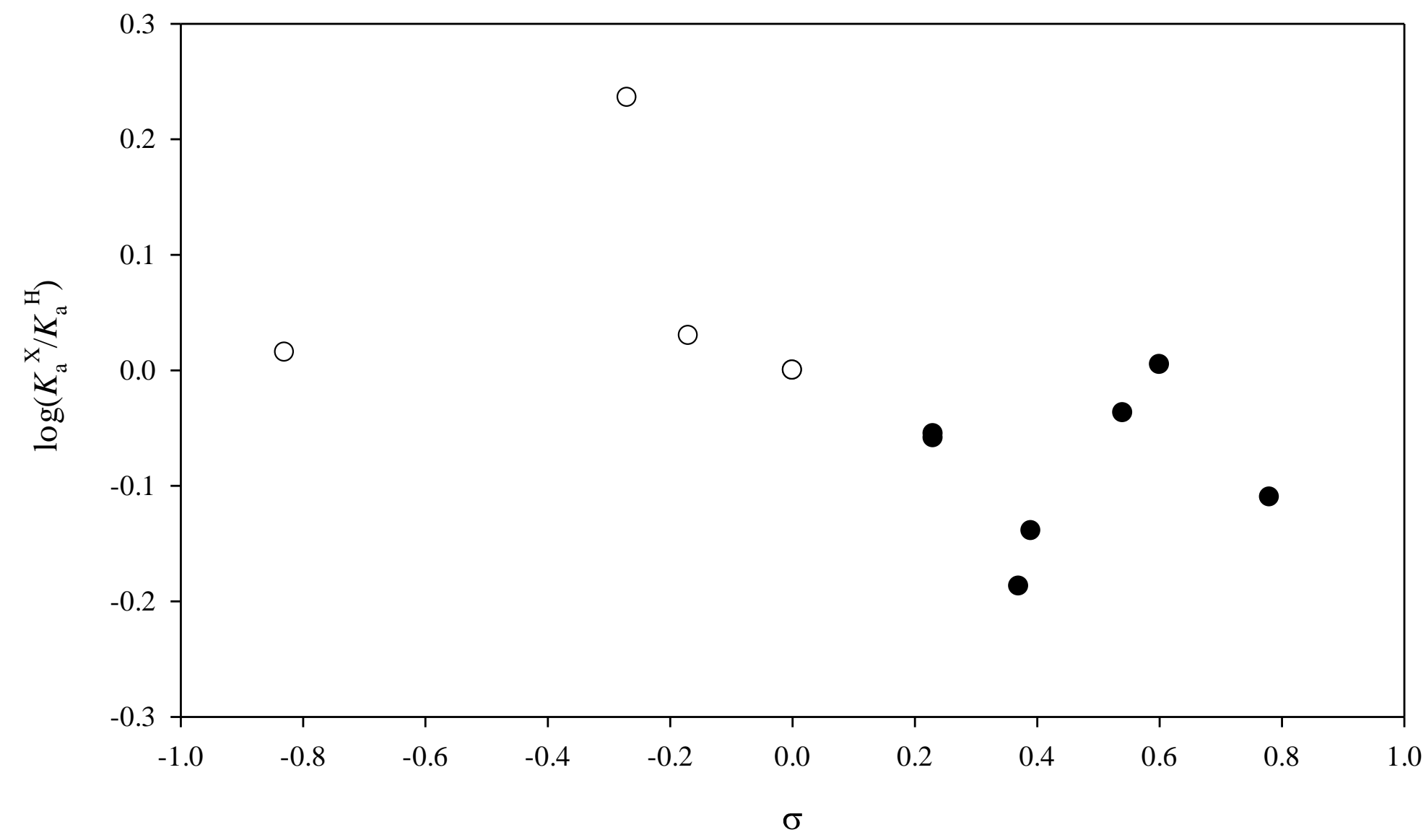

Figure 16: Hammett Plot of Dissociation Constants $\left(K_{\mathrm{a}}\right)$ of the Hydroxyl Group for the Hydroxide Reaction of $\alpha$-Hydroxyhippuric Acid Derivatives in Water, at $25^{\circ} \mathrm{C}$ and $I=1.0 \mathrm{M}(\mathrm{KCl})$. 
First-Order Rate Constant $\left(\boldsymbol{k}_{1}\right)$ : Also provided in Table 3 are the first-order rate constants or the limiting rate for the hydroxide-dependent reaction $\left(k_{1}\right)$. This rate constant has been referred to as the limiting rate, as it is the fastest rate at which the hydroxide-independent will react for a particular compound (see Figure 11). It is clear, from the data in Table 3, that the substituents on the aromatic ring of $\mathbf{2}$ have a substantial effect on the rate of the reaction, with the $\mathbf{2 d}$ reacting approximately four times faster than $\alpha$-hydroxyhippuric acid (2a). This result can be rationalized as $k_{1}$ is the rate-limiting step of the reaction and it involves the departure of the benzamidate leaving group (see Scheme 20). From Table 3, as the substituent on the aromatic ring of the amide becomes increasingly electron-withdrawing, the $k_{1}$ value increases. This observation supports the idea that there was a buildup of negative charge in the transition state of the reaction leading to the departure of the benzamidate leaving group. The electron-withdrawing groups must be inductively stabilizing the developing negative charge and assisting in the departure of the benzamidate leaving group.

The substituent effect can be more clearly observed in Figure 17 where the Hammett correlation has been plotted for the $k_{1}$ rate constant. The linearity of the plot indicates that the $\alpha$ hydroxyhippuric acid derivatives undergo a similar mechanism of breakdown, where the positive slope value indicates that a build-up of negative charge is being generated in the transition state of the rate-determining step. As mentioned previously this charge build-up can be stabilized by the electron withdrawing substituents on the aromatic ring via inductive effects. The $\rho$-value of for the plot shown in Figure 17 was $\rho$-value $=0.73$. This value is in reasonable agreement with the $\rho$-value $=0.62$, determined by Feken. ${ }^{69}$ When the Feken data were added to the data determined for the derivatives of $\mathbf{2}$ studied here the $\rho$-value changed to -0.74 (see Figure 18). 


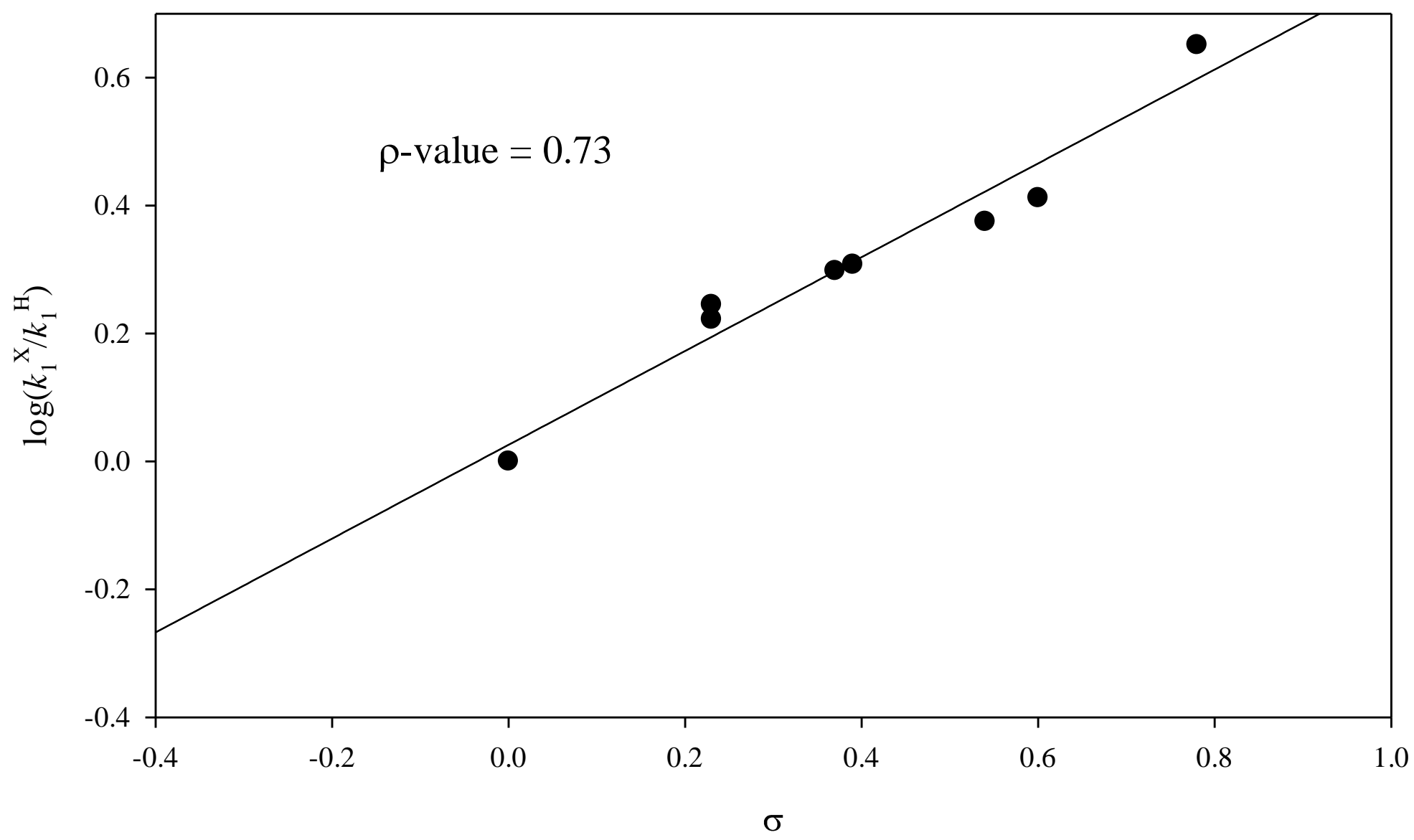

Figure 17: Hammett Plot of First-Order Rate Constants $\left(k_{1}\right)$ for the Hydroxide Reaction of $\alpha$-Hydroxyhippuric Acid Derivatives with Electron withdrawing groups in Water, at $25^{\circ} \mathrm{C}$ and $I=1.0 \mathrm{M}(\mathrm{KCl})$. 


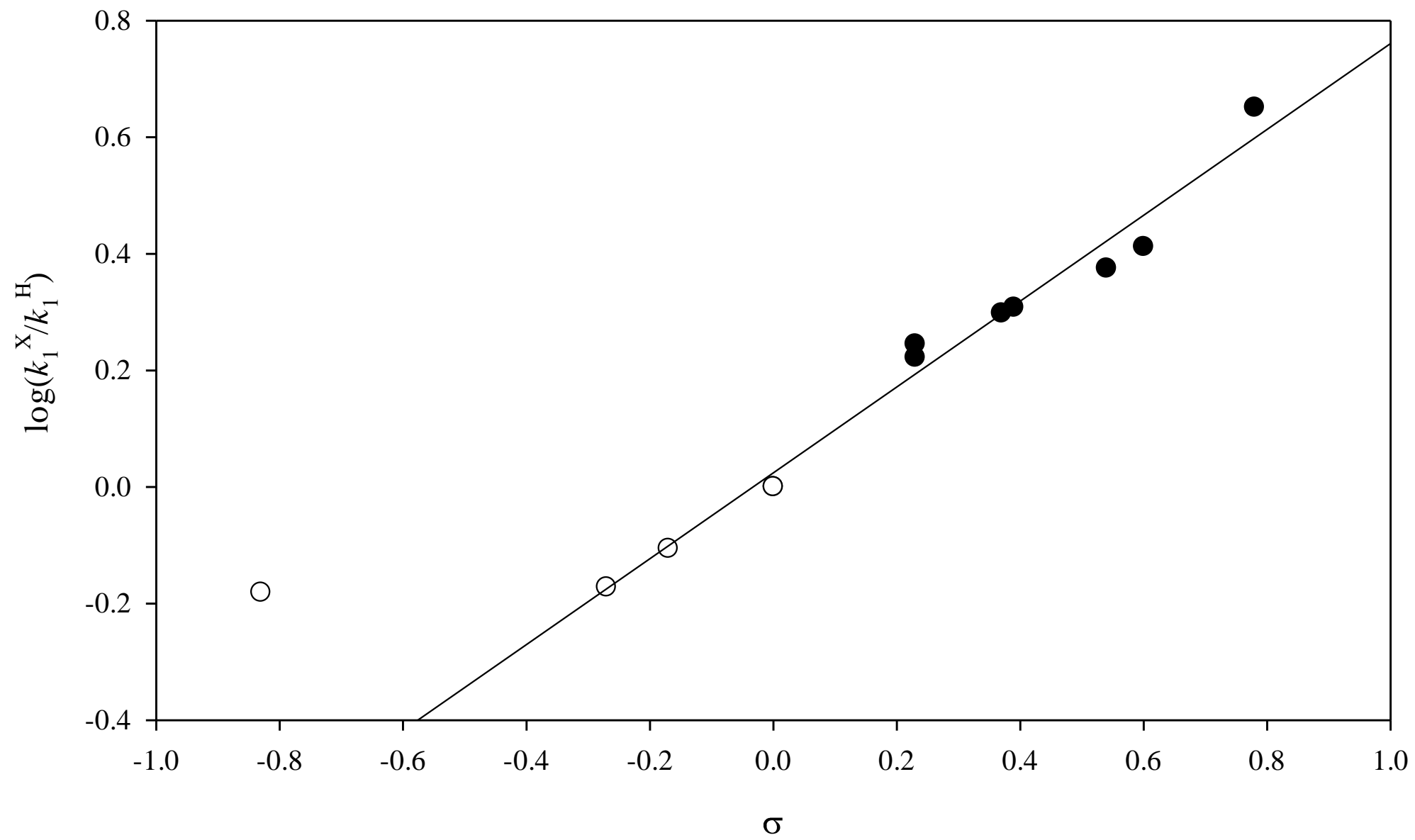

Figure 18: Hammett Plot of First-Order Rate Constants $\left(k_{1}\right)$ for the Hydroxide Reaction of $\alpha$-Hydroxyhippuric Acid Derivatives in Water, at $25^{\circ} \mathrm{C}$ and $I=1.0 \mathrm{M}(\mathrm{KCl})$. 
The strong correlation of the data from two independent studies indicates that all of the compounds studied react by the same mechanism. The only data point that does not fall on the line was that for the $N, N$-dimethylamino compound. The $N, N$-dimethylamino compound has fallen off the line in many of the studies involving carbinolamide chemistry. It is becoming clear that it may not be the data that is the problem but rather the Hammett sigma value for the effect of $N, N$-dimethylamino in the para-position that may have been the problem. This datum point aside, the correlation of the remainder of the data was quite good.

The $\rho$-value of the derivatives of 2 being 0.74 is similar to those values determined for $N$ (hydroxymethyl)benzamide $(\rho \text {-value }=0.67)^{8}$ and $N$-(hydroxybenzyl)benzamide $(\rho$-value $=$ 0.65). ${ }^{3}$ The $\rho$-value for the derivatives of $\mathbf{2}$ would suggest that $\alpha$-hydroxyhippuric acid was more sensitive to the effects of the substituents than are the two previously studied systems. This greater sensitivity could be related to differences in charge development during the rate-limiting step. That is, there was more charge development on the benzamidate during the reaction of 2 than with $N$-(hydroxymethyl)benzamide and $N$-(hydroxybenzyl)benzamide derivatives. This would suggest that there was greater bond breaking in the case of the derivatives of $2 \mathrm{vs}$. the other compounds studied.

What is interesting is the fact that in all the compounds that have been studied, it is the same set of leaving groups that have been investigated. Thus, the nucleofugality has stayed the same yet fluctuations in the $\rho$-value have occurred. The larger $\rho$-value observed for the derivatives of $\mathbf{2}$ probably stems from the greater electronic push from the negative charge on the hydroxyl group and the negative charge on the carboxylate. 


\section{Conclusions}

The derivatives of $\mathbf{2}$ studied here were all substituted with electron withdrawing groups, but, as shown in several plots, provide an expansion of our understanding of the reactivity of these compounds when coupled with the results of previous studies. ${ }^{69}$ The compounds studied here are intrinsically interesting but the fact that they are substrates for the PAM enzyme means that the results of these studies could have direct implications to the enzymatic catalyzed reaction.

The results presented here point to an E1cb-type reaction for the hydroxide-dependent reaction. That is, there is a specific base deprotonation of the hydroxyl group of the carbinolamide to generate the conjugate base, and it is this species that undergoes ratedetermining breakdown (see Scheme 20). This conclusion was supported by the shape of the $k_{\text {obsd }}$ $v s .\left[\mathrm{HO}^{-}\right]$plot, that changed from a first-order dependence at lower $\left[\mathrm{HO}^{-}\right]$, to a zero-order dependence at higher concentrations. This observation indicated that, while hydroxide affects the rate of the reaction, it does not appear to be involved in the rate-determining step. Further support for this conclusion comes in the form of buffer catalysis studies which showed no evidence for the presence of a buffer catalyzed reaction, indicating that proton transfer was not occurring in the rate-determining step of the reaction.

The Hammett correlation of the $K_{\mathrm{a}}$ values showed that the substituents had very little effect on the $K_{\mathrm{a}}$ of the hydroxyl group of the derivatives of 2. Figure 16 shows the Hammett plot of all available data for the $K_{\mathrm{a}}$ of the derivatives of $\mathbf{2}$. While no correlation line was shown, there does seem to be a slight downward slope to the data which would be contrary to the expected effect of the electron-withdrawing groups on the $K_{\mathrm{a}}$ of the hydroxyl group. This plot was simply interpreted as there was no discernable change in the $K_{\mathrm{a}}$ of the hydroxyl group over the range of 
derivatives of $\mathbf{2}$ that have been studied. The substituents have a more significant effect on the departure of the amidate leaving group.

The data support a rate-determining step involving the departure of the benzamidate leaving group from the conjugate base of the carbinolamide (see Scheme 20). The Hammett plot of the values of $k_{1}$ show a significant effect on the nature of the substituent on the derivatives of 2 (see Figure 18). The linear plot of the $k_{1}^{\prime}$ (Figure 14) and $k_{1}$ values (Figure 18) indicate that all the compounds react via the same mechanism which involved the generation of an amidate. The ability of the electron-withdrawing groups to stabilize the developing negative charge on the benzamidate leaving groups, increases their nucleofugality relative to those bearing electrondonating groups.

These results imply that any rate enhancement generated by PAL on the reaction of carbinolamides would not be due to acid/base catalysis involving the hydroxyl group of the carbinolamide. The data for the derivatives of $\mathbf{2}$ clearly indicates that the conjugate base of $\mathbf{2}$ (26) has a significant lifetime and it is the departure of the amidate leaving group that must be catalyzed. Implied in these statements is the assumption that the hydroxide-dependent route is the mechanism being used by PAL. 


\section{WORKS CITED}

(1) Ankem, R. V.; Murphy, J. L.; Nagorski, R. W. Tetrahedron Lett. 2008, 49, 6547.

(2) Stewart, S. C. Master of Science Thesis, Illinois State University, 2012.

(3) Koyanagi, T.; Siena, P. M.; Przybyla, D. E.; Rafie, M. I.; Nagorski, R. W. J. Org. Chem. 2020, 85, 1115.

(4) Mennenga, A. G.; Johnson, A. L.; Nagorski, R. W. Tetrahedron Lett. 2005, 46, 3079.

(5) Murphy, J. L.; Tenn, W. J.; Labuda, J. J.; Nagorski, R. W. Tetrahedron Lett. 2009, 50, 7358.

(6) Sansone, M. F.; Koyanagi, T.; Przybyla, D. E.; Nagorski, R. W. Tetrahedron Lett. 2010, $51,6031$.

(7) Tenn, W. J.; French, N. L.; Nagorski, R. W. Org. Lett 2001, 3, 75.

(8) Tenn, W. J., III; Murphy, J. L.; Bim-Merle, J. K.; Brown, J. A.; Junia, A. J.; Price, M. A.; Nagorski, R. W. J. Org. Chem. 2007, 72, 6075.

(9) Bradbury, A. F.; Finnie, M. D. A.; Smyth, D. G. Nature 1982, 298, 686.

(10) Chung, F. L.; Nath, R. G.; Nagao, M.; Nishikawa, A.; Zhou, G. D.; Randerath, K. Mutat. Res. 1999, 424, 71.

(11) Eipper, B. A.; Mains, R. E. Annu.Rev. Physiol. 1988, 50, 333.

(12) Marnett, L. J. Mutat. Res. 1999, 424, 83.

(13) McIninch, J. K.; McIninch, J. D.; May, S. W. J. Biol. Chem. 2003, 278, 50091.

(14) Takada, Y.; Noguchi, T. Biochem. J. 1986, 235, 391.

(15) Vilanova, B.; Fernandez, D.; Casasnovas, R.; Pomar, A. M.; Alvarez-Idaboy, J. R.; Hernandez-Haro, N.; Grand, A.; Adrover, M.; Donoso, J.; Frau, J.; Munoz, F.; Ortega-Castro, J. Int. J. Biol. Macromol. 2017, 98, 664. 
(16) Young, S. D.; Tamburini, P. P. J. Am. Chem. Soc. 1989, 111, 1933.

(17) Agatsuma, T.; Akama, T.; Nara, S.; Matsumiya, S.; Nakai, R.; Ogawa, H.; Otaki, S.; Ikeda, S.-i.; Saitoh, Y.; Kanda, Y. Org. Lett. 2002, 4, 4387.

(18) Asami, Y.; Kakeya, H.; Onose, R.; Yoshida, A.; Matsuzaki, H.; Osada, H. Org. Lett 2002, 4, 2845.

(19) Emoto, M.; Yano, K.; Choijamts, B.; Sakai, S.; Hirasawa, S.; Wakamori, S.; Aizawa, M.; Nabeshima, K.; Tachibana, K.; Kanomata, N. Anticancer Res. 2015, 35, 2739.

(20) Hayashi, Y.; Shoji, M.; Yamaguchi, J.; Sato, K.; Yamaguchi, S.; Mukaiyama, T.; Sakai, K.; Asami, Y.; Kakeya, H.; Osada, H. J. Am. Chem. Soc. 2002, 124, 12078.

(21) Kakeya, H.; Takahashi, I.; Okada, G.; Isono, K.; Osada, H. J. Antibiot 1995, 48, 733.

(22) Lawson, M. R.; Dyer, K.; Berger, J. M. bioRxiv, Biochem. 2016, 1.

(23) Li, L.; Tang, M.-C.; Gao, S.; Soliman, S.; Hang, L.; Xu, W.; Tang, Y.; Tang, S.; Ye, T.; Watanabe, K. J. Am. Chem. Soc. 2018, 140, 2067.

(24) Miyamura, S.; Ogasawara, N.; Otsuka, H.; Niwayama, S.; Takana, H.; Take, T.; Uchiyama, T.; Ochiai, H.; Abe, K.; Koizumi, K.; Asao, K.; Matuski, K.; Hoshino, T. J. Antibiot. 1972, 25, 610 .

(25) Miyoshi, T.; Miyari, N.; Aoki, H.; Kohsaka, M.; Sakai, H.; Imanaka, H. J. Antibiot. 1972, 25, 569 .

(26) Nakai, R.; Ogawa, H.; Asai, A.; Ando, K.; Agatsuma, T.; Matsumiya, S.; Akinaga, S.; Yamashita, Y.; Mizukami, T. J. Antibiot 2000, 53, 294.

(27) Singh, S. B.; Goetz, M. A.; Jones, E. T.; Bills, G. F.; Giacobbe, R. A.; Herranz, L.; Stevensmiles, S.; Williams, D. L. J. Org. Chem. 1995, 60, 7040. 
(28) Suzuki, S.; Hosoe, T.; Nozawa, K.; Kawai, K.; Yaguchi, T.; Udagawa, S. J. Nat. Prod 2000, 63, 768.

(29) Vela, M.; Kohn, H. J. Org. Chem. 1992, 57, 5223.

(30) Williams, R. M.; Durham, C. A. Chem. Rev. 1988, 88, 511.

(31) Williams, R. M.; Tomizawa, K.; Armstrong, R. W.; Dung, J.-S. J. Am. Chem. Soc. 1987, $109,4028$.

(32) Zaugg, H. E.; Martin, W. B. Org. Reactions 1965, 14, 52.

(33) Burgus, R.; Dunn, T. F.; Desiderio, D. M.; Ward, D. N.; Vale, W.; Guillemin, R.; Felix, A. M.; Gillessen, D.; Studer, R. O. Endocrinology 1970, 86, 573.

(34) Driscoll, W. J.; Konig, S.; Fales, H. M.; Pannell, L. K.; Eipper, B. A.; Mueller, G. P. Biochemistry 2000, 39, 8007.

(35) Francisco, W. A.; Merkler, D. J.; Blackburn, N. J.; Klinman, J. P. Biochemistry 1998, 37, 8244.

(36) Freeman, J. C.; Villafranca, J. J. J. Am. Chem. Soc. 1993, 115, 4923.

(37) Girard, B.; Ouafik, L.; Boudouresque, F. Cell \& Tissue Research 1999, 298, 489.

(38) King, L.; Barnes, S.; Glufke, U.; Henz, M. E.; Kirk, M.; Merkler, K. A.; Vederas, J. C.; Wilcox, B. J.; Merkler, D. J. Arch. Biochem. and Biophys. 2000, 374, 107.

(39) Merkler, D. J.; Kulathila, R.; Ash, D. E. Arch. Biochem. and Biophys. 1995, 317, 93.

(40) Merkler, D. J.; Kulathila, R.; Consalvo, A. P.; Young, S. D.; Ash, D. E. Biochemistry $1992,31,7282$.

(41) Moore, A. B.; May, S. W. Biochemical Journal 1999, 341, 33.

(42) Nishino, S.; Kunita, M.; Kani, Y.; Ohba, S.; Matsushima, H.; Tokii, T.; Nishida, Y. Inorganic Chemistry Communications 2000, 3, 145. 
(43) Ramer, S. E.; Cheng, H.; Palcic, M. M.; Vederas, J. C. J. Am. Chem. Soc. 1988, 110, 8526.

(44) Rittel, W.; Maier, R.; Brugger, M.; Kamber, B.; Riniker, B.; Sieber, P. Experientia 1976, $32,246$.

(45) Wilcox, B. J.; Ritenour-Rodgers, K. J.; Asser, A. S.; Baumgart, L. E.; Baumgart, M. A.;

Boger, D. L.; DeBlassio, J. L.; deLong, M. A.; Glufke, U.; Henz, M. E.; King, L.;

Merkler, K. A.; Patterson, J. E.; Robleski, J. J.; Vederas, J. C.; Merkler, D. J.

Biochemistry 1999, 38, 3235.

(46) Bundgaard, H. In Design of Prodrugs; Bundgaard, H., Ed.; Elsevier: Amsterdam, 1985, $\mathrm{p} 1$.

(47) Bundgaard, H.; Buur, A. Int. J. Pharm. 1987, 37, 185.

(48) Bundgaard, H.; Johansen, M. Int. J. Pharm. 1980, 5, 67.

(49) Bundgaard, H.; Johansen, M. Int. J. Pharm. 1984, 22, 45.

(50) Johansen, M.; Bundgaard, H. Arch. Pharm. Chem. Sci. Edn. 1979, 7, 175.

(51) Abuzar, S.; Kohn, H. J. Am. Chem. Soc. 1988, 110, 4089.

(52) Abuzar, S.; Kohn, H. J. Am. Chem. Soc. 1989, 111, 4895.

(53) Abuzar, S.; Kohn, H. J. Org. Chem. 1989, 54, 4000.

(54) Abuzar, S.; Kohn, H. J. Am. Chem. Soc. 1990, 112, 3114.

(55) Park, H.-g.; Vela, M.; Kohn, H. J. Am. Chem. Soc. 1994, 116, 471.

(56) Park, H.-g.; Zhang, X.; Moon, H.-S.; Zwiefka, A.; Cox, K.; Gaskell, S. J.; Widger, W. R.; Kohn, H. Arch. Biochem. Biophys. 1995, 323, 447.

(57) Someya, A.; Iseki, M.; Tanaka, N. J Antibiot (Tokyo) 1978, 31, 712. 
(58) Vincent, F.; Widger, W. R.; Openshaw, M.; Gaskell, S. J.; Kohn, H. Biochemistry 2000, $39,9067$.

(59) Nair, J.; Barbin, A.; Velic, I.; Bartsch, H. Mutat Res 1999, 424, 59.

(60) Shapiro, R.; Cohen, B. I.; Shiuey, S.-J.; Maurer, H. Biochemistry 1969, 8, 238.

(61) Katopodis, A. G.; Ping, D. S.; Smith, C. E.; May, S. W. Biochemistry 1991, 30, 6189.

(62) Bell, J.; Ash, D. E.; Snyder, L. M.; Kulathila, R.; Blackburn, N. J.; Merkler, D. J. Biochemistry 1997, 36, 16239.

(63) Eipper, B. A.; Perkins, S. N.; Husten, E. J.; Johnson, R. C.; Keutmann, H. T.; Mains, R. E. J. Biol. Chem. 1991, 266, 7827.

(64) Kolhekar, A. S.; Bell, J.; Shiozaki, E. N.; Jin, L. X.; Keutmann, H. T.; Hand, T. A.; Mains, R. E.; Eipper, B. A. Biochemistry 2002, 41, 12384.

(65) Merkler, D. J.; Schramm, V. L. Biochemistry 1993, 32, 5792.

(66) Takahashi, K.; Harada, S.; Higashimoto, Y.; Shimokawa, C.; Sato, H.; Sugishima, M.; Kaida, Y.; Noguchi, M. Biochemistry 2009, 48, 1654.

(67) Tyminski, K. S., Illinois State University, 2016.

(68) Lowry, T. H.; Richardson, K. S. Mechanism and Theory in Organic Chemistry; Harper \& Row, Publishers: New York, 1987.

(69) Feken, K. Master of Science Thesis, Illinois State University, 2013.

(70) Lawson, M. R.; Dyer, K.; Berger, J. M. Proc. Natl. Acad. Sci. U. S. A. 2016, 113, 13714.

(71) De, M.; Bell, J.; Blackburn, N. J.; Mains, R. E.; Eipper, B. A. J. Biol. Chem 2006, 281, 20873.

(72) Murphy, J. L.; Tenn, W. J.; Labuda, J. J.; Nagorski, R. W. Tet. Lett. 2009, 50, 7358. 
(73) In Vogel's Textbook of Practical Organic Chemistry; 5th ed.; Furniss, B. S., Hannaford, A. J., Smith, P. W. G., Tatchell, A. R., Eds.; John Wiley \& Sons: New York, 1989, p 1073.

(74) Dutcher, J. D.; Kjaer, A. J. Am. Chem. Soc. 1951, 73, 4139.

(75) Owston, N. A.; Parker, A. J.; Williams, J. M. J. Org. Lett. 2007, 9, 73.

(76) Reed, K. L.; Gupton, J. T.; Solarz, T. L. Synth. Commun. 1990, 20, 563.

(77) Hauser, C. R.; Hoffenberg, D. S. J. Org. Chem. 1955, 20, 1448.

(78) Molander, G. A.; Cavalcanti, L. N. J. Org. Chem. 2011, 76, 7195.

(79) Shapiro, S. L.; Parrino, V. A.; Freedman, L. J. Am. Chem. Soc. 1959, 81, 3728.

(80) Haas, P. J. Chem. Soc., Trans. 1912, 101, 1254.

(81) Murphy, J. L. Master of Science Thesis, Illinois State University, 2007.

(82) Gruen, L. C.; McTigue, P. T. J. Chem. Soc. 1963, 5217.

(83) Gruen, L. C.; McTigue, P. T. J. Chem. Soc. 1963, 5224.

(84) McClelland, R. A.; Coe, M. J. Am. Chem. Soc. 1983, 105, 2718.

(85) Lewis, C. A., Jr.; Wolfenden, R. J. Amer. Chem. Soc. 1973, 95, 6685.

(86) Hine, J.; Hine, M. J. Am. Chem. Soc. 1952, 74, 5266.

(87) Homer, R. B.; Johnson, C. D. The Chemistry of Amides; Interscience Publishers: New York, 1970.

(88) Brown, M., Halfiger Determination of Organic Structures by Physical Methods; Academic Press: New York, 1955. 
APPENDIX A: SUPPLEMENTAL INFORMATION 


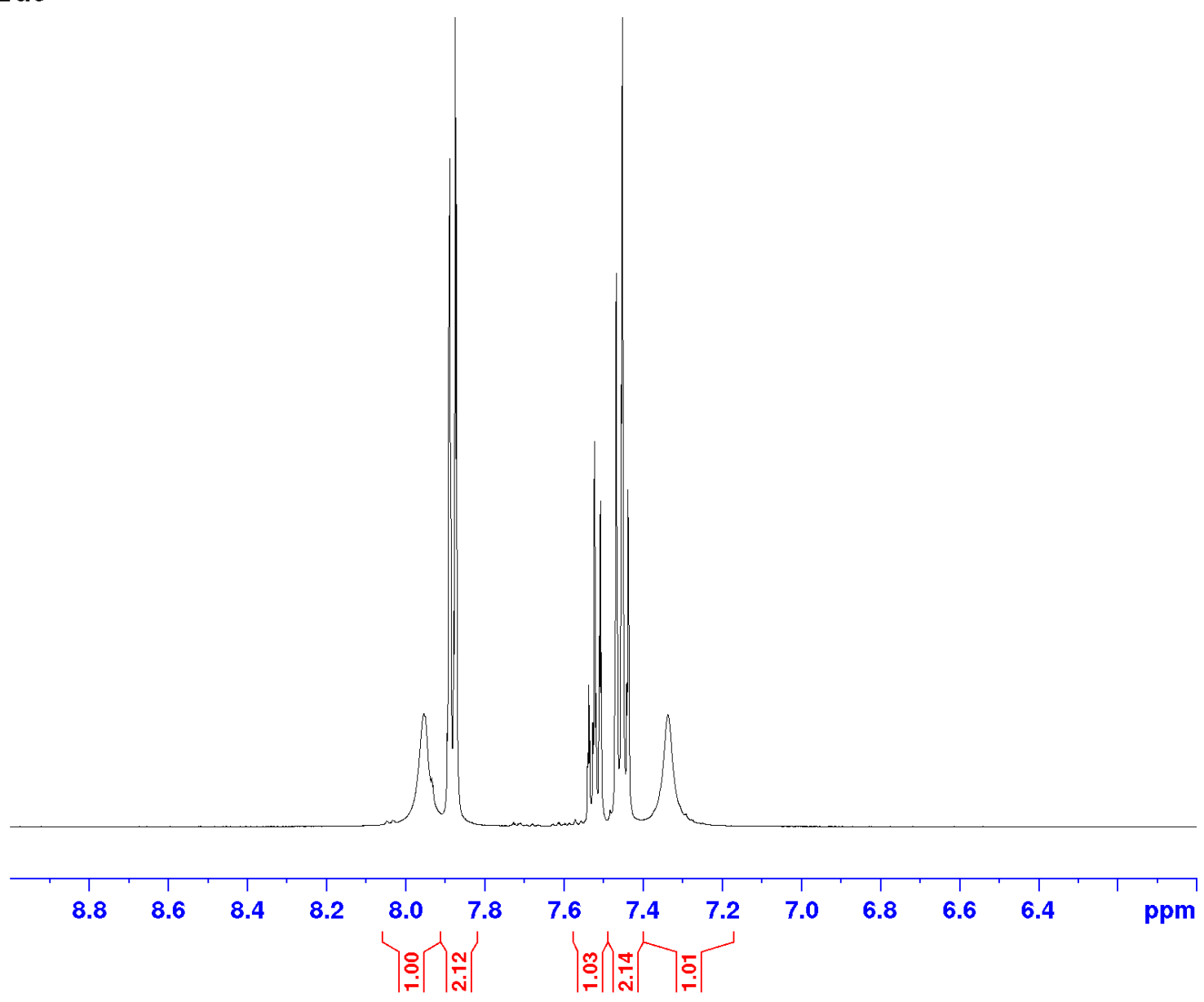

Figure S1: $500 \mathrm{MHz}{ }^{1} \mathrm{H}-\mathrm{NMR}$ of Benzamide. 
4-chlorobenzamide

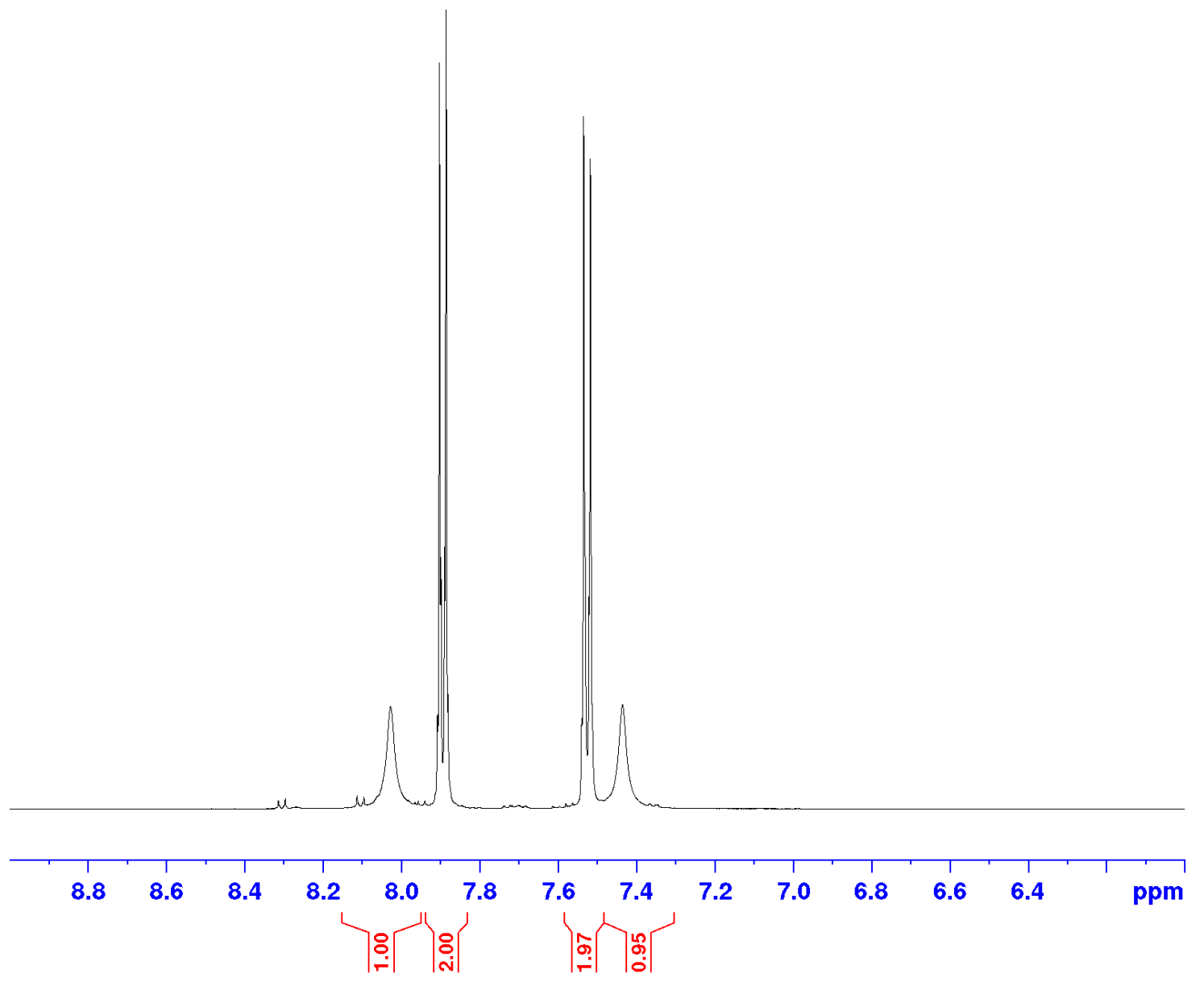

Figure S2: $500 \mathrm{MHz}{ }^{1} \mathrm{H}-\mathrm{NMR}$ of 4-Chlorobenzamide. 


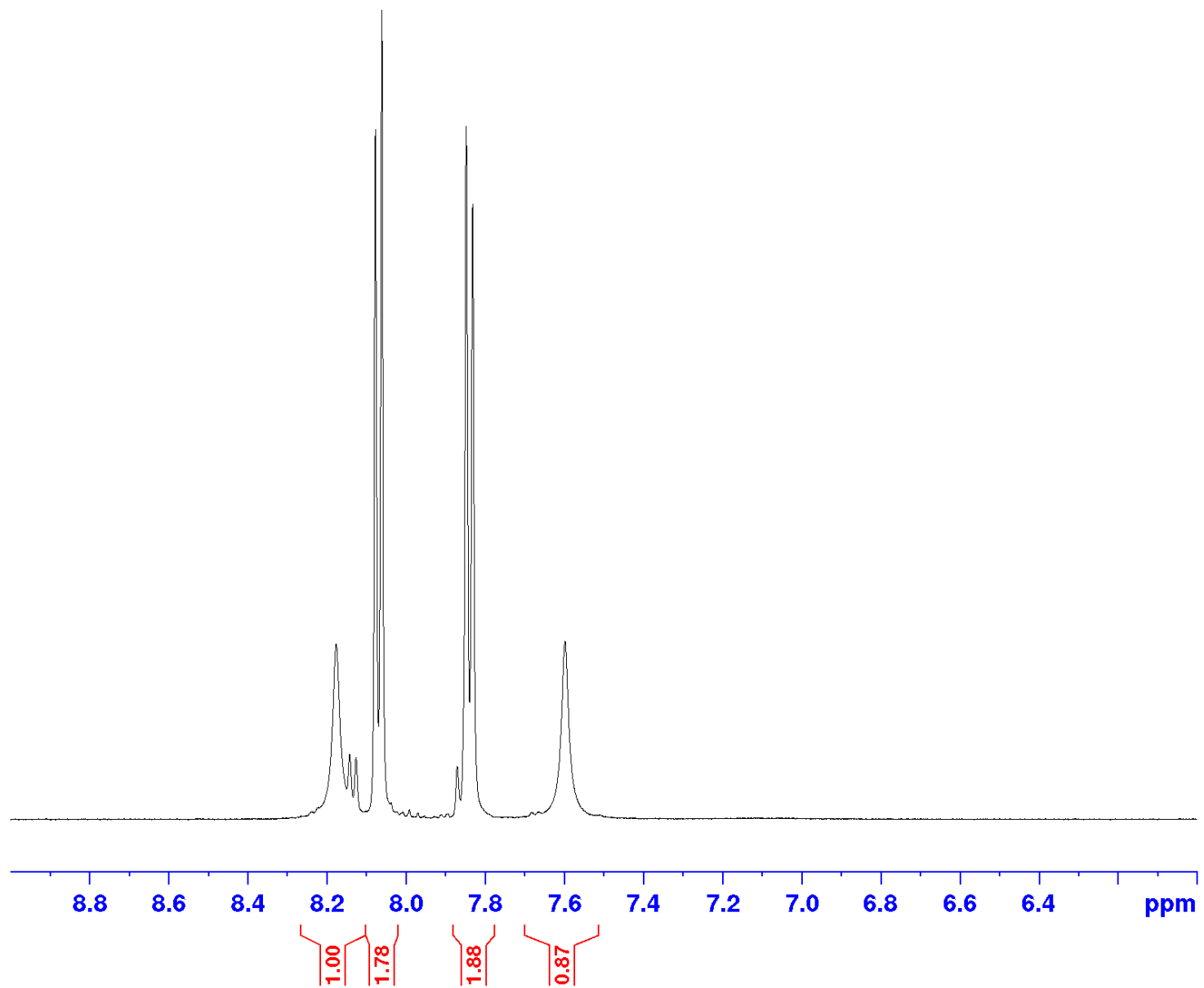

Figure S3: $500 \mathrm{MHz}{ }^{1} \mathrm{H}-\mathrm{NMR}$ of 4-(Trifluoromethyl)benzamide. 


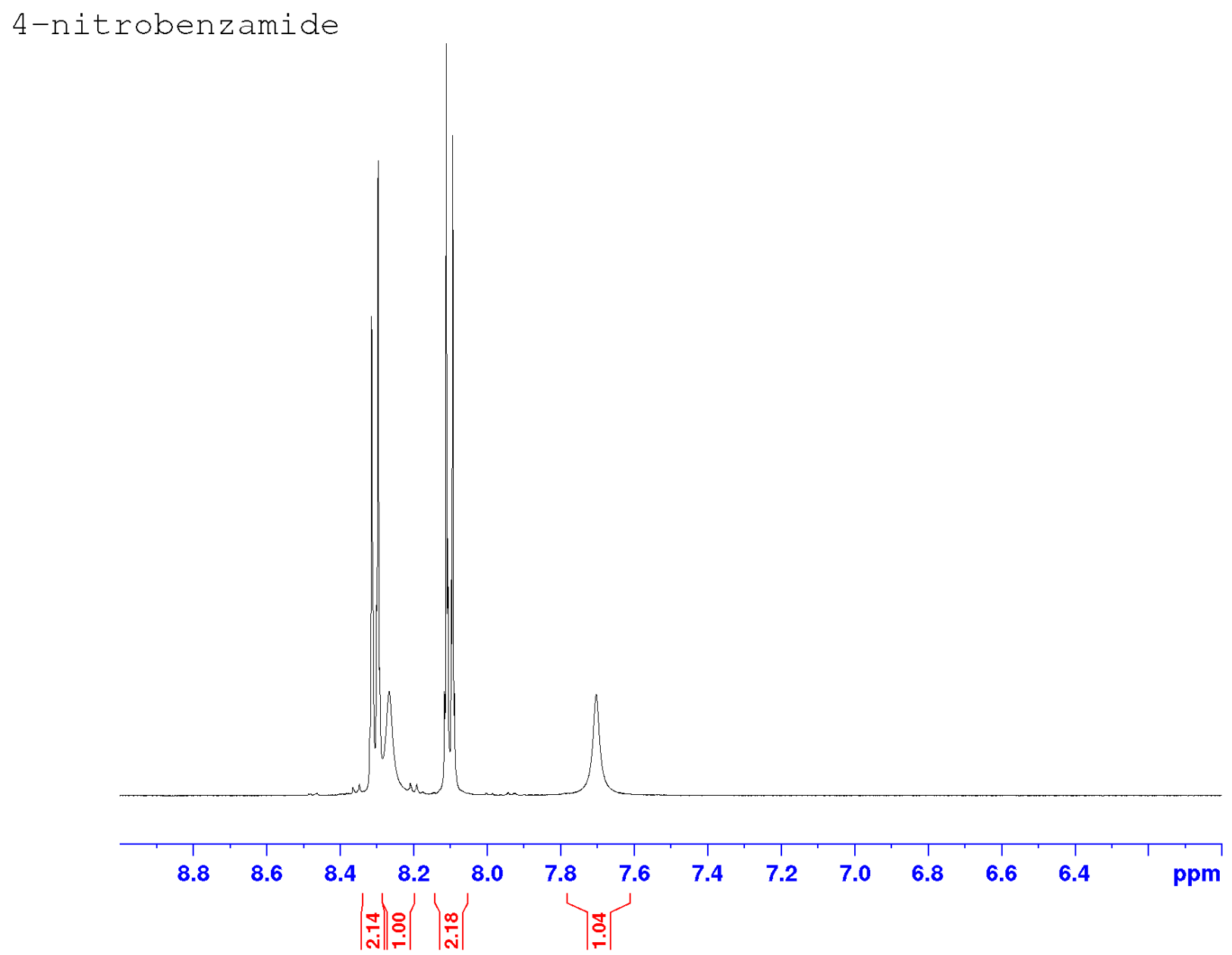

Figure S4: $500 \mathrm{MHz}{ }^{1} \mathrm{H}-\mathrm{NMR}$ of 4-Nitrobenzamide. 
3-chlorobenzamide

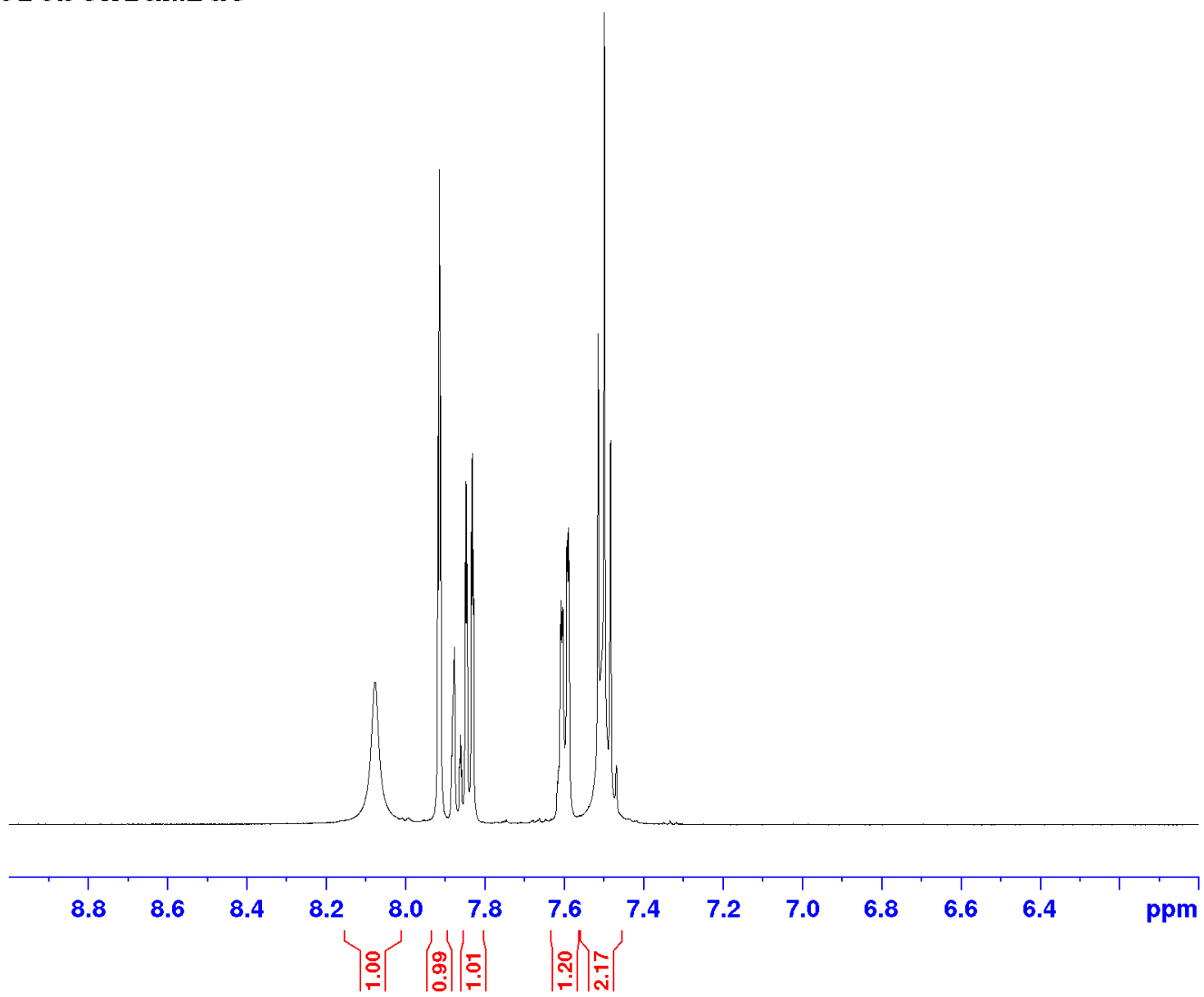

Figure S5: $500 \mathrm{MHz}{ }^{1} \mathrm{H}-\mathrm{NMR}$ of 3-Chlorobenzamide. 
3-bromobenzamide

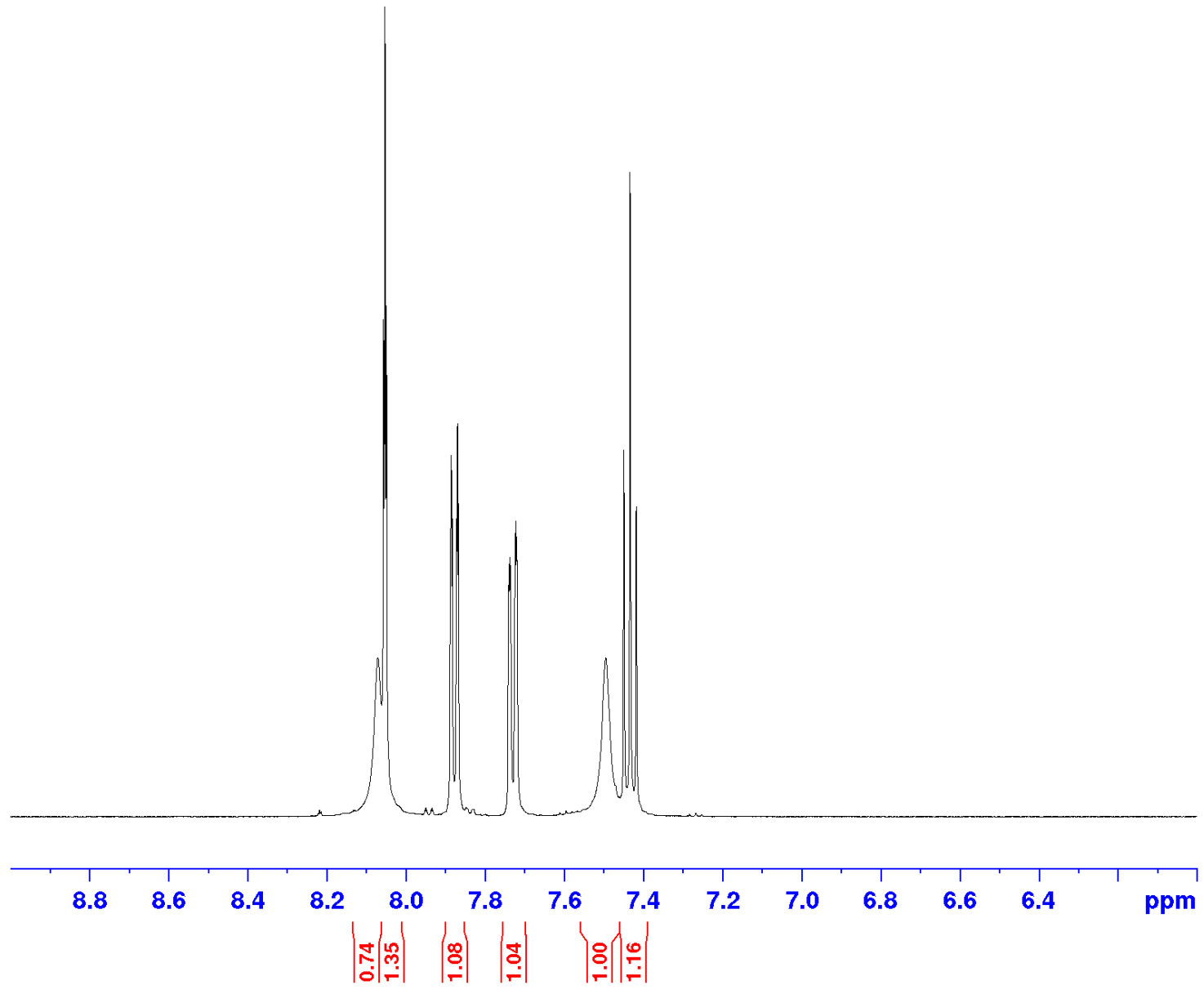

Figure S6: $500 \mathrm{MHz}{ }^{1} \mathrm{H}-\mathrm{NMR}$ of 3-Bromobenzamide. 


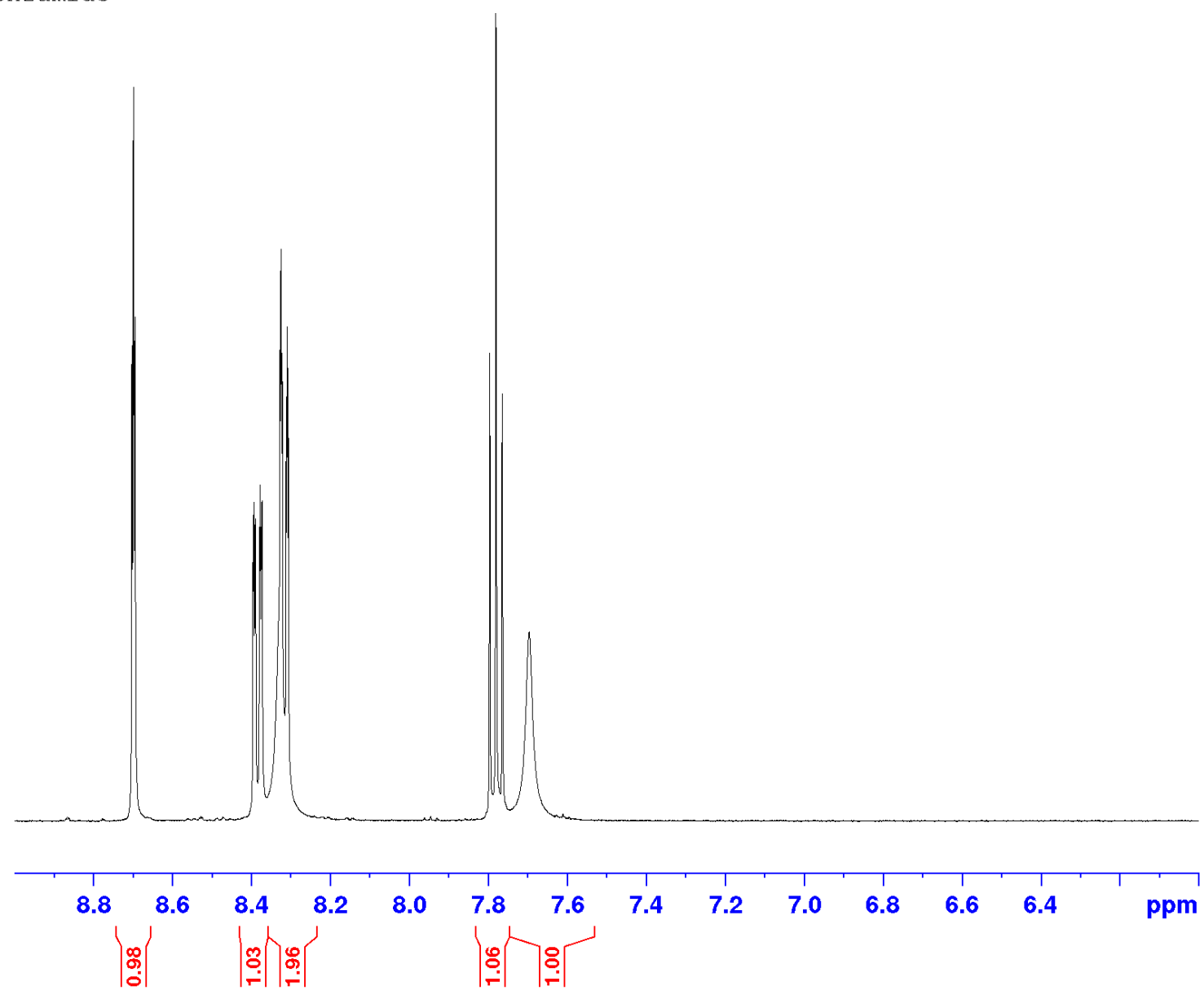

Figure S7: $500 \mathrm{MHz}{ }^{1} \mathrm{H}-\mathrm{NMR}$ of 3-Nitrobenzamide. 


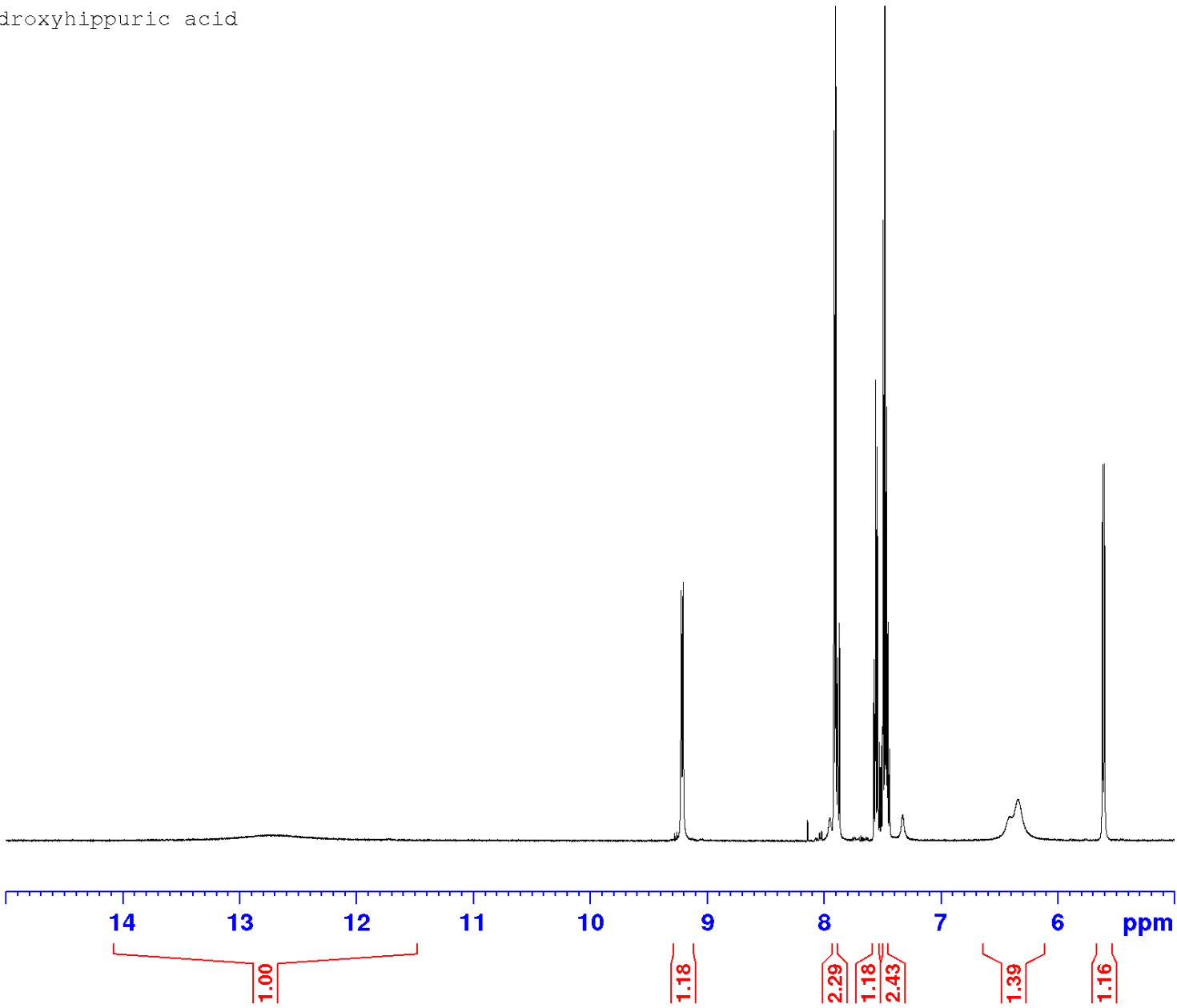

Figure S8: $500 \mathrm{MHz}{ }^{1} \mathrm{H}-\mathrm{NMR}$ of $\alpha$-Hydroxyhippuric Acid. 


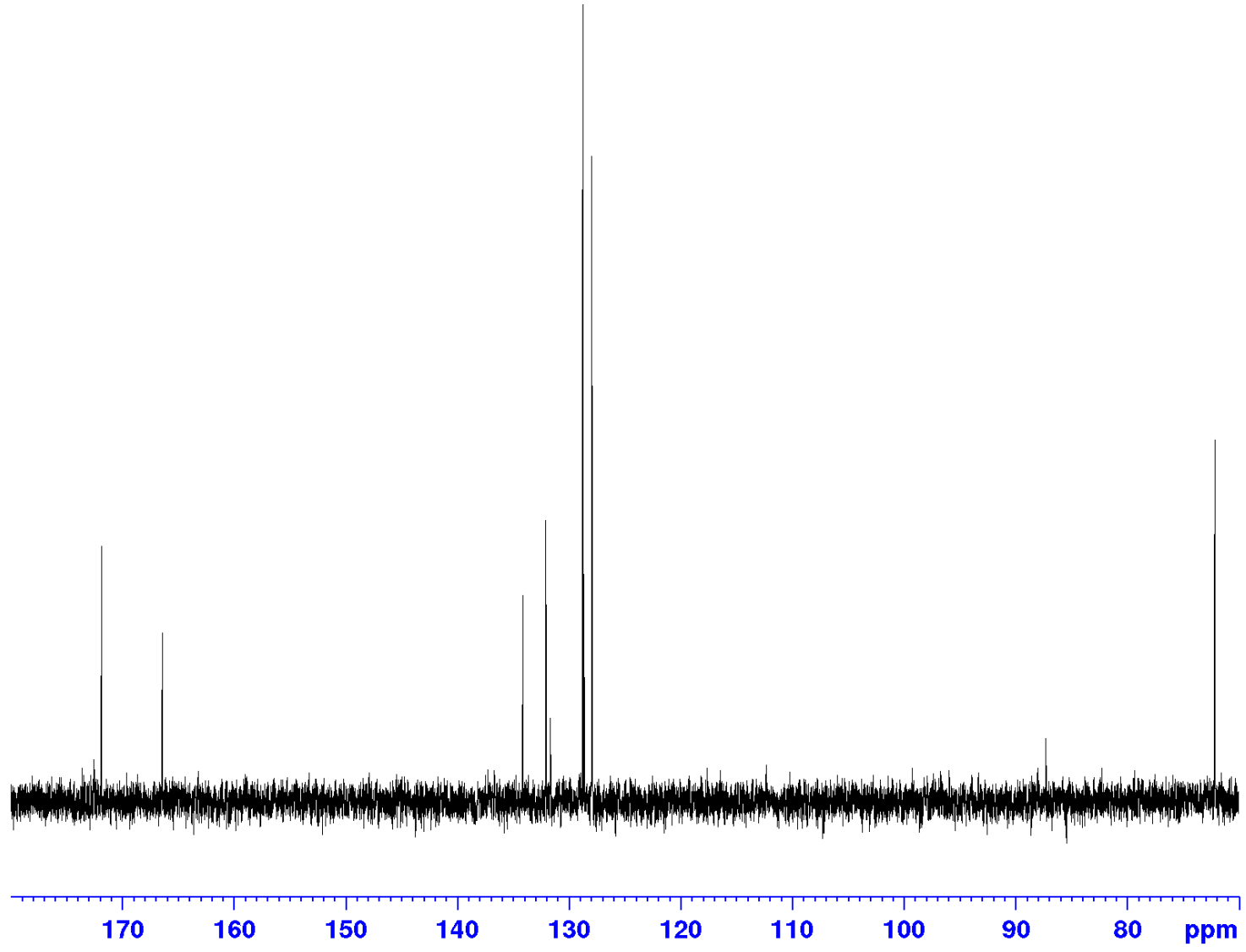

Figure S9: $125 \mathrm{MHz}{ }^{13} \mathrm{C}-\mathrm{NMR}$ of $\alpha$-Hydroxyhippuric Acid. 


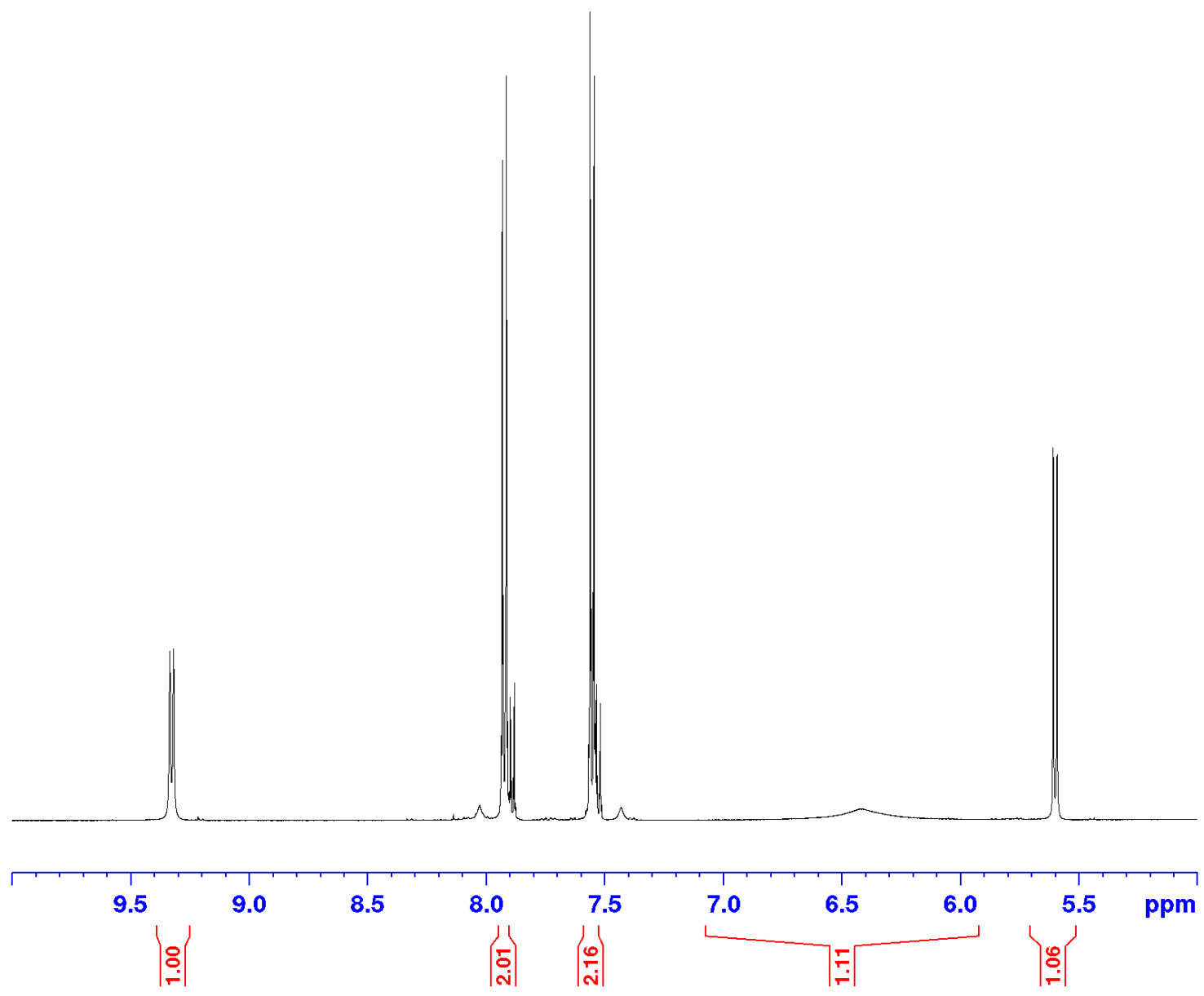

Figure S10: $500 \mathrm{MHz}{ }^{1} \mathrm{H}-\mathrm{NMR}$ of 4-Chloro- $\alpha$-Hydroxyhippuric Acid. 


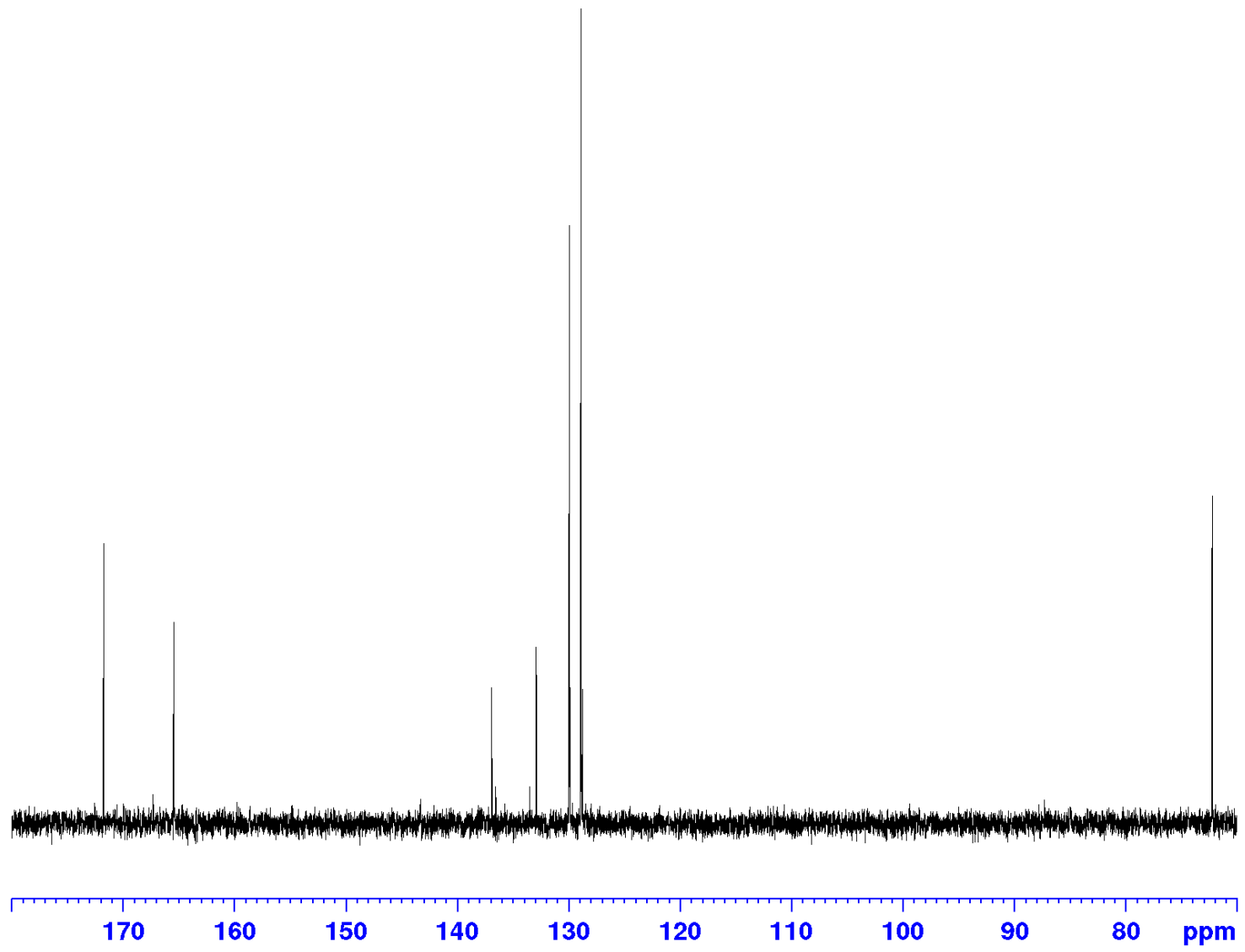

Figure S11: $125 \mathrm{MHz}{ }^{13} \mathrm{C}-\mathrm{NMR}$ of 4-Chloro- $\alpha$-Hydroxyhippuric Acid. 


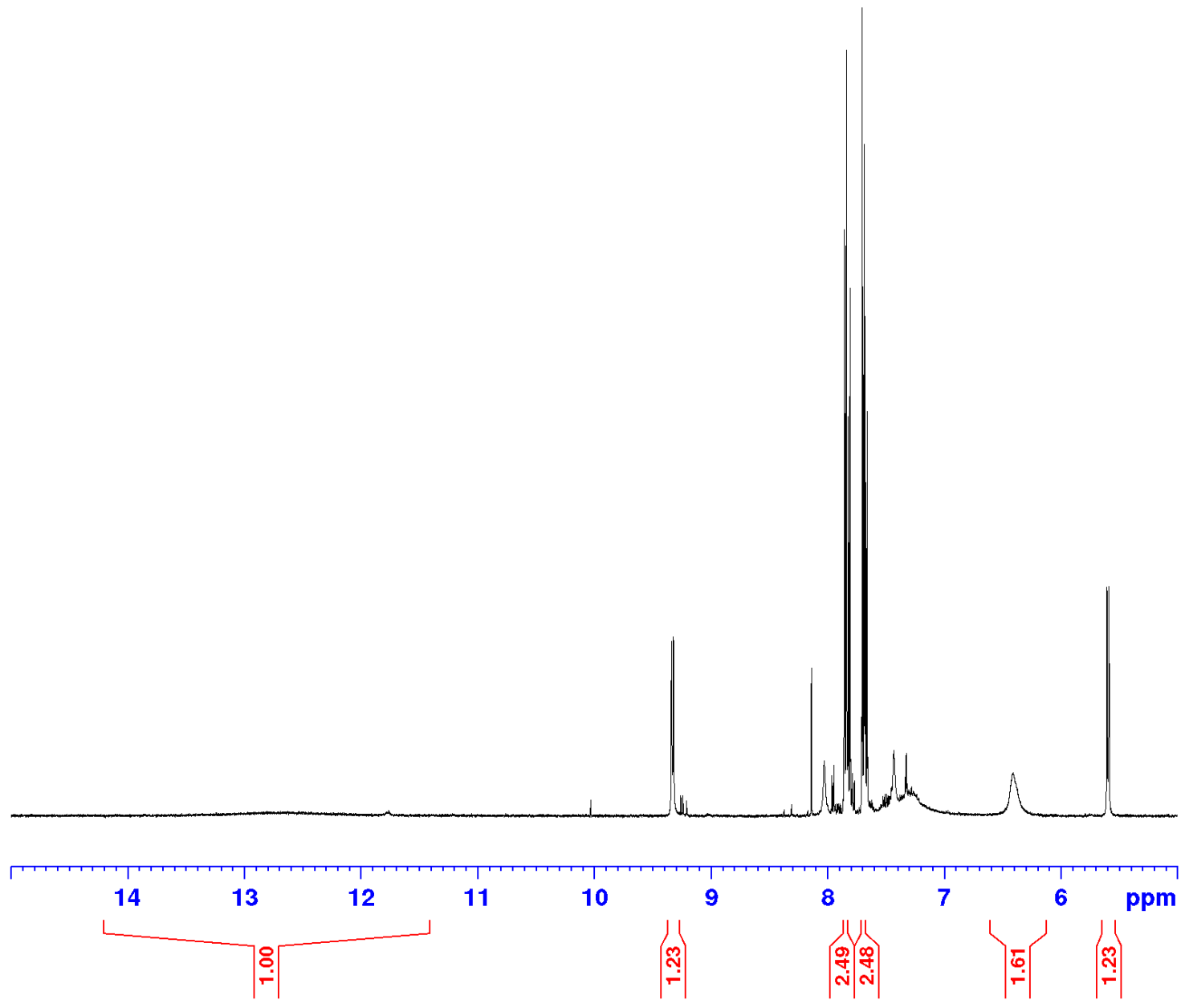

Figure S12: $500 \mathrm{MHz}{ }^{1} \mathrm{H}-\mathrm{NMR}$ of 4-Bromo- $\alpha$-Hydroxyhippuric Acid. 


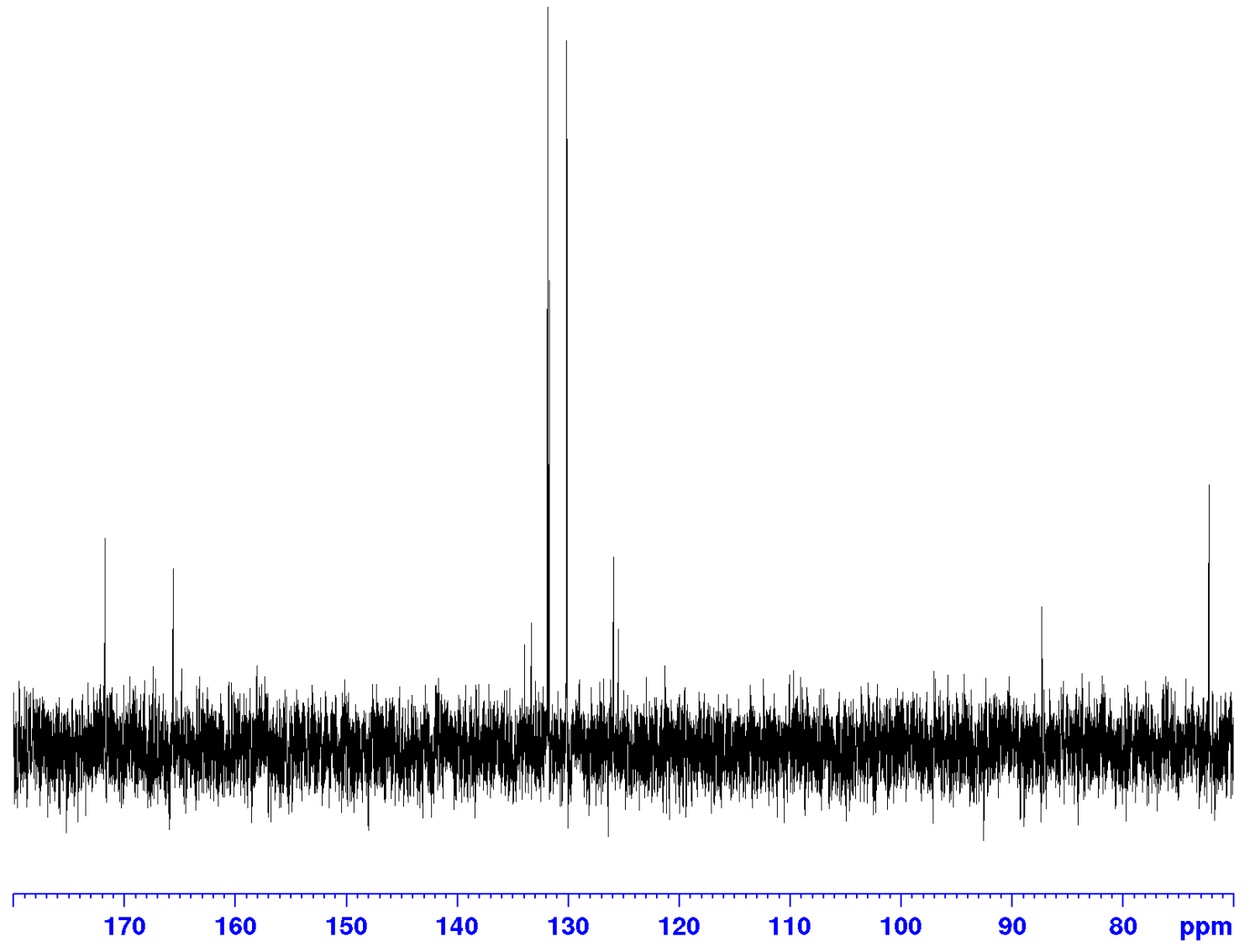

Figure S13: $125 \mathrm{MHz}{ }^{13} \mathrm{C}-\mathrm{NMR}$ of 4-Bromo- $\alpha$-Hydroxyhippuric Acid. 


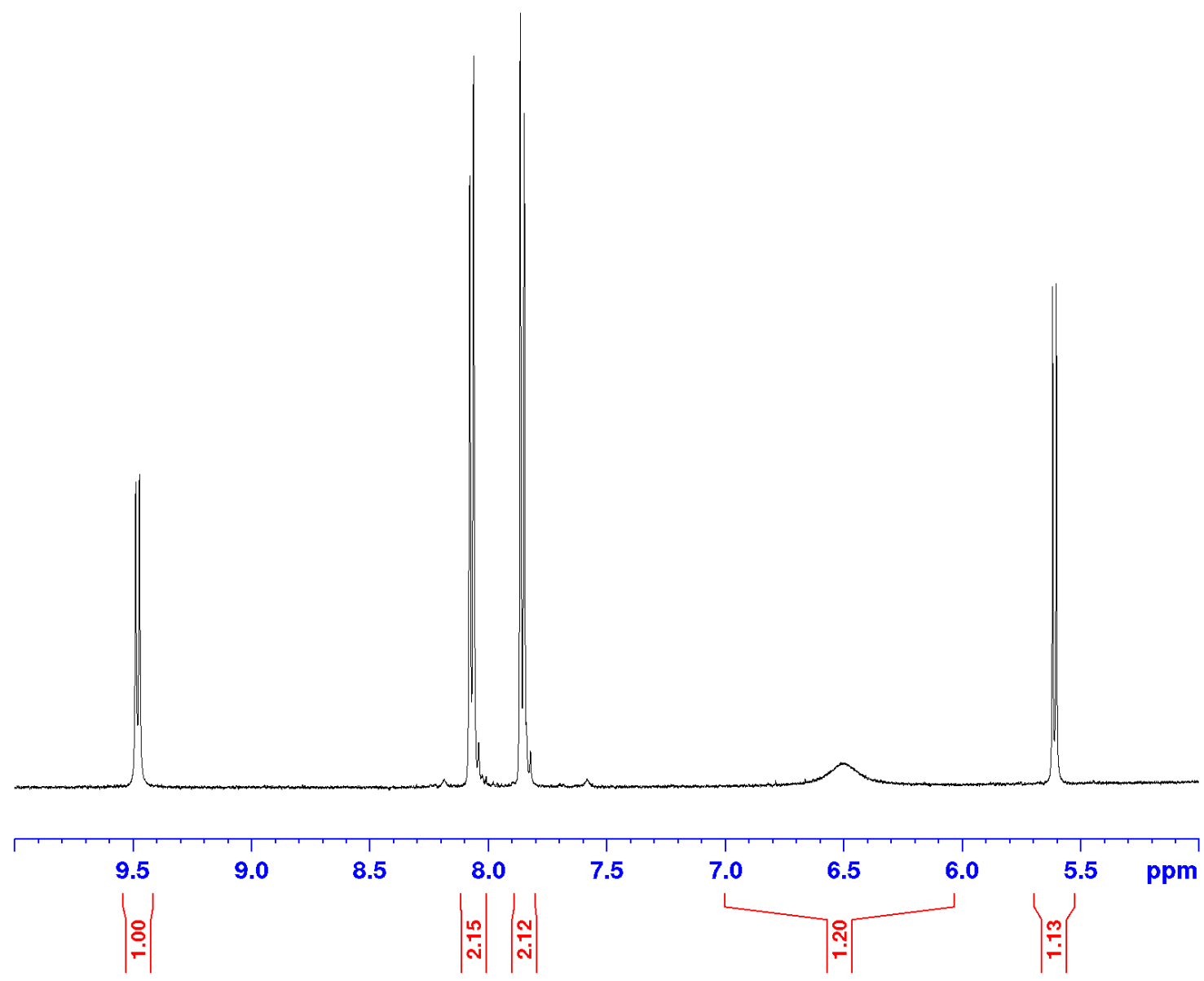

Figure S14: $500 \mathrm{MHz}{ }^{1} \mathrm{H}-\mathrm{NMR}$ of 4-(Trifluoromethyl)- $\alpha$-Hydroxyhippuric Acid. 


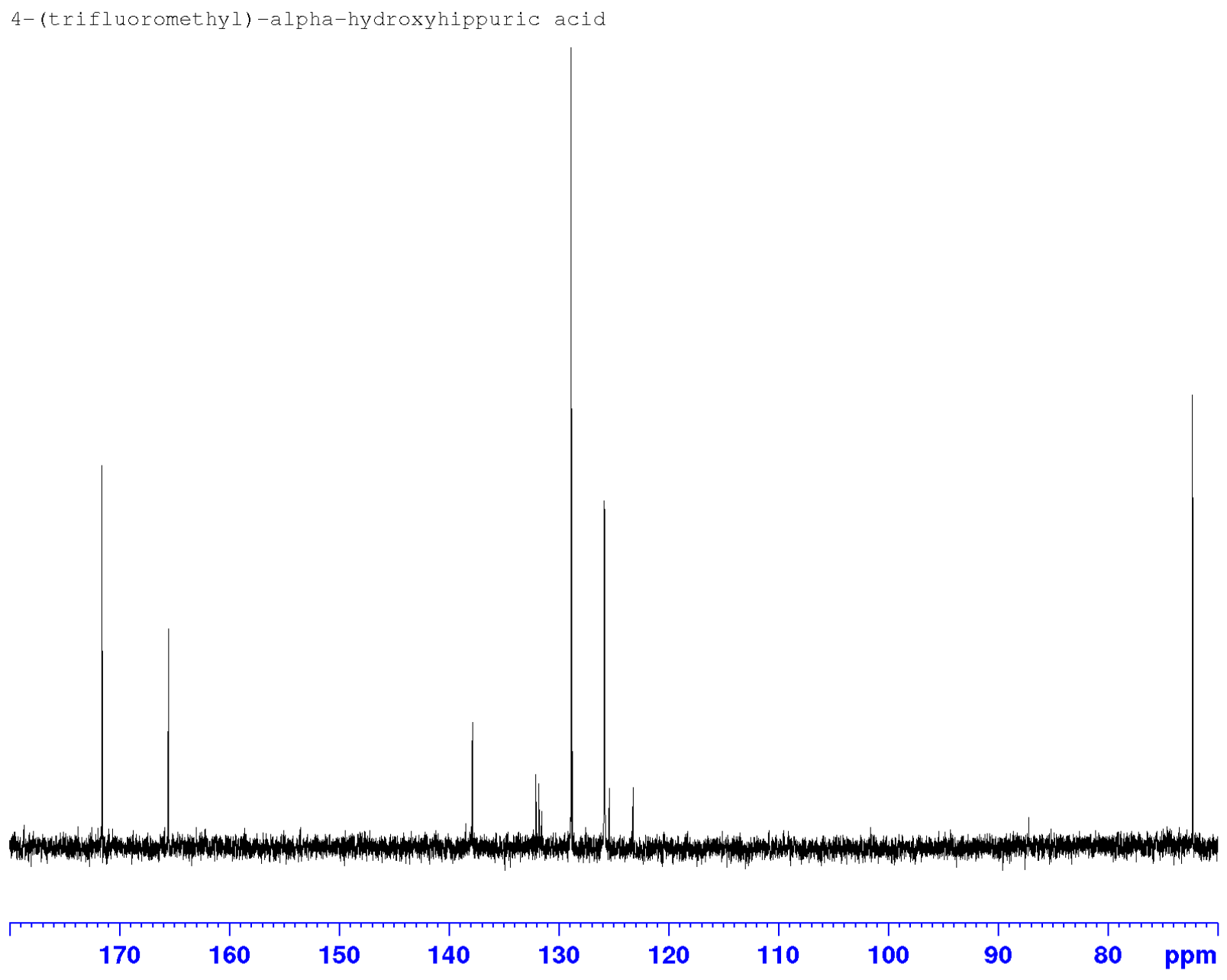

Figure S15: $125 \mathrm{MHz}{ }^{13} \mathrm{C}-\mathrm{NMR}$ of 4-(Trifluoromethyl)- $\alpha$-Hydroxyhippuric Acid. 


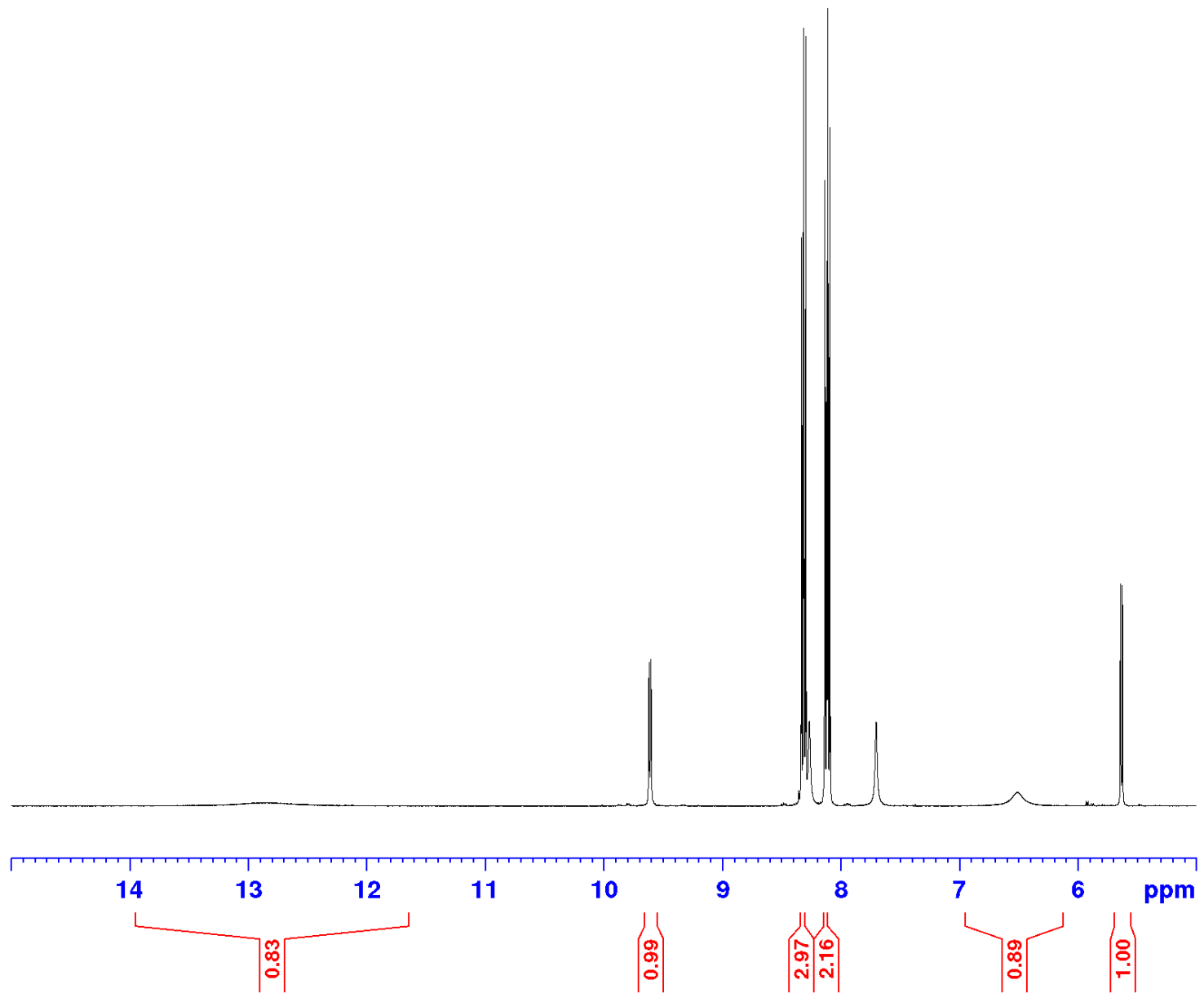

Figure S16: $500 \mathrm{MHz}{ }^{1} \mathrm{H}-\mathrm{NMR}$ of 4-Nitro- $\alpha$-Hydroxyhippuric Acid. 


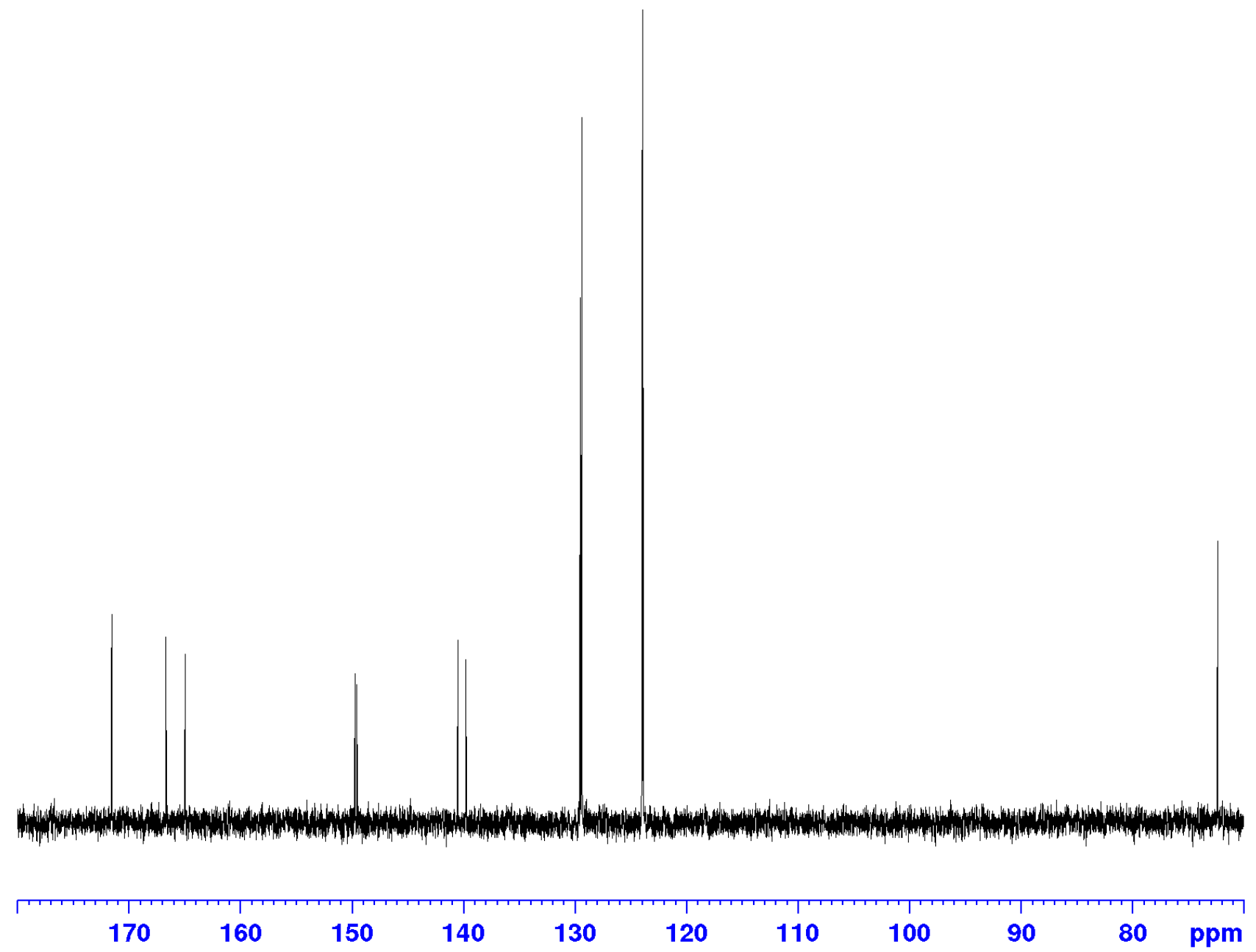

Figure S17: $125 \mathrm{MHz}{ }^{13} \mathrm{C}-\mathrm{NMR}$ of 4-Nitro- $\alpha$-Hydroxyhippuric Acid. 


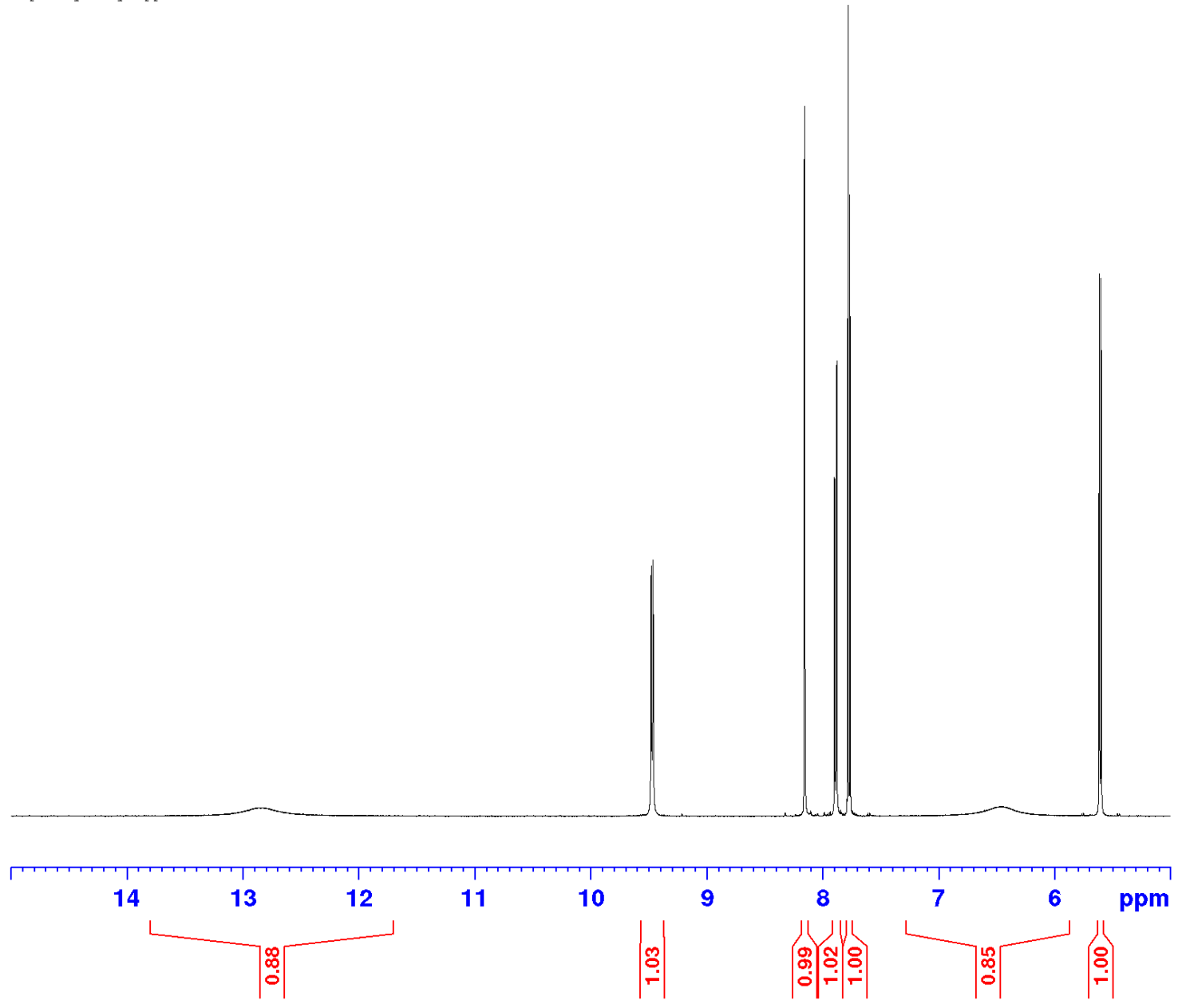

Figure S18: $500 \mathrm{MHz}{ }^{1} \mathrm{H}-\mathrm{NMR}$ of 3,4-Dichloro- $\alpha$-Hydroxyhippuric Acid. 


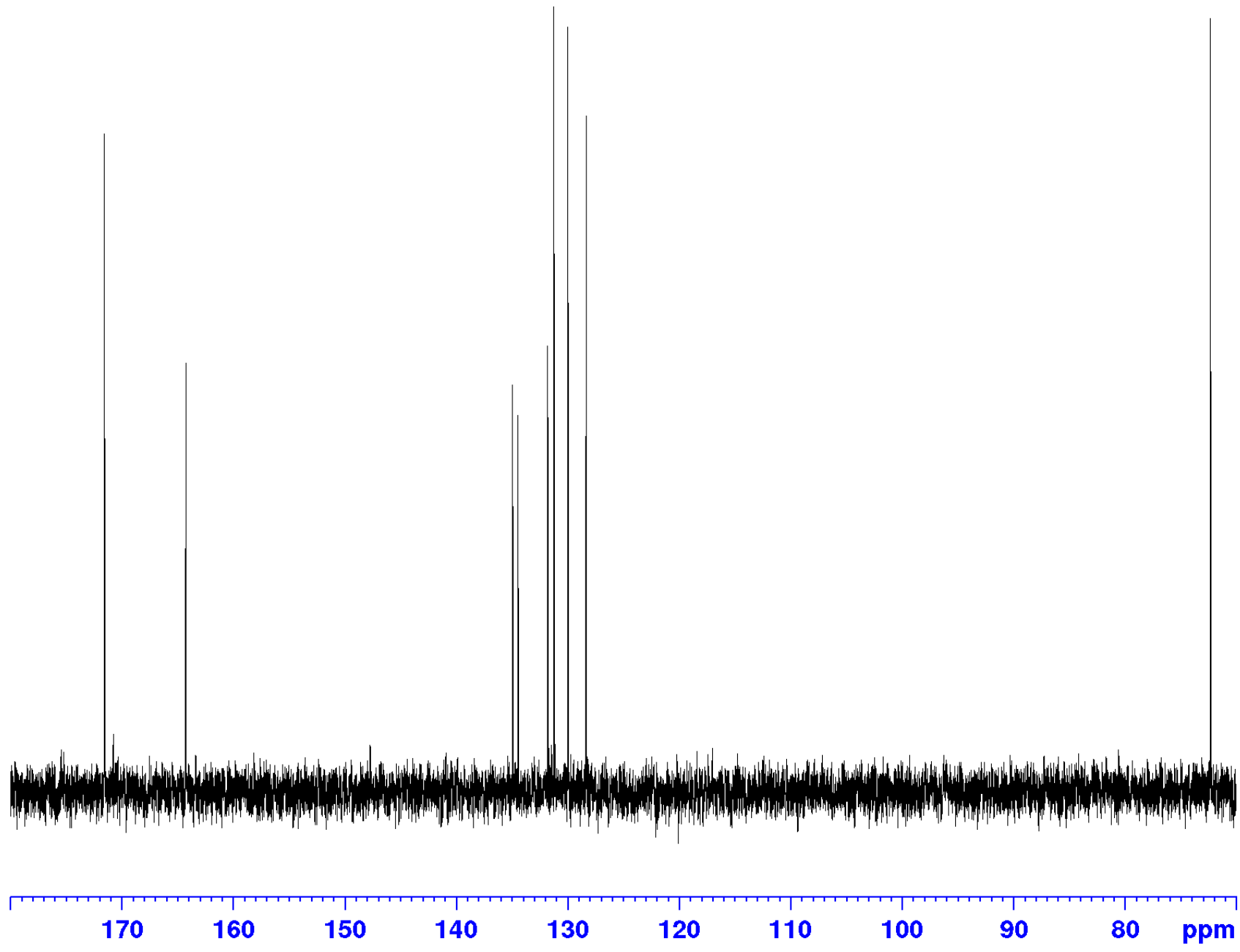

Figure S19: $125 \mathrm{MHz}{ }^{13} \mathrm{C}-\mathrm{NMR}$ of 3,4-Dichloro- $\alpha$-Hydroxyhippuric Acid. 


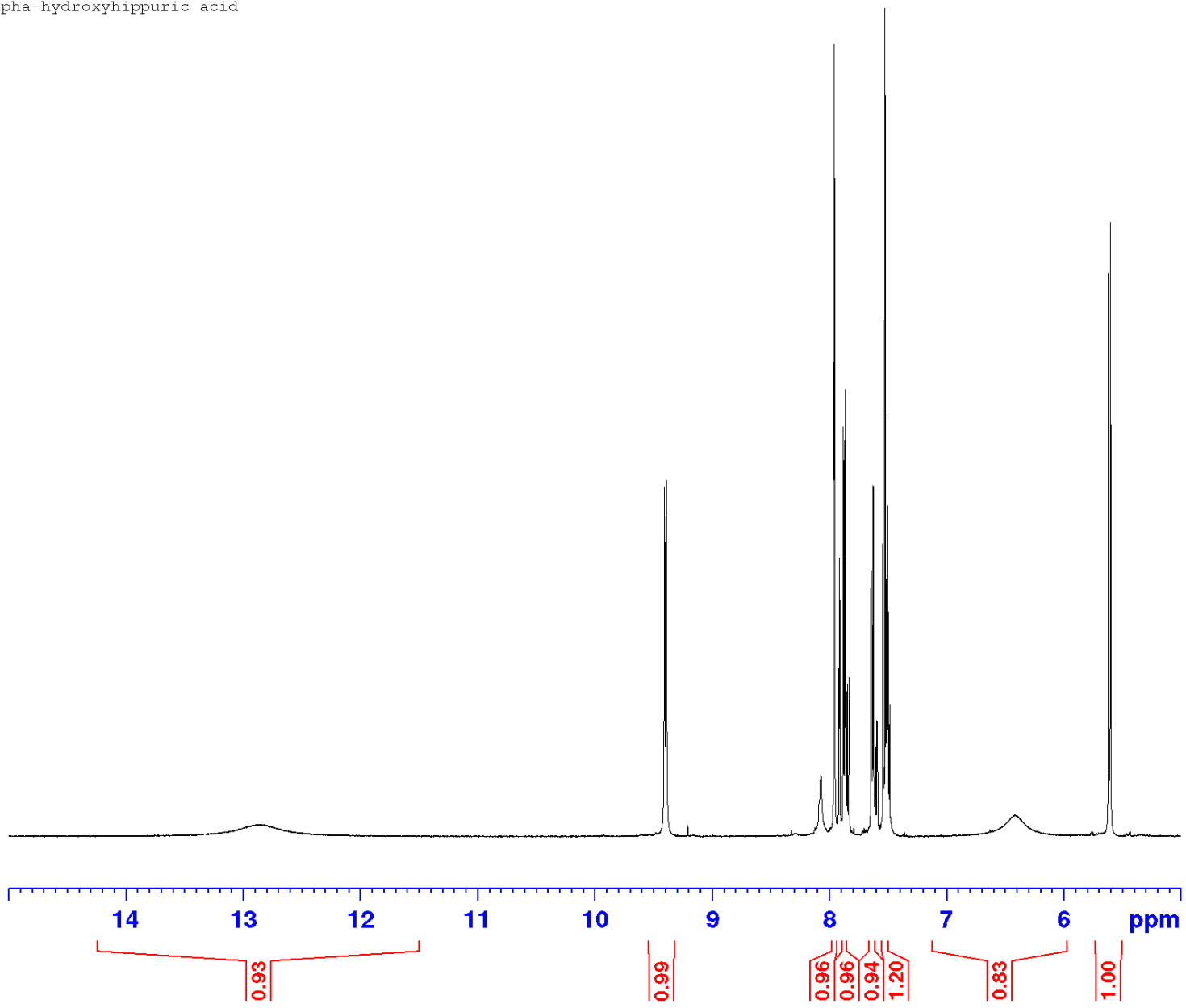

Figure S20: $500 \mathrm{MHz}{ }^{1} \mathrm{H}-\mathrm{NMR}$ of 3-Chloro- $\alpha$-Hydroxyhippuric Acid. 


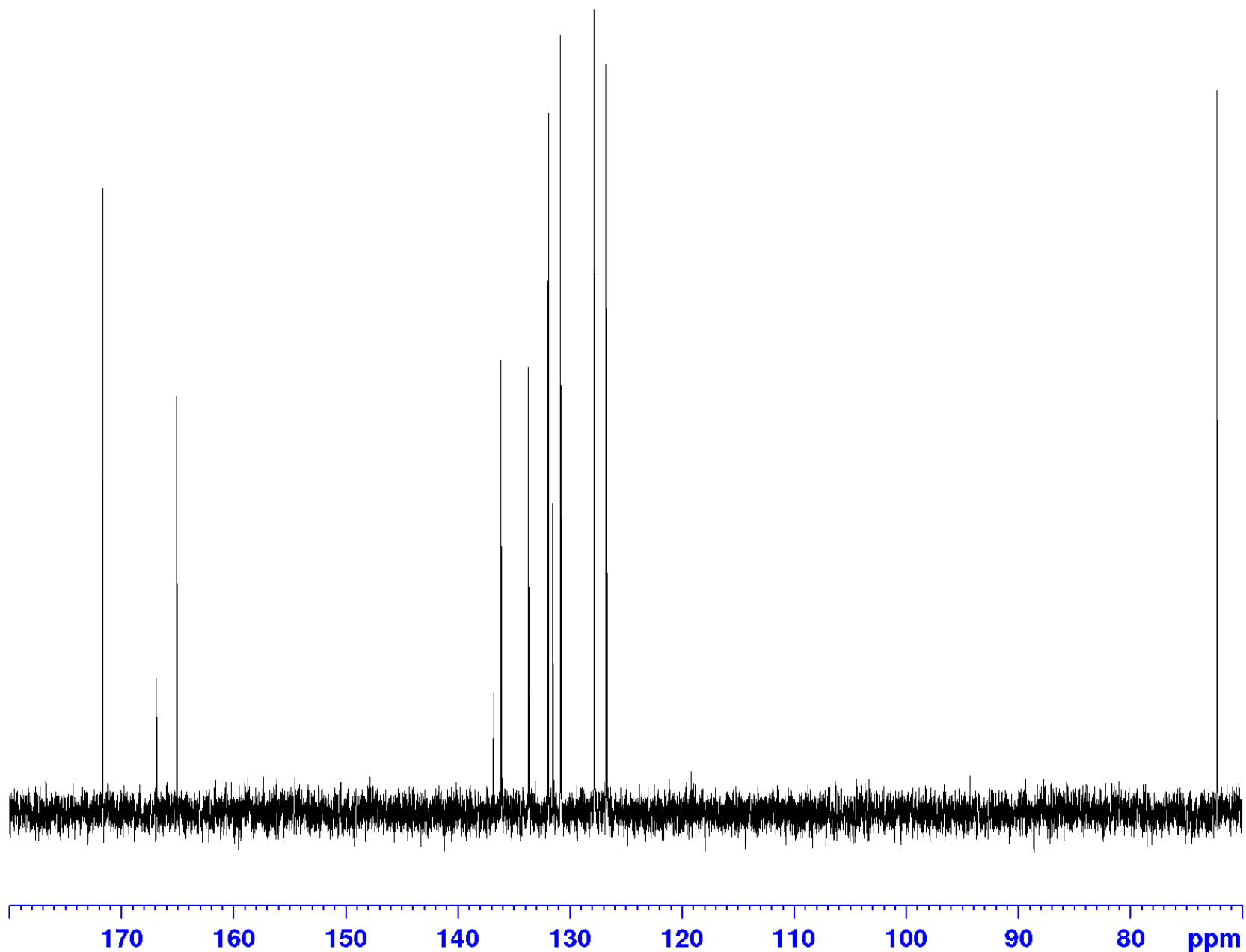

Figure S21: $125 \mathrm{MHz}{ }^{13} \mathrm{C}-\mathrm{NMR}$ of 3-Chloro- $\alpha$-Hydroxyhippuric Acid. 


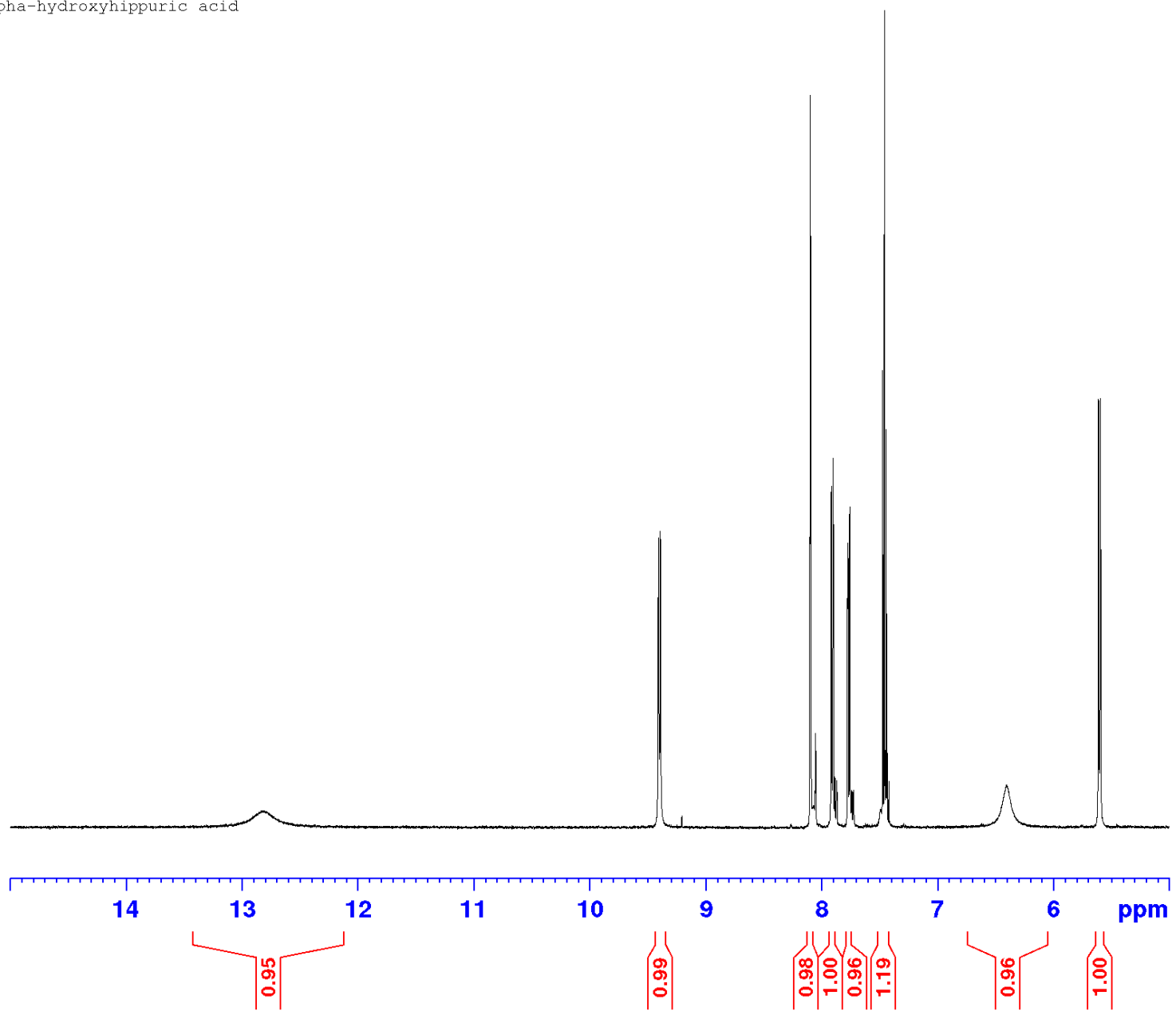

Figure S22: $500 \mathrm{MHz}{ }^{1} \mathrm{H}-\mathrm{NMR}$ of 3-Bromo- $\alpha$-Hydroxyhippuric Acid. 


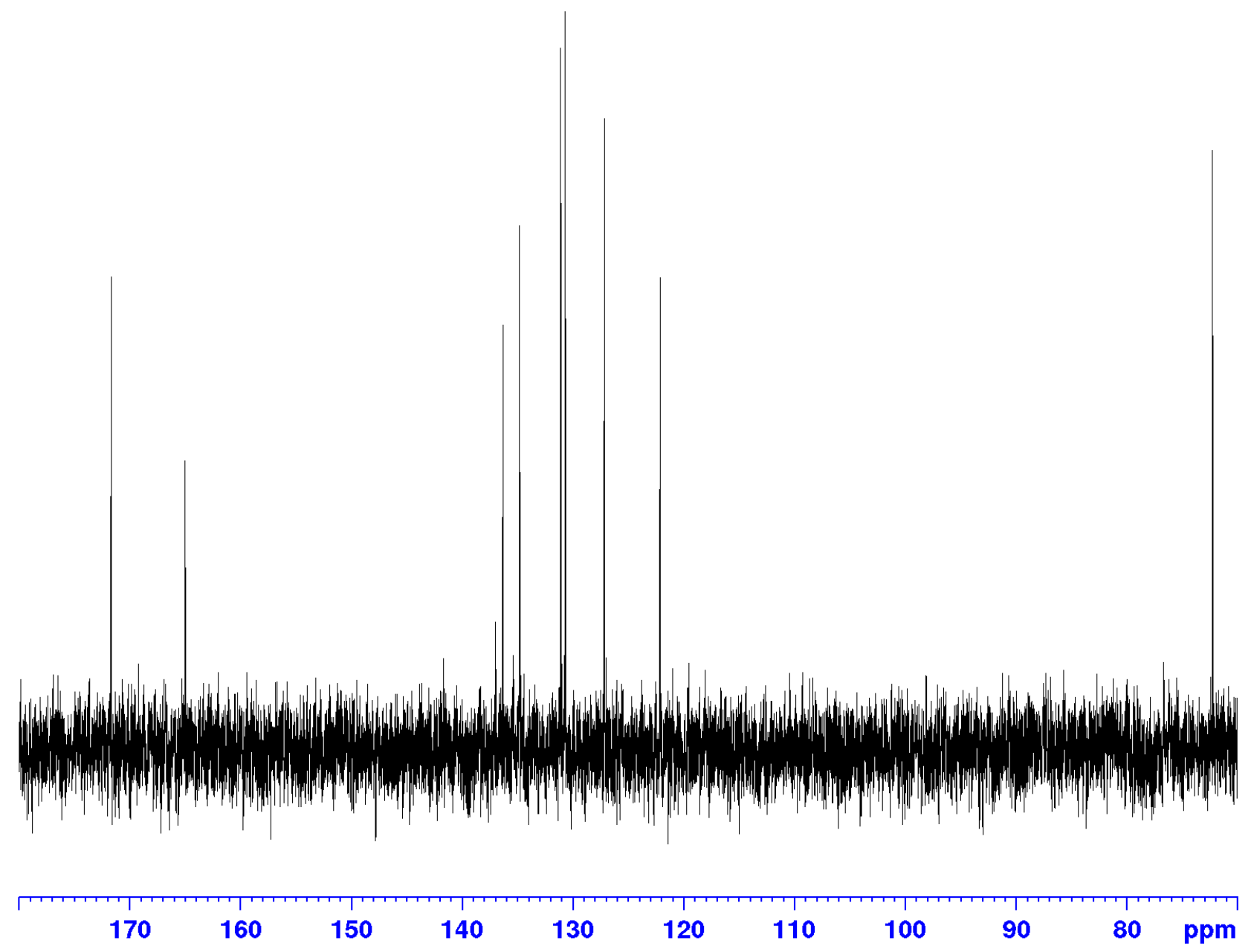

Figure S23: $125 \mathrm{MHz}{ }^{13} \mathrm{C}-\mathrm{NMR}$ of 3-Bromo- $\alpha$-Hydroxyhippuric Acid. 


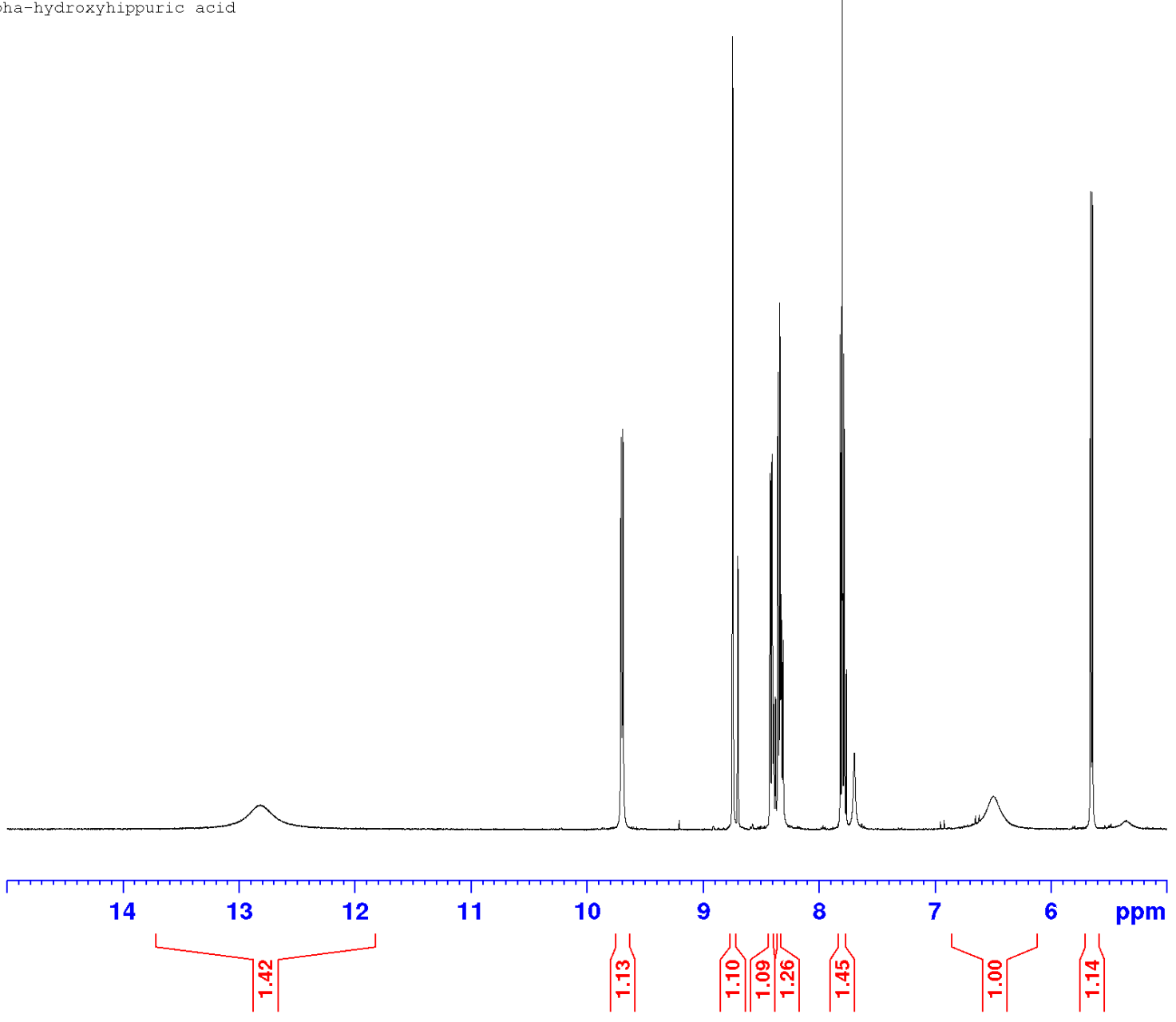

Figure S24: $500 \mathrm{MHz}{ }^{1} \mathrm{H}-\mathrm{NMR}$ of 3-Nitro- $\alpha$-Hydroxyhippuric Acid. 


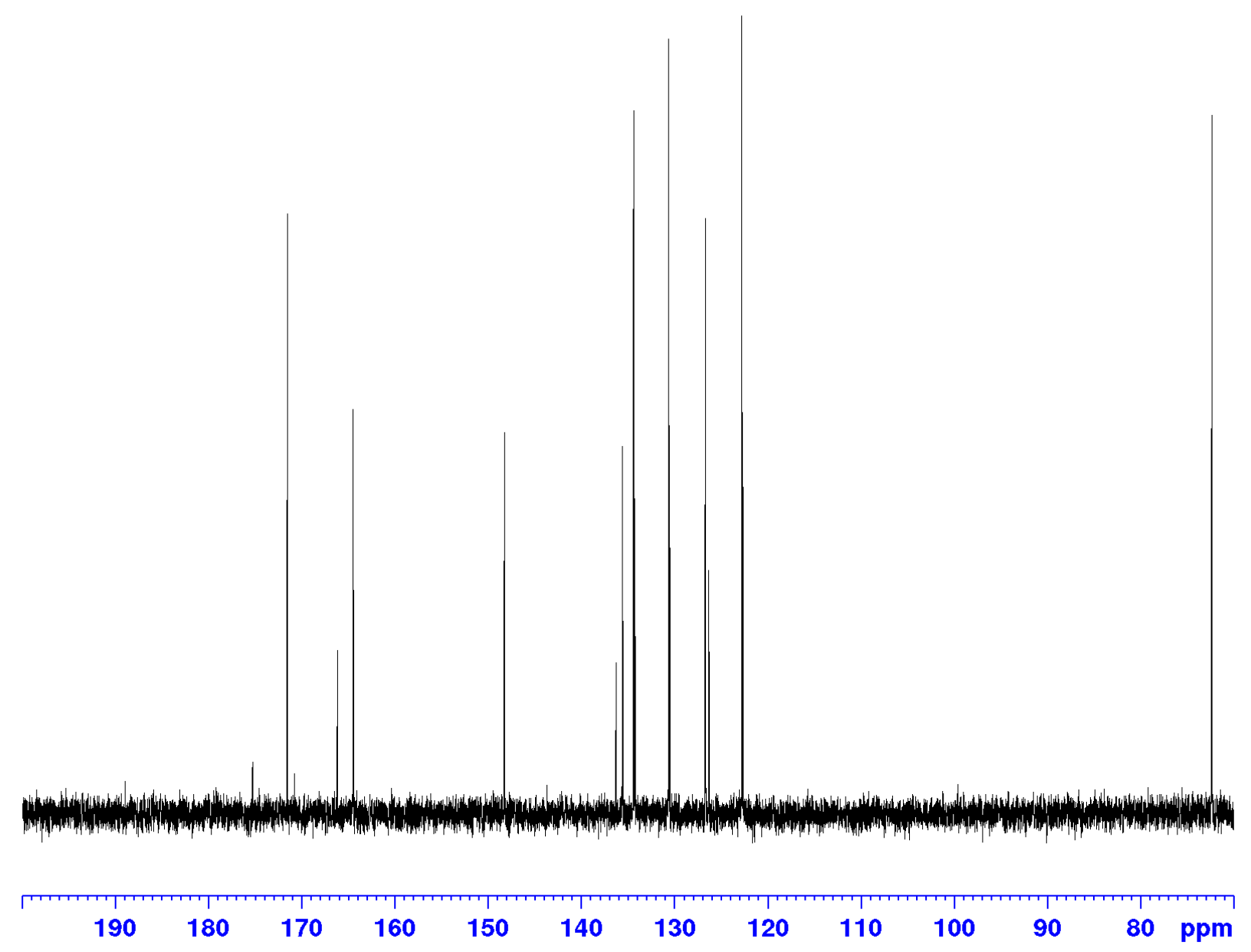

Figure S25: $125 \mathrm{MHz}{ }^{13} \mathrm{C}-\mathrm{NMR}$ of 3-Nitro- $\alpha$-Hydroxyhippuric Acid. 
KF 4-nitro-alpha-hydroxyhippuric acid

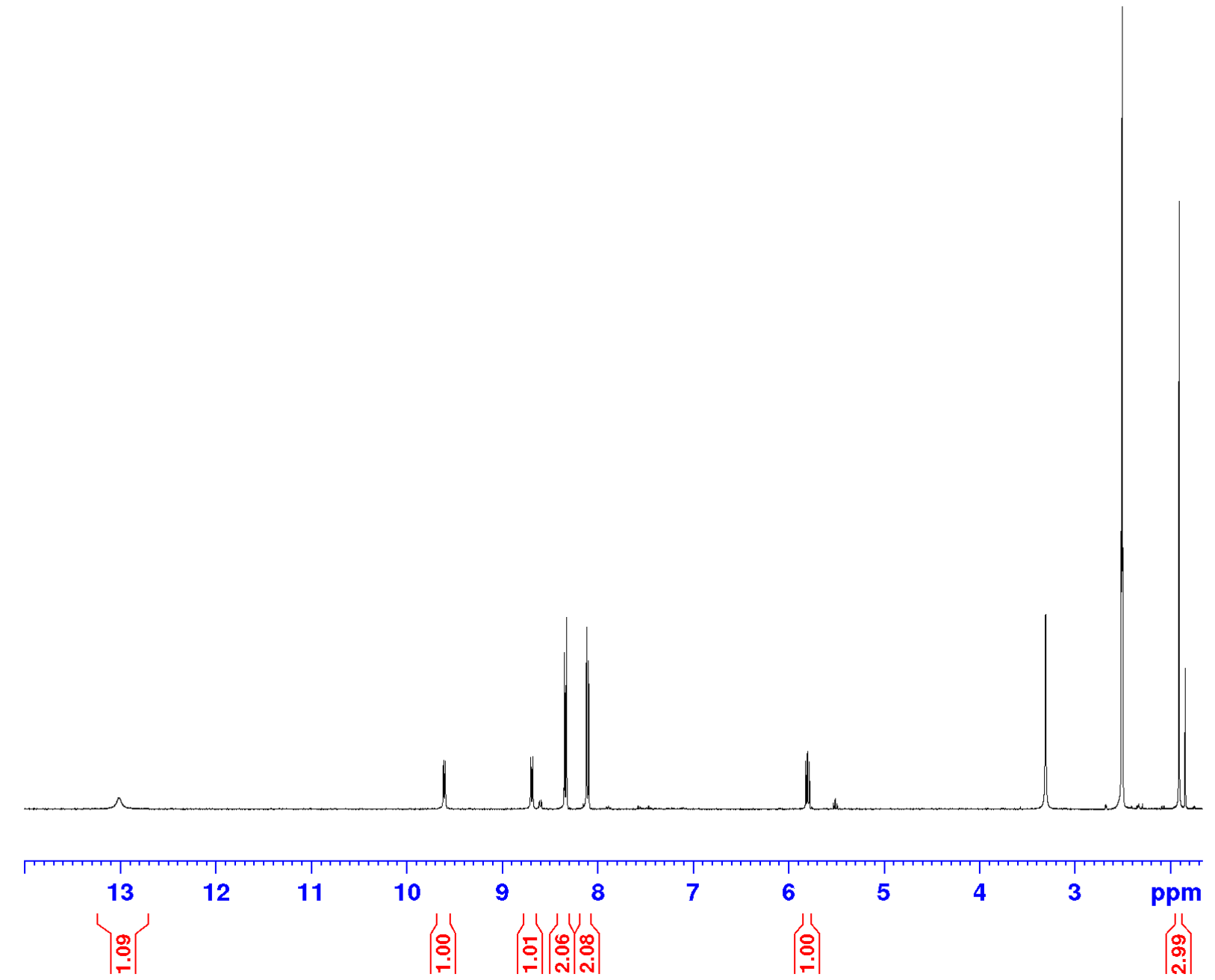

Figure S26: $400 \mathrm{MHz}{ }^{1} \mathrm{H}-\mathrm{NMR}$ of 2-Ethanamido-(4-nitrobenzamido)acetic Acid (23) in DMSO-d6. 


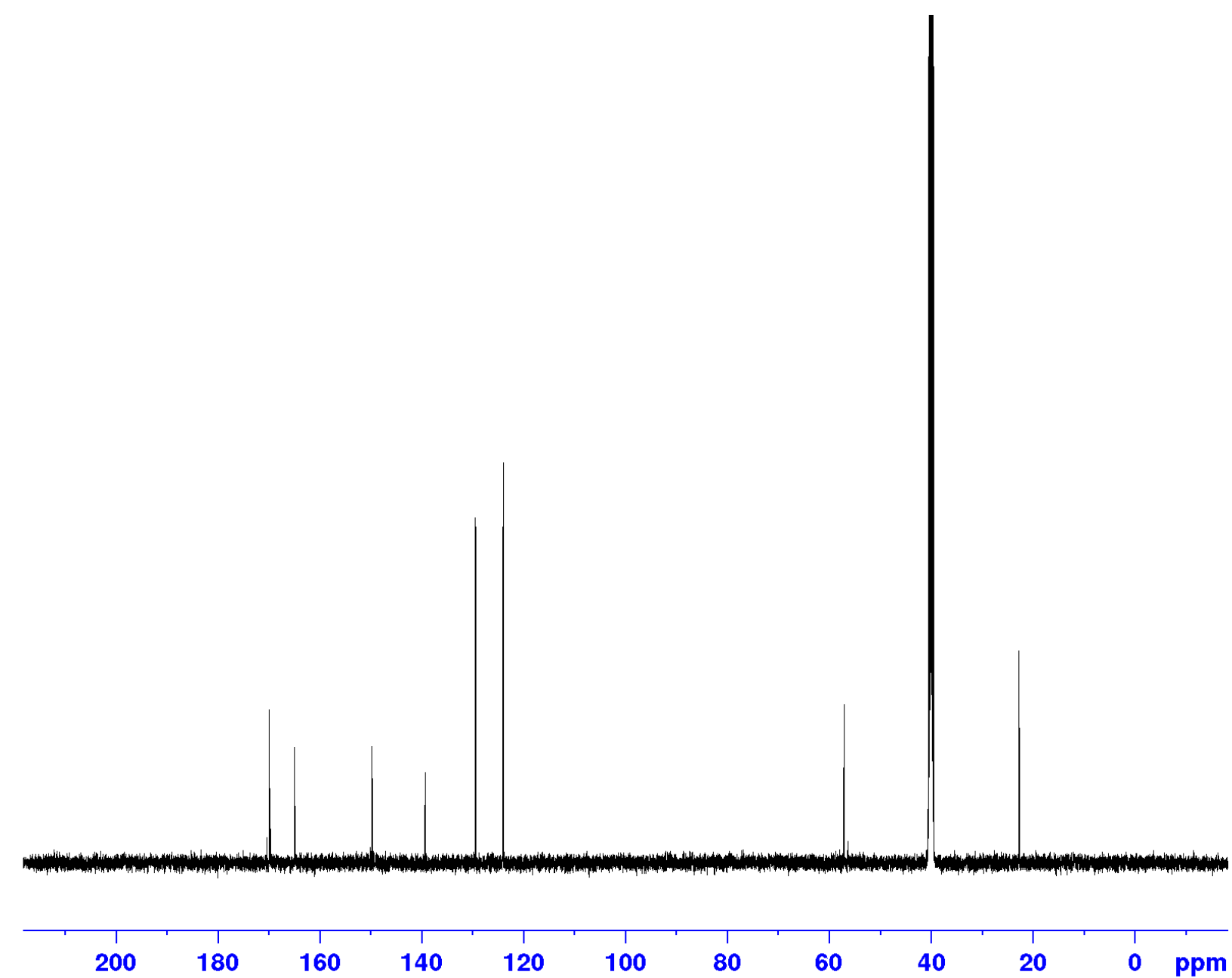

Figure S27: $125 \mathrm{MHz}{ }^{13} \mathrm{C}-\mathrm{NMR}$ of 2-Ethanamido-(4-nitrobenzamido)acetic Acid (23) in DMSO-d6. 
Table S1: Stopped-Flow Observed Rates and Average $k_{\text {obsd }}\left(\mathrm{s}^{-1}\right)$ for 4-Chloro- $\alpha$-hydroxyhippuric Acid (2b) Under Basic Conditions in $\mathrm{H}_{2} \mathrm{O}$, at $25^{\circ} \mathrm{C}, I=1.0 \mathrm{M}(\mathrm{KCl})$.

\begin{tabular}{|c|c|c|c|c|c|c|c|c|c|c|c|}
\hline$[\mathrm{KOH}](\mathrm{M})$ & \multicolumn{9}{|c|}{ Observed Experimental Rates $\left(\mathrm{s}^{-1}\right)$} & $k_{\text {obsd }}\left(\mathrm{s}^{-1}\right)$ \\
\hline 0.01 & 0.1053 & 0.10524 & 0.10199 & & & & & & & & $0.104+/-0.002$ \\
\hline 0.015 & 0.150 & 0.123 & 0.111 & 0.106 & 0.131 & 0.131 & & & & & $0.13+/-0.02$ \\
\hline 0.025 & 0.116 & 0.108 & 0.111 & 0.112 & 0.111 & 0.119 & & & & & $0.113+/-0.004$ \\
\hline 0.05 & 0.214 & 0.251 & 0.229 & 0.254 & 0.236 & 0.230 & & & & & $0.24+/-0.01$ \\
\hline 0.075 & 0.423 & 0.363 & 0.370 & 0.370 & 0.370 & 0.460 & & & & & $0.39+/-0.04$ \\
\hline 0.1 & 0.439 & 0.460 & 0.460 & 0.543 & 0.470 & 0.508 & 0.500 & & & & $0.48+/-0.04$ \\
\hline 0.2 & 0.67 & 0.71 & 0.79 & 0.83 & 0.83 & 0.82 & 0.84 & 0.78 & & & $0.78+/-0.06$ \\
\hline 0.3 & 0.76 & 0.76 & 0.77 & 0.76 & 0.77 & 0.78 & 0.782 & & & & $0.77+/-0.01$ \\
\hline 0.4 & 0.86 & 0.89 & 0.91 & 0.92 & 0.92 & 0.90 & 0.90 & 0.91 & & & $0.90+/-0.02$ \\
\hline 0.5 & 0.90 & 0.98 & 0.98 & 0.98 & 0.98 & 0.99 & & & & & $0.97+/-0.03$ \\
\hline 0.6 & 1.05 & 1.05 & 1.20 & 1.30 & 1.32 & & & & & & $1.18+/-0.13$ \\
\hline 0.7 & 1.01 & 1.09 & 1.12 & 1.01 & 1.05 & 1.06 & 1.06 & & & & $1.06+/-0.04$ \\
\hline 0.8 & 1.02 & 1.29 & 1.39 & 1.47 & 1.50 & 1.48 & 1.48 & & & & $1.38+/-0.17$ \\
\hline 0.9 & 1.21 & 1.43 & 1.45 & 1.48 & 1.33 & 1.36 & 1.40 & 1.41 & 1.47 & 1.45 & $1.38+/-0.08$ \\
\hline 1.0 & 1.19 & 1.37 & 1.33 & 1.33 & 1.38 & 1.45 & 1.15 & & & & $1.3+/-0.1$ \\
\hline
\end{tabular}


Table S2: Stopped-Flow Observed Rates and Average $k_{\text {obsd }}\left(\mathrm{s}^{-1}\right)$ for 4-Bromo- $\alpha$-hydroxyhippuric Acid (2c) Under Basic Conditions in $\mathrm{H}_{2} \mathrm{O}$, at $25^{\circ} \mathrm{C}, I=1.0 \mathrm{M}(\mathrm{KCl})$.

\begin{tabular}{|c|c|c|c|c|c|c|c|c|c|c|c|c|}
\hline$[\mathrm{KOH}](\mathrm{M})$ & \multicolumn{9}{|c|}{ Observed Experimental Rates $\left(\mathrm{s}^{-1}\right)$} & $k_{\text {obsd }}\left(\mathrm{s}^{-1}\right)$ \\
\hline 0.01 & 0.10008 & 0.09581 & 0.09887 & & & & & & & & & $0.098+/-0.002$ \\
\hline 0.015 & 0.099 & 0.079 & 0.075 & 0.104 & 0.093 & 0.090 & 0.089 & & & & & $0.09+/-0.01$ \\
\hline 0.025 & 0.145 & 0.139 & 0.131 & 0.126 & 0.122 & 0.125 & & & & & & $0.131+/-0.007$ \\
\hline 0.05 & 0.255 & 0.281 & 0.276 & 0.264 & 0.273 & 0.230 & & & & & & $0.26+/-0.02$ \\
\hline 0.075 & 0.313 & 0.350 & 0.406 & 0.415 & 0.410 & 0.418 & & & & & & $0.39+/-0.03$ \\
\hline 0.1 & 0.460 & 0.442 & 0.456 & 0.473 & 0.483 & 0.444 & 0.425 & & & & & $0.45+/-0.02$ \\
\hline 0.2 & 0.65 & 0.70 & 0.70 & 0.71 & 0.70 & 0.70 & 0.69 & & & & & $0.69+/-0.02$ \\
\hline 0.3 & 0.75 & 0.85 & 0.87 & 0.86 & 0.84 & 0.83 & & & & & & $0.83+/-0.04$ \\
\hline 0.4 & 0.98 & 1.05 & 1.04 & 0.97 & 0.96 & 1.06 & 1.06 & 1.06 & & & & $1.02+/-0.04$ \\
\hline 0.5 & 0.89 & 1.02 & 1.02 & 1.02 & 0.94 & 1.00 & 1.01 & & & & & $0.99+/-0.05$ \\
\hline 0.6 & 0.96 & 1.08 & 1.08 & 1.06 & 1.10 & 1.07 & 1.08 & 1.06 & & & & $1.06+/-0.04$ \\
\hline 0.7 & 1.07 & 1.14 & 1.13 & 1.14 & 1.14 & 1.15 & 1.14 & 1.16 & & & & $1.13+/-0.03$ \\
\hline 0.8 & 1.33 & 1.23 & 1.48 & 1.62 & 1.60 & 1.49 & 1.56 & 1.55 & & & & $1.48+/-0.14$ \\
\hline 0.9 & 1.32 & 1.37 & 1.06 & 1.48 & 1.51 & 1.22 & 1.28 & 1.36 & 1.38 & 1.37 & 1.37 & $1.34+/-0.12$ \\
\hline 1.0 & 1.23 & 1.23 & 1.35 & 1.36 & 1.37 & 1.34 & 1.35 & & & & & $1.32+/-0.06$ \\
\hline
\end{tabular}


Table S3: Stopped-Flow Observed Rates and Average $k_{\text {obsd }}\left(\mathrm{s}^{-1}\right)$ for 4-Nitro- $\alpha$-hydroxyhippuric Acid (2d) Under Basic Conditions in $\mathrm{H}_{2} \mathrm{O}$, at $25^{\circ} \mathrm{C}, I=1.0 \mathrm{M}(\mathrm{KCl})$.

\begin{tabular}{|c|c|c|c|c|c|c|c|c|c|c|c|c|c|c|c|}
\hline$[\mathrm{KOH}](\mathrm{M})$ & \multicolumn{14}{|c|}{ Observed Experimental Rates $\left(\mathrm{s}^{-1}\right)$} & $k_{\text {obsd }}\left(\mathrm{s}^{-1}\right)$ \\
\hline 0.01 & 0.09887 & 0.10008 & 0.09538 & & & & & & & & & & & & $0.098+/-0.002$ \\
\hline 0.015 & 0.37 & 0.37 & 0.35 & 0.34 & 0.36 & 0.324 & & & & & & & & & $0.352+/-0.02$ \\
\hline 0.05 & 0.83 & 0.80 & 1.00 & 0.87 & 1.00 & & & & & & & & & & $0.90+/-0.09$ \\
\hline 0.075 & 0.99 & 1.27 & 1.27 & 1.35 & 1.35 & 1.22 & & & & & & & & & $1.2+/-0.1$ \\
\hline 0.1 & 0.82 & 1.14 & 1.57 & 0.98 & 1.28 & 1.35 & 1.25 & 1.40 & & & & & & & $1.2+/-0.2$ \\
\hline 0.3 & 2.02 & 2.20 & 2.09 & 2.29 & 2.30 & & & & & & & & & & $2.2+/-0.1$ \\
\hline 0.4 & 1.63 & 2.30 & 2.59 & 2.50 & 2.70 & 2.80 & 2.50 & 2.60 & & & & & & & $2.6+/-0.4$ \\
\hline 0.5 & 2.6 & 2.8 & 2.7 & 2.9 & 2.9 & 2.8 & 2.9 & & & & & & & & $2.8+/-0.1$ \\
\hline 0.6 & 2.21 & 2.89 & 3.05 & 3.30 & 2.80 & 3.00 & & & & & & & & & $2.9+/-0.4$ \\
\hline 0.7 & 2.3 & 2.7 & 2.7 & 2.7 & 3.0 & 3.3 & & & & & & & & & $2.8+/-0.3$ \\
\hline
\end{tabular}


Table S4: Stopped-Flow Observed Rates and Average $k_{\text {obsd }}\left(\mathrm{s}^{-1}\right)$ for 4-(Trifluoromethyl)- $\alpha$-hydroxyhippuric Acid (2e) Under Basic

Conditions in $\mathrm{H}_{2} \mathrm{O}$, at $25^{\circ} \mathrm{C}, I=1.0 \mathrm{M}(\mathrm{KCl})$.

\begin{tabular}{|c|c|c|c|c|c|c|c|c|c|c|c|c|c|c|c|}
\hline$[\mathrm{KOH}](\mathrm{M})$ & \multicolumn{14}{|c|}{ Observed Experimental Rates $\left(\mathrm{s}^{-1}\right)$} & $k_{\text {obsd }}\left(\mathrm{s}^{-1}\right)$ \\
\hline 0.01 & 0.1399 & 0.13401 & 0.12963 & & & & & & & & & & & & $0.13+/-0.01$ \\
\hline 0.015 & 0.235 & 0.219 & 0.225 & 0.227 & 0.224 & 0.254 & 0.276 & & & & & & & & $0.24+/-0.02$ \\
\hline 0.025 & 0.304 & 0.312 & 0.299 & 0.316 & 0.306 & 0.310 & & & & & & & & & $0.31+/-0.01$ \\
\hline 0.05 & 0.430 & 0.413 & 0.461 & 0.498 & 0.512 & 0.510 & & & & & & & & & $0.47+/-0.04$ \\
\hline 0.075 & 0.69 & 0.70 & 0.71 & 0.70 & 0.70 & 0.68 & & & & & & & & & $0.70+/-0.01$ \\
\hline 0.1 & 0.814 & 0.726 & 0.740 & 0.730 & 0.727 & 0.745 & & & & & & & & & $0.75+/-0.03$ \\
\hline 0.2 & 1.070 & 1.086 & 1.090 & 1.120 & 1.109 & 1.114 & & & & & & & & & $1.10+/-0.02$ \\
\hline 0.3 & 1.260 & 1.250 & 1.273 & 1.298 & 1.270 & 1.240 & & & & & & & & & $1.27+/-0.02$ \\
\hline 0.4 & 1.07 & 1.47 & 1.45 & 1.46 & 1.45 & 1.45 & & & & & & & & & $1.4+/-0.2$ \\
\hline 0.5 & 1.58 & 1.58 & 1.59 & 1.59 & 1.61 & 1.60 & 1.58 & & & & & & & & $1.59+/-0.01$ \\
\hline 0.6 & 0.92 & 1.65 & 1.70 & 1.71 & 1.71 & & & & & & & & & & $1.69+/-0.03$ \\
\hline 0.7 & 1.74 & 1.79 & 1.75 & 1.78 & 1.73 & 1.76 & 1.79 & & & & & & & & $1.76+/-0.02$ \\
\hline 0.8 & 1.70 & 1.40 & 1.66 & 1.57 & 1.63 & 1.63 & 1.79 & 1.75 & & & & & & & $1.6+/-0.1$ \\
\hline 0.9 & 1.87 & 2.06 & 2.12 & 2.17 & 1.97 & 1.90 & 1.95 & 1.91 & 1.91 & 1.93 & 1.95 & 1.94 & 1.93 & & $1.97+/-0.09$ \\
\hline 1.0 & 1.94 & 2.03 & 2.07 & 2.02 & 2.06 & 2.03 & 1.466 & 2.01 & 1.99 & 2.04 & 1.95 & 2.02 & 2.02 & 2.02 & $1.98+/-0.15$ \\
\hline
\end{tabular}


Table S5: Stopped-Flow Observed Rates and Average $k_{\text {obsd }}\left(\mathrm{s}^{-1}\right)$ for 3,4-Dichloro- $\alpha$-hydroxyhippuric Acid (2f) Under Basic Conditions in $\mathrm{H}_{2} \mathrm{O}$, at $25^{\circ} \mathrm{C}, I=1.0 \mathrm{M}(\mathrm{KCl})$.

\begin{tabular}{|c|c|c|c|c|c|c|c|c|c|}
\hline$[\mathrm{KOH}](\mathrm{M})$ & \multicolumn{7}{|c|}{ Observed Experimental Rates $\left(\mathrm{s}^{-1}\right)$} & $k_{\text {obsd }}\left(\mathrm{s}^{-1}\right)$ \\
\hline 0.01 & 0.15447 & 0.1803 & 0.15527 & & & & & & $0.16+/-0.01$ \\
\hline 0.015 & 0.223 & 0.206 & 0.206 & 0.200 & 0.199 & 0.200 & & & $0.21+/-0.01$ \\
\hline 0.025 & 0.307 & 0.321 & 0.321 & 0.341 & 0.348 & 0.344 & & & $0.33+/-0.02$ \\
\hline 0.05 & 0.525 & 0.548 & 0.547 & 0.517 & 0.551 & & & & $0.54+/-0.02$ \\
\hline 0.075 & 0.648 & 0.690 & 0.700 & 0.680 & 0.660 & 0.690 & & & $0.68+/-0.02$ \\
\hline 0.1 & 0.92 & 0.94 & 0.91 & 0.98 & 0.95 & 0.93 & 0.95 & & $0.94+/-0.02$ \\
\hline 0.2 & 1.18 & 1.18 & 0.95 & 1.21 & 1.21 & 1.19 & & & $1.2+/-0.1$ \\
\hline 0.3 & 1.14 & 1.32 & 1.52 & 1.55 & 1.69 & 1.54 & 1.57 & & $1.5+/-0.2$ \\
\hline 0.4 & 0.91 & 1.12 & 1.25 & 1.80 & 1.90 & 2.10 & & & $1.5+/-0.5$ \\
\hline 0.5 & 0.92 & 1.44 & 2.10 & 1.90 & 1.80 & 1.80 & & & $1.7+/-0.4$ \\
\hline 0.6 & 1.48 & 1.88 & 1.89 & 1.88 & 1.98 & 1.91 & & & $1.8+/-0.2$ \\
\hline 0.7 & 1.22 & 1.90 & 1.99 & 1.66 & 2.07 & 2.05 & & & $1.9+/-0.2$ \\
\hline 0.8 & 1.76 & 2.00 & 2.10 & 2.14 & 2.10 & 2.14 & 2.14 & 2.00 & $2.0+/-0.1$ \\
\hline 0.9 & 1.66 & 1.68 & 2.18 & 2.04 & 2.10 & 2.00 & 2.11 & 2.2 & $2.1+/-0.1$ \\
\hline 1.0 & 2.60 & 2.18 & 2.20 & 2.34 & 2.40 & 2.37 & 2.37 & 2.40 & $2.4+/-0.1$ \\
\hline
\end{tabular}


Table S6: Stopped-Flow Observed Rates and Average $k_{\text {obsd }}\left(\mathrm{s}^{-1}\right)$ for 3-Chloro- $\alpha$-hydroxyhippuric Acid (2g) Under Basic Conditions in $\mathrm{H}_{2} \mathrm{O}$, at $25^{\circ} \mathrm{C}, I=1.0 \mathrm{M}(\mathrm{KCl})$.

\begin{tabular}{|c|c|c|c|c|c|c|c|c|c|c|c|c|c|c|c|}
\hline$[\mathrm{KOH}](\mathrm{M})$ & \multicolumn{14}{|c|}{ Observed Experimental Rates $\left(\mathrm{s}^{-1}\right)$} & $k_{\text {obsd }}\left(\mathrm{s}^{-1}\right)$ \\
\hline 0.01 & 0.10642 & 0.1007 & 0.09915 & 0.13435 & & & & & & & & & & & $0.11+/-0.02$ \\
\hline 0.015 & 0.227 & 0.226 & 0.230 & 0.228 & 0.233 & 0.252 & & & & & & & & & $0.23+/-0.01$ \\
\hline 0.05 & 0.35 & 0.38 & 0.42 & 0.42 & 0.42 & 0.43 & & & & & & & & & $0.40+/-0.03$ \\
\hline 0.075 & 0.469 & 0.486 & 0.497 & 0.471 & 0.483 & 0.498 & & & & & & & & & $0.48+/-0.01$ \\
\hline 0.1 & 0.554 & 0.559 & 0.546 & 0.624 & 0.616 & 0.623 & 0.613 & 0.619 & & & & & & & $0.59+/-0.03$ \\
\hline 0.3 & 0.930 & 1.130 & 1.128 & 1.150 & 1.137 & 1.130 & & & & & & & & & $1.10+/-0.08$ \\
\hline 0.4 & 1.12 & 1.19 & 1.22 & 1.23 & 1.27 & 1.26 & & & & & & & & & $1.22+/-0.05$ \\
\hline 0.5 & 1.24 & 1.32 & 1.30 & 1.34 & 1.34 & 1.33 & & & & & & & & & $1.31+/-0.04$ \\
\hline 0.6 & 1.31 & 1.36 & 1.37 & 1.40 & 1.41 & 1.38 & & & & & & & & & $1.37+/-0.04$ \\
\hline 0.7 & 1.40 & 1.45 & 1.49 & 1.48 & 1.45 & 1.50 & 1.49 & & & & & & & & $1.47+/-0.04$ \\
\hline
\end{tabular}


Table S7: Stopped-Flow Observed Rates and Average $k_{\text {obsd }}\left(\mathrm{s}^{-1}\right)$ for 3-Bromo- $\alpha$-hydroxyhippuric Acid (2h) Under Basic Conditions in $\mathrm{H}_{2} \mathrm{O}$, at $25^{\circ} \mathrm{C}, I=1.0 \mathrm{M}(\mathrm{KCl})$.

\begin{tabular}{|c|c|c|c|c|c|c|c|c|c|c|c|c|c|}
\hline$[\mathrm{KOH}](\mathrm{M})$ & \multicolumn{12}{|c|}{ Observed Experimental Rates $\left(\mathrm{s}^{-1}\right)$} & $k_{\text {obsd }}\left(\mathrm{s}^{-1}\right)$ \\
\hline 0.01 & 0.10033 & 0.12464 & 0.13062 & 0.14054 & 0.12644 & & & & & & & & $0.12+/-0.01$ \\
\hline 0.015 & 0.281 & 0.237 & 0.230 & 0.222 & 0.232 & 0.225 & & & & & & & $0.24+/-0.02$ \\
\hline 0.025 & 0.239 & 0.237 & 0.237 & 0.235 & 0.240 & 0.249 & & & & & & & $0.240+/-0.005$ \\
\hline 0.05 & 0.350 & 0.390 & 0.410 & 0.415 & 0.415 & 0.390 & & & & & & & $0.39+/-0.02$ \\
\hline 0.075 & 0.514 & 0.530 & 0.553 & 0.570 & 0.566 & 0.570 & & & & & & & $0.55+/-0.02$ \\
\hline 0.1 & 0.582 & 0.670 & 0.620 & 0.634 & 0.670 & 0.634 & 0.637 & 0.636 & & & & & $0.64+/-0.03$ \\
\hline 0.2 & 0.881 & 0.883 & 0.880 & 0.920 & 0.888 & 0.870 & & & & & & & $0.89+/-0.02$ \\
\hline 0.3 & 1.00 & 1.01 & 1.02 & 1.08 & 1.09 & & & & & & & & $1.04+/-0.04$ \\
\hline 0.4 & 1.14 & 1.26 & 1.26 & 1.24 & 1.25 & 1.23 & 1.30 & & & & & & $1.24+/-0.05$ \\
\hline 0.5 & 1.23 & 1.31 & 1.40 & 1.31 & 1.35 & & & & & & & & $1.32+/-0.06$ \\
\hline 0.6 & 1.44 & 1.47 & 1.50 & 1.49 & 1.57 & 1.52 & 1.54 & & & & & & $1.50+/-0.04$ \\
\hline 0.7 & 1.48 & 1.49 & 1.51 & 1.57 & 1.58 & 1.57 & 1.61 & & & & & & $1.54+/-0.05$ \\
\hline 0.8 & 1.51 & 1.60 & 1.61 & 1.58 & 1.63 & 1.56 & 1.53 & & & & & & $1.57+/-0.04$ \\
\hline 0.9 & 1.02 & 1.56 & 1.59 & 1.62 & 1.65 & 1.65 & 1.69 & 1.60 & & & & & $1.62+/-0.04$ \\
\hline 1.0 & 1.82 & 1.93 & 2.02 & 1.97 & 2.07 & 2.00 & 1.70 & 1.91 & 1.92 & 1.93 & 2.00 & 1.98 & $1.9+/-0.1$ \\
\hline
\end{tabular}


Table S8: UV-Vis Spectrophotometric Observed Rates and Average $k_{\mathrm{obsd}}\left(\mathrm{s}^{-1}\right)$ for $\alpha$-Hydroxyhippuric Acid $(\mathbf{2 a})$ at $\sim \mathrm{pH} 11.0$ buffered with Potassium Phosphate Monobasic, in $\mathrm{H}_{2} \mathrm{O}$ at $25^{\circ} \mathrm{C}, I=1.0 \mathrm{M}(\mathrm{KCl})$.

\begin{tabular}{|c|c|c|c|c|c|c|}
\hline$[\text { Phosphate }]^{\text {tot }}(\mathrm{M})$ & $\mathrm{p} H$ & \multicolumn{4}{|c|}{ Observed Experimental Rates $\left(\mathrm{s}^{-1}\right)$} & $k_{\text {obsd }}\left(\mathrm{s}^{-1}\right)$ \\
\hline 0.1500 & 11.29 & 0.01242 & 0.0123 & 0.0126 & - & $0.01244+/-0.0002$ \\
\hline 0.1000 & 11.14 & 0.01038 & 0.01102 & 0.0099 & - & $0.0104+/-0.0006$ \\
\hline 0.0750 & 11.12 & 0.0094 & 0.0096 & 0.01009 & - & $0.0097+/-0.0004$ \\
\hline
\end{tabular}

Table S9: UV-Vis Spectrophotometric Observed Rates and Average $k_{\mathrm{obsd}}\left(\mathrm{s}^{-1}\right)$ for $\alpha$-Hydroxyhippuric Acid $(\mathbf{2 a})$ at $\mathrm{p} H \sim 10.5$ buffered with Potassium Bicarbonate, in $\mathrm{H}_{2} \mathrm{O}$ at $25^{\circ} \mathrm{C}, I=1.0 \mathrm{M}(\mathrm{KCl})$.

\begin{tabular}{|c|c|c|c|c|c|c|}
\hline$[\text { Carbonate }]^{\text {tot }}(\mathrm{M})$ & $\mathrm{p} H$ & \multicolumn{4}{|c|}{ Observed Experimental Rates $\left(\mathrm{s}^{-1}\right)$} & $k_{\text {obsd }}\left(\mathrm{s}^{-1}\right)$ \\
\hline 0.1000 & 10.63 & 0.003426 & 0.00342 & 0.00371 & - & $0.0035+/-0.0002$ \\
\hline 0.0667 & 10.60 & 0.00402 & 0.00398 & 0.00421 & - & $0.0041+/-0.0001$ \\
\hline 0.0500 & 10.57 & 0.003725 & 0.00344 & 0.00339 & - & $0.0035+/-0.0002$ \\
\hline
\end{tabular}

Table S10: UV-Vis Spectrophotometric Observed Rates and Average $k_{\mathrm{obsd}}\left(\mathrm{s}^{-1}\right)$ for $\alpha$-Hydroxyhippuric Acid $(\mathbf{2 a})$ at $\mathrm{p} H \sim 10.0$ buffered with Potassium Bicarbonate, in $\mathrm{H}_{2} \mathrm{O}$ at $25^{\circ} \mathrm{C}, I=1.0 \mathrm{M}(\mathrm{KCl})$.

\begin{tabular}{|c|c|c|c|c|c|c|}
\hline [Carbonate $^{\text {tot }}(\mathrm{M})$ & $\mathrm{pH}$ & \multicolumn{3}{|c|}{ Observed Experimental Rates $\left(\mathrm{s}^{-1}\right)$} & $k_{\text {obsd }}\left(\mathrm{s}^{-1}\right)$ \\
\hline 0.1000 & 9.76 & 0.000562 & 0.000614 & 0.000580 & 0.000784 & $0.0006+/-0.0001$ \\
\hline 0.0667 & 9.72 & 0.000757 & 0.000750 & 0.000761 & - & $0.000756+/-0.000006$ \\
\hline 0.0500 & 9.65 & 0.000483 & 0.000640 & 0.000635 & - & $0.00059+/-0.00009$ \\
\hline
\end{tabular}


Table 11: UV-Vis Spectrophotometric Observed Rates and Average $k_{\text {obsd }}\left(\mathrm{s}^{-1}\right)$ for $\alpha$-Hydroxyhippuric Acid (2a) at $\mathrm{p} H \sim 9.5$ buffered with Potassium Pyrophosphate, in $\mathrm{H}_{2} \mathrm{O}$ at $25^{\circ} \mathrm{C}, I=1.0 \mathrm{M}(\mathrm{KCl})$.

\begin{tabular}{|c|c|c|c|c|c|c|}
\hline$\left[\right.$ Pyro $^{\text {tot }}(\mathrm{M})$ & $\mathrm{p} H$ & \multicolumn{3}{|c|}{ Observed Experimental Rates $\left(\mathrm{s}^{-1}\right)$} & $k_{\text {obsd }}\left(\mathrm{s}^{-1}\right)$ \\
\hline 0.1000 & 9.43 & 0.000260 & 0.000295 & 0.000300 & - & $0.00029+/-0.00002$ \\
\hline 0.0667 & 9.31 & 0.000227 & 0.000217 & 0.000213 & - & $0.000219+/-0.000007$ \\
\hline 0.0500 & 9.19 & 0.000200 & 0.000198 & 0.000197 & - & $0.000198+/-0.000002$ \\
\hline
\end{tabular}

Table S12: UV-Vis Spectrophotometric Observed Rates and Average $k_{\mathrm{obsd}}\left(\mathrm{s}^{-1}\right)$ for $\alpha$-Hydroxyhippuric Acid (2a) at $\mathrm{pH} \sim 9.0$ buffered with Potassium Pyrophosphate, in $\mathrm{H}_{2} \mathrm{O}$ at $25^{\circ} \mathrm{C}, I=1.0 \mathrm{M}(\mathrm{KCl})$.

\begin{tabular}{|c|c|c|c|c|c|c|}
\hline$\left[\right.$ Pyro $^{\text {tot }}(\mathrm{M})$ & $\mathrm{p} H$ & \multicolumn{3}{|c|}{ Observed Experimental Rates $\left(\mathrm{s}^{-1}\right)$} & $k_{\text {obsd }}\left(\mathrm{s}^{-1}\right)$ \\
\hline 0.1000 & 9.09 & 0.000142 & 0.000147 & 0.000143 & - & $0.000144+/-0.000003$ \\
\hline 0.0667 & 8.99 & 0.000118 & 0.000120 & 0.000122 & - & $0.000120+/-0.000002$ \\
\hline 0.0500 & 8.89 & 0.000102 & 0.000115 & 0.000107 & - & $0.000108+/-0.000007$ \\
\hline
\end{tabular}

Table S13: UV-Vis Spectrophotometric Observed Rates and Average $k_{\mathrm{obsd}}\left(\mathrm{s}^{-1}\right)$ for 4-Chloro- $\alpha$-hydroxyhippuric Acid (2b) at $\mathrm{pH}$

$\sim 11.5$ buffered with Potassium Phosphate Monobasic, in $\mathrm{H}_{2} \mathrm{O}$ at $25^{\circ} \mathrm{C}, I=1.0 \mathrm{M}(\mathrm{KCl})$.

\begin{tabular}{|c|c|c|c|c|c|c|}
\hline [Phosphate $^{\text {tot }}(\mathrm{M})$ & $\mathrm{p} H$ & \multicolumn{3}{|c|}{ Observed Experimental Rates $\left(\mathrm{s}^{-1}\right)$} & $k_{\text {obsd }}\left(\mathrm{s}^{-1}\right)$ \\
\hline 0.1000 & 11.83 & 0.0559 & 0.0538 & 0.0560 & 0.0653 & $0.0578+/-0.005$ \\
\hline 0.0667 & 11.82 & 0.0444 & 0.0470 & 0.0480 & - & $0.0465+/-0.002$ \\
\hline 0.0500 & 11.78 & 0.0460 & 0.0460 & 0.0454 & 0.0480 & $0.0463+/-0.001$ \\
\hline
\end{tabular}


Table S14: UV-Vis Spectrophotometric Observed Rates and Average $k_{\mathrm{obsd}}\left(\mathrm{s}^{-1}\right)$ for 4-Chloro- $\alpha$-hydroxyhippuric Acid (2b) at $\mathrm{pH}$

$\sim 11.0$ buffered with Potassium Phosphate Monobasic, in $\mathrm{H}_{2} \mathrm{O}$ at $25^{\circ} \mathrm{C}, I=1.0 \mathrm{M}(\mathrm{KCl})$.

\begin{tabular}{|c|c|c|c|c|c|c|}
\hline [Phosphate $^{\text {tot }}(\mathrm{M})$ & $\mathrm{p} H$ & \multicolumn{3}{|c|}{ Observed Experimental Rates $\left(\mathrm{s}^{-1}\right)$} & $k_{\text {obsd }}\left(\mathrm{s}^{-1}\right)$ \\
\hline 0.1500 & 11.32 & 0.0201 & 0.0203 & 0.0205 & - & $0.0203+/-0.0002$ \\
\hline 0.1000 & 11.22 & 0.0165 & 0.0165 & 0.0181 & - & $0.017+/-0.001$ \\
\hline 0.0750 & 11.18 & 0.0185 & 0.0146 & 0.0162 & - & $0.016+/-0.002$ \\
\hline
\end{tabular}

Table S15: UV-Vis Spectrophotometric Observed Rates and Average $k_{\text {obsd }}\left(\mathrm{s}^{-1}\right)$ for 4-Chloro- $\alpha$-hydroxyhippuric Acid (2b) at $\mathrm{pH}$ $\sim 10.5$ buffered with Potassium Bicarbonate, in $\mathrm{H}_{2} \mathrm{O}$ at $25^{\circ} \mathrm{C}, I=1.0 \mathrm{M}(\mathrm{KCl})$.

\begin{tabular}{|c|c|c|c|c|c|c|}
\hline [Carbonate $^{\text {tot }}(\mathrm{M})$ & $\mathrm{p} H$ & \multicolumn{4}{|c|}{ Observed Experimental Rates $\left(\mathrm{s}^{-1}\right)$} & $k_{\text {obsd }}\left(\mathrm{s}^{-1}\right)$ \\
\hline 0.1000 & 10.69 & 0.0058 & 0.0062 & 0.0061 & - & $0.0060+/-0.0002$ \\
\hline 0.0667 & 10.69 & 0.0056 & 0.0057 & 0.0057 & - & $0.0056+/-0.0001$ \\
\hline 0.0500 & 10.66 & 0.0054 & 0.0053 & 0.0052 & - & $0.0053+/-0.0001$ \\
\hline
\end{tabular}

Table S16: UV-Vis Spectrophotometric Observed Rates and Average $k_{\mathrm{obsd}}\left(\mathrm{s}^{-1}\right)$ for 4-Chloro- $\alpha$-hydroxyhippuric Acid (2b) at $\mathrm{pH}$ $\sim 10.0$ buffered with Potassium Bicarbonate, in $\mathrm{H}_{2} \mathrm{O}$ at $25^{\circ} \mathrm{C}, I=1.0 \mathrm{M}(\mathrm{KCl})$.

\begin{tabular}{|c|c|c|c|c|c|c|}
\hline [Carbonate $^{\text {tot }}(\mathrm{M})$ & $\mathrm{p} H$ & \multicolumn{3}{|c|}{ Observed Experimental Rates $\left(\mathrm{s}^{-1}\right)$} & $k_{\text {obsd }}\left(\mathrm{s}^{-1}\right)$ \\
\hline 0.1000 & 9.86 & 0.001013 & 0.001012 & 0.001017 & - & $0.001014+/-0.000003$ \\
\hline 0.0667 & 9.87 & 0.001017 & 0.001002 & 0.000995 & - & $0.00100+/-0.00001$ \\
\hline 0.0500 & 9.86 & 0.0011 & 0.0010 & 0.0009 & - & $0.0010+/-0.0001$ \\
\hline
\end{tabular}


Table S17: UV-Vis Spectrophotometric Observed Rates and Average $k_{\mathrm{obsd}}\left(\mathrm{s}^{-1}\right)$ for 4-Chloro- $\alpha$-hydroxyhippuric Acid (2b) at $\mathrm{pH} \sim 9.5$ buffered with Potassium Pyrophosphate, in $\mathrm{H}_{2} \mathrm{O}$ at $25^{\circ} \mathrm{C}, I=1.0 \mathrm{M}(\mathrm{KCl})$.

\begin{tabular}{|c|c|c|c|c|c|c|}
\hline$\left[\right.$ Pyro $^{\text {tot }}(\mathrm{M})$ & $\mathrm{pH}$ & \multicolumn{3}{|c|}{ Observed Experimental Rates $\left(\mathrm{s}^{-1}\right)$} & $k_{\text {obsd }}\left(\mathrm{s}^{-1}\right)$ \\
\hline 0.1000 & 9.47 & 0.000568 & 0.000592 & 0.000553 & - & $0.00057+/-0.00002$ \\
\hline 0.0667 & 9.41 & 0.000447 & 0.000443 & 0.000452 & - & $0.000447+/-0.000004$ \\
\hline 0.0500 & 9.29 & 0.0004 & 0.0004 & 0.0004 & - & $0.00039+/-0.00002$ \\
\hline
\end{tabular}

Table S18: UV-Vis Spectrophotometric Observed Rates and Average $k_{\mathrm{obsd}}\left(\mathrm{s}^{-1}\right)$ for 4-Chloro- $\alpha$-hydroxyhippuric Acid $(\mathbf{2 b})$ at $\mathrm{p} H \sim 9.0$ buffered with Potassium Pyrophosphate, in $\mathrm{H}_{2} \mathrm{O}$ at $25^{\circ} \mathrm{C}, I=1.0 \mathrm{M}(\mathrm{KCl})$.

\begin{tabular}{|c|c|c|c|c|c|c|}
\hline [Pyro $^{\text {tot }}(\mathrm{M})$ & $\mathrm{p} H$ & \multicolumn{3}{|c|}{ Observed Experimental Rates $\left(\mathrm{s}^{-1}\right)$} & $k_{\text {obsd }}\left(\mathrm{s}^{-1}\right)$ \\
\hline 0.1000 & 9.08 & 0.000250 & 0.000280 & 0.000260 & - & $0.00026+/-0.00002$ \\
\hline 0.0667 & 8.90 & 0.000210 & 0.000248 & 0.000212 & - & $0.00022+/-0.00002$ \\
\hline 0.0500 & 8.95 & 0.00020 & 0.00021 & 0.00019 & - & $0.00020+/-0.00001$ \\
\hline
\end{tabular}

Table S19: UV-Vis Spectrophotometric Observed Rates and Average $k_{\mathrm{obsd}}\left(\mathrm{s}^{-1}\right)$ for 4-Bromo- $\alpha$-hydroxyhippuric Acid (2c) at $\mathrm{pH}$

$\sim 11.5$ buffered with Potassium Phosphate Monobasic, in $\mathrm{H}_{2} \mathrm{O}$ at $25^{\circ} \mathrm{C}, I=1.0 \mathrm{M}(\mathrm{KCl})$.

\begin{tabular}{|c|c|c|c|c|c|c|}
\hline [Phosphate $^{\text {tot }}(\mathrm{M})$ & $\mathrm{pH}$ & \multicolumn{4}{|c|}{ Observed Experimental Rates $\left(\mathrm{s}^{-1}\right)$} & $k_{\text {obsd }}\left(\mathrm{s}^{-1}\right)$ \\
\hline 0.1000 & 11.78 & 0.0729 & 0.0782 & 0.0705 & - & $0.074+/-0.004$ \\
\hline 0.0667 & 11.70 & 0.0628 & 0.0724 & 0.0688 & - & $0.068+/-0.005$ \\
\hline 0.0500 & 11.63 & 0.0589 & 0.0641 & 0.0538 & - & $0.059+/-0.005$ \\
\hline
\end{tabular}


Table S20: UV-Vis Spectrophotometric Observed Rates and Average $k_{\mathrm{obsd}}\left(\mathrm{s}^{-1}\right)$ for 4-Bromo- $\alpha$-hydroxyhippuric Acid (2c) at $\mathrm{p} H$

$\sim 11.0$ buffered with Potassium Phosphate Monobasic, in $\mathrm{H}_{2} \mathrm{O}$ at $25^{\circ} \mathrm{C}, I=1.0 \mathrm{M}(\mathrm{KCl})$.

\begin{tabular}{|c|c|c|c|c|c|c|}
\hline$[\text { Phosphate }]^{\text {tot }}(\mathrm{M})$ & $\mathrm{p} H$ & \multicolumn{4}{|c|}{ Observed Experimental Rates $\left(\mathrm{s}^{-1}\right)$} & $k_{\text {obsd }}\left(\mathrm{s}^{-1}\right)$ \\
\hline 0.1500 & 11.21 & 0.0211 & 0.0220 & 0.0220 & - & $0.022+/-0.001$ \\
\hline 0.1000 & 11.09 & 0.0210 & 0.0202 & 0.0190 & - & $0.020+/-0.001$ \\
\hline 0.0750 & 11.02 & 0.0186 & 0.0189 & 0.0170 & - & $0.018+/-0.001$ \\
\hline
\end{tabular}

Table S21: UV-Vis Spectrophotometric Observed Rates and Average $k_{\text {obsd }}\left(\mathrm{s}^{-1}\right)$ for 4-Bromo- $\alpha$-hydroxyhippuric Acid (2c) at $\mathrm{pH}$ $\sim 10.5$ buffered with Potassium Bicarbonate, in $\mathrm{H}_{2} \mathrm{O}$ at $25^{\circ} \mathrm{C}, I=1.0 \mathrm{M}(\mathrm{KCl})$.

\begin{tabular}{|c|c|c|c|c|c|c|}
\hline [Carbonate $^{\text {tot }}(\mathrm{M})$ & $\mathrm{p} H$ & \multicolumn{6}{|c|}{ Observed Experimental Rates $\left(\mathrm{s}^{-1}\right)$} & $k_{\text {obsd }}\left(\mathrm{s}^{-1}\right)$ \\
\hline 0.1000 & 10.60 & 0.0065 & 0.0072 & 0.0067 & - & $0.0068+/-0.0004$ \\
\hline 0.0667 & 10.55 & 0.0067 & 0.0064 & 0.0063 & - & $0.0065+/-0.0002$ \\
\hline 0.0500 & 10.54 & 0.0064 & 0.0064 & 0.0063 & - & $0.00634+/-0.00005$ \\
\hline
\end{tabular}

Table S22: UV-Vis Spectrophotometric Observed Rates and Average $k_{\mathrm{obsd}}\left(\mathrm{s}^{-1}\right)$ for 4-Bromo- $\alpha$-hydroxyhippuric Acid (2c) at $\mathrm{pH}$ $\sim 10.0$ buffered with Potassium Bicarbonate, in $\mathrm{H}_{2} \mathrm{O}$ at $25^{\circ} \mathrm{C}, I=1.0 \mathrm{M}(\mathrm{KCl})$.

\begin{tabular}{|c|c|c|c|c|c|c|}
\hline [Carbonate $^{\text {tot }}(\mathrm{M})$ & $\mathrm{p} H$ & \multicolumn{6}{|c|}{ Observed Experimental Rates $\left(\mathrm{s}^{-1}\right)$} & $k_{\text {obsd }}\left(\mathrm{s}^{-1}\right)$ \\
\hline 0.1000 & 9.75 & 0.0011 & 0.0010 & 0.0010 & - & $0.00104+/-0.00001$ \\
\hline 0.0667 & 9.71 & 0.0011 & 0.0010 & 0.0011 & - & $0.00105+/-0.00003$ \\
\hline 0.0500 & 9.72 & 0.0010 & 0.0009 & 0.0010 & - & $0.00098+/-0.00005$ \\
\hline
\end{tabular}


Table S23: UV-Vis Spectrophotometric Observed Rates and Average $k_{\mathrm{obsd}}\left(\mathrm{s}^{-1}\right)$ for 4-Bromo- $\alpha$-hydroxyhippuric Acid (2c) at $\mathrm{p} H \sim 9.5$ buffered with Potassium Pyrophosphate, in $\mathrm{H}_{2} \mathrm{O}$ at $25^{\circ} \mathrm{C}, I=1.0 \mathrm{M}(\mathrm{KCl})$.

\begin{tabular}{|c|c|c|c|c|c|c|}
\hline$\left[\right.$ Pyro $^{\text {tot }}(\mathrm{M})$ & $\mathrm{p} H$ & \multicolumn{4}{|c|}{ Observed Experimental Rates $\left(\mathrm{s}^{-1}\right)$} & $k_{\text {obsd }}\left(\mathrm{s}^{-1}\right)$ \\
\hline 0.1000 & 9.44 & 0.0006 & 0.0006 & 0.0006 & - & $0.00061+/-0.00001$ \\
\hline 0.0667 & 9.33 & 0.0005 & 0.0005 & 0.0005 & - & $0.00046+/-0.000003$ \\
\hline 0.0500 & 9.26 & 0.0004 & 0.0005 & 0.0004 & - & $0.00044+/-0.00001$ \\
\hline
\end{tabular}

Table S24: UV-Vis Spectrophotometric Observed Rates and Average $k_{\mathrm{obsd}}\left(\mathrm{s}^{-1}\right)$ for 4-Bromo- $\alpha$-hydroxyhippuric Acid (2c) at $\mathrm{pH} \sim 9.0$ buffered with Potassium Pyrophosphate, in $\mathrm{H}_{2} \mathrm{O}$ at $25^{\circ} \mathrm{C}, I=1.0 \mathrm{M}(\mathrm{KCl})$.

\begin{tabular}{|c|c|c|c|c|c|c|}
\hline$\left[\right.$ Pyro $^{\text {tot }}(\mathrm{M})$ & $\mathrm{p} H$ & \multicolumn{6}{|c|}{ Observed Experimental Rates $\left(\mathrm{s}^{-1}\right)$} & $k_{\text {obsd }}\left(\mathrm{s}^{-1}\right)$ \\
\hline 0.1000 & 8.91 & 0.0003 & 0.0003 & 0.0003 & - & $0.00028+/-0.00001$ \\
\hline 0.0667 & 8.89 & 0.0002 & 0.0002 & 0.0002 & - & $0.000242+/-0.000005$ \\
\hline 0.0500 & 8.86 & 0.0002 & 0.0002 & 0.0002 & - & $0.000214+/-0.000004$ \\
\hline
\end{tabular}

Table S25: UV-Vis Spectrophotometric Observed Rates and Average $k_{\text {obsd }}\left(\mathrm{s}^{-1}\right)$ for 4-Nitro- $\alpha$-hydroxyhippuric Acid $(\mathbf{2 d})$ at $\mathrm{pH} \sim 11.5$ buffered with Potassium Phosphate Monobasic, in $\mathrm{H}_{2} \mathrm{O}$ at $25^{\circ} \mathrm{C}, I=1.0 \mathrm{M}(\mathrm{KCl})$.

\begin{tabular}{|c|c|c|c|c|c|c|}
\hline [Phosphate $^{\text {tot }}(\mathrm{M})$ & $\mathrm{p} H$ & \multicolumn{3}{|c|}{ Observed Experimental Rates $\left(\mathrm{s}^{-1}\right)$} & $k_{\text {obsd }}\left(\mathrm{s}^{-1}\right)$ \\
\hline 0.1000 & 11.76 & 0.1620 & 0.1817 & 0.1762 & - & $0.17+/-0.01$ \\
\hline 0.0667 & 11.66 & 0.1267 & 0.1551 & 0.1701 & 0.1133 & $0.014+/-0.03$ \\
\hline 0.0500 & 11.60 & 0.1136 & 0.1079 & 0.1193 & - & $0.114+/-0.006$ \\
\hline
\end{tabular}


Table S26: UV-Vis Spectrophotometric Observed Rates and Average $k_{\mathrm{obsd}}\left(\mathrm{s}^{-1}\right)$ for 4-Nitro- $\alpha$-hydroxyhippuric Acid (2d) at $\mathrm{pH} \sim 11.0$ buffered with Potassium Phosphate Monobasic, in $\mathrm{H}_{2} \mathrm{O}$ at $25^{\circ} \mathrm{C}, I=1.0 \mathrm{M}(\mathrm{KCl})$.

\begin{tabular}{|c|c|c|c|c|c|c|}
\hline [Phosphate $^{\text {tot }}(\mathrm{M})$ & $\mathrm{p} H$ & \multicolumn{4}{|c|}{ Observed Experimental Rates $\left(\mathrm{s}^{-1}\right)$} & $k_{\text {obsd }}\left(\mathrm{s}^{-1}\right)$ \\
\hline 0.1500 & 10.97 & 0.0511 & 0.0675 & 0.0418 & 0.0516 & $0.05+/-0.01$ \\
\hline 0.0667 & 10.89 & 0.0427 & 0.0361 & 0.0439 & - & $0.041+/-0.004$ \\
\hline 0.0500 & 10.86 & 0.0438 & 0.0374 & 0.0488 & - & $0.043+/-0.006$ \\
\hline
\end{tabular}

Table S27: UV-Vis Spectrophotometric Observed Rates and Average $k_{\text {obsd }}\left(\mathrm{s}^{-1}\right)$ for 4-Nitro- $\alpha$-hydroxyhippuric Acid $(\mathbf{2 d})$ at $\mathrm{p} H \sim 10.5$ buffered with Potassium Bicarbonate, in $\mathrm{H}_{2} \mathrm{O}$ at $25^{\circ} \mathrm{C}, I=1.0 \mathrm{M}(\mathrm{KCl})$.

\begin{tabular}{|c|c|c|c|c|c|c|}
\hline [Carbonate $^{\text {tot }}(\mathrm{M})$ & $\mathrm{p} H$ & \multicolumn{6}{|c|}{ Observed Experimental Rates $\left(\mathrm{s}^{-1}\right)$} & $k_{\text {obsd }}\left(\mathrm{s}^{-1}\right)$ \\
\hline 0.1000 & 10.45 & 0.0234 & 0.0253 & 0.0237 & - & $0.024+/-0.001$ \\
\hline 0.0667 & 10.41 & 0.0189 & 0.0190 & 0.0247 & - & $0.021+/-0.003$ \\
\hline 0.0500 & 10.39 & 0.0211 & 0.0220 & 0.0221 & - & $0.022+/-0.001$ \\
\hline
\end{tabular}

Table S28: UV-Vis Spectrophotometric Observed Rates and Average $k_{\text {obsd }}\left(\mathrm{s}^{-1}\right)$ for 4-Nitro- $\alpha$-hydroxyhippuric Acid $(\mathbf{2 d})$ at $\mathrm{pH} \sim 10.0$ buffered with Potassium Bicarbonate, in $\mathrm{H}_{2} \mathrm{O}$ at $25^{\circ} \mathrm{C}, I=1.0 \mathrm{M}(\mathrm{KCl})$.

\begin{tabular}{|c|c|c|c|c|c|c|}
\hline [Carbonate $^{\text {tot }}(\mathrm{M})$ & $\mathrm{pH}$ & \multicolumn{4}{|c|}{ Observed Experimental Rates $\left(\mathrm{s}^{-1}\right)$} & $k_{\text {obsd }}\left(\mathrm{s}^{-1}\right)$ \\
\hline 0.1000 & 9.71 & 0.0038 & 0.0040 & 0.0040 & - & $0.0039+/-0.0001$ \\
\hline 0.0667 & 9.70 & 0.0039 & 0.0036 & 0.0038 & - & $0.0038+/-0.0002$ \\
\hline 0.0500 & 9.71 & 0.0039 & 0.0039 & 0.0036 & - & $0.0038+/-0.0002$ \\
\hline
\end{tabular}


Table S29: UV-Vis Spectrophotometric Observed Rates and Average $k_{\text {obsd }}\left(\mathrm{s}^{-1}\right)$ for 4-Nitro- $\alpha$-hydroxyhippuric Acid (2d) at $\mathrm{p} H \sim 9.5$ buffered with Potassium Pyrophosphate, in $\mathrm{H}_{2} \mathrm{O}$ at $25^{\circ} \mathrm{C}, I=1.0 \mathrm{M}(\mathrm{KCl})$.

\begin{tabular}{|c|c|c|c|c|c|c|}
\hline$\left[\right.$ Pyro $^{\text {tot }}(\mathrm{M})$ & $\mathrm{p} H$ & \multicolumn{4}{|c|}{ Observed Experimental Rates $\left(\mathrm{s}^{-1}\right)$} & $k_{\text {obsd }}\left(\mathrm{s}^{-1}\right)$ \\
\hline 0.1000 & 9.47 & 0.0023 & 0.0022 & 0.0025 & - & $0.0023+/-0.0001$ \\
\hline 0.0667 & 9.31 & 0.0017 & 0.0018 & 0.0016 & - & $0.0017+/-0.0001$ \\
\hline 0.0500 & 9.23 & 0.0014 & 0.0015 & 0.0015 & - & $0.00145+/-0.00003$ \\
\hline
\end{tabular}

Table S30: UV-Vis Spectrophotometric Observed Rates and Average $k_{\mathrm{obsd}}\left(\mathrm{s}^{-1}\right)$ for 4-Nitro- $\alpha$-hydroxyhippuric Acid (2d) at $\mathrm{pH} \sim 9.0$ buffered with Potassium Pyrophosphate, in $\mathrm{H}_{2} \mathrm{O}$ at $25^{\circ} \mathrm{C}, I=1.0 \mathrm{M}(\mathrm{KCl})$.

\begin{tabular}{|c|c|c|c|c|c|c|}
\hline$\left[_{\text {Pyro }}^{\text {tot }}(\mathrm{M})\right.$ & $\mathrm{p} H$ & \multicolumn{3}{|c|}{ Observed Experimental Rates $\left(\mathrm{s}^{-1}\right)$} & $k_{\text {obsd }}\left(\mathrm{s}^{-1}\right)$ \\
\hline 0.1000 & 9.06 & 0.0011 & 0.0011 & 0.0011 & - & $0.00107+/-0.00001$ \\
\hline 0.0667 & 8.90 & 0.0009 & 0.00087 & 0.00087 & - & $0.00087+/-0.00001$ \\
\hline 0.0500 & 8.85 & 0.0008 & 0.00077 & 0.00076 & - & $0.00078+/-0.00002$ \\
\hline
\end{tabular}

Table S31: UV-Vis Spectrophotometric Observed Rates and Average $k_{\text {obsd }}\left(\mathrm{s}^{-1}\right)$ for 4-Nitro- $\alpha$-hydroxyhippuric Acid (2d) at $\sim \mathrm{pH} 8.5$ buffered with Potassium Pyrophosphate, in $\mathrm{H}_{2} \mathrm{O}$ at $25^{\circ} \mathrm{C}, I=1.0 \mathrm{M}(\mathrm{KCl})$.

\begin{tabular}{|c|c|c|c|c|c|c|}
\hline Pyro $^{\text {tot }}(\mathrm{M})$ & $\mathrm{p} H$ & \multicolumn{4}{|c|}{ Observed Experimental Rates $\left(\mathrm{s}^{-1}\right)$} & $k_{\text {obsd }}\left(\mathrm{s}^{-1}\right)$ \\
\hline 0.1000 & 8.68 & 0.0003 & 0.00031 & 0.00032 & - & $0.00032+/-0.00001$ \\
\hline 0.0667 & 8.60 & 0.0002 & 0.00024 & 0.00024 & - & $0.00023+/-0.00001$ \\
\hline 0.0500 & 8.55 & 0.0002 & 0.0003 & 0.0002 & - & $0.00023+/-0.00005$ \\
\hline
\end{tabular}


Table S32: UV-Vis Spectrophotometric Observed Rates and Average $k_{\text {obsd }}\left(\mathrm{s}^{-1}\right)$ for 4-(Trifluoromethyl)- $\alpha$-hydroxyhippuric Acid (2e) at $\mathrm{pH} 11.5$ buffered with Potassium Phosphate Monobasic, in $\mathrm{H}_{2} \mathrm{O}$ at $25^{\circ} \mathrm{C}, I=1.0 \mathrm{M}(\mathrm{KCl})$.

\begin{tabular}{|c|c|c|c|c|c|c|}
\hline [Phosphate $^{\text {tot }}(\mathrm{M})$ & $\mathrm{p} H$ & \multicolumn{3}{|c|}{ Observed Experimental Rates $\left(\mathrm{s}^{-1}\right)$} & $k_{\text {obsd }}\left(\mathrm{s}^{-1}\right)$ \\
\hline 0.1000 & 11.78 & 0.0863 & 0.0718 & 0.0667 & - & $0.07+/-0.01$ \\
\hline 0.0667 & 11.62 & 0.0671 & 0.0737 & 0.0827 & - & $0.075+/-0.008$ \\
\hline 0.0500 & 11.66 & 0.0736 & 0.0825 & 0.0797 & - & $0.079+/-0.005$ \\
\hline
\end{tabular}

Table S33: UV-Vis Spectrophotometric Observed Rates and Average $k_{\text {obsd }}\left(\mathrm{s}^{-1}\right)$ for 4-(Trifluoromethyl)- $\alpha$-hydroxyhippuric Acid (2e) at $\mathrm{pH} 11.0$ buffered with Potassium Phosphate Monobasic, in $\mathrm{H}_{2} \mathrm{O}$ at $25^{\circ} \mathrm{C}, I=1.0 \mathrm{M}(\mathrm{KCl})$.

\begin{tabular}{|c|c|c|c|c|c|c|}
\hline [Phosphate $^{\text {tot }}(\mathrm{M})$ & $\mathrm{pH}$ & \multicolumn{4}{|c|}{ Observed Experimental Rates $\left(\mathrm{s}^{-1}\right)$} & $k_{\text {obsd }}\left(\mathrm{s}^{-1}\right)$ \\
\hline 0.1000 & 11.19 & 0.0220 & 0.0230 & 0.0218 & - & $0.022+/-0.001$ \\
\hline 0.0667 & 10.89 & 0.0171 & 0.0171 & 0.0168 & - & $0.0170+/-0.0002$ \\
\hline 0.0500 & 10.91 & 0.0126 & 0.0159 & 0.0153 & - & $0.015+/-0.002$ \\
\hline
\end{tabular}

Table S34: UV-Vis Spectrophotometic Observed Rates and Average $k_{\text {obsd }}\left(\mathrm{s}^{-1}\right)$ for 4-(Trifluoromethyl)- $\alpha$-hydrroxyhippuric Acid (2e) at $\mathrm{pH} \sim 10.5$ buffered with Potassium Bicarbonate, in $\mathrm{H}_{2} \mathrm{O}$ at $25^{\circ} \mathrm{C}, I=1.0 \mathrm{M}(\mathrm{KCl})$.

\begin{tabular}{|c|c|c|c|c|c|c|}
\hline [Carbonate] $^{\text {tot }}(\mathrm{M})$ & $\mathrm{p} H$ & \multicolumn{3}{|c|}{ Observed Experimental Rates $\left(\mathrm{s}^{-1}\right)$} & $k_{\text {obsd }}\left(\mathrm{s}^{-1}\right)$ \\
\hline 0.1000 & 10.61 & 0.0091 & 0.0093 & 0.0093 & - & $0.0092+/-0.0001$ \\
\hline 0.0667 & 10.59 & 0.0087 & 0.0085 & 0.0086 & - & $0.0086+/-0.0001$ \\
\hline 0.0500 & 10.56 & 0.0088 & 0.0081 & 0.0084 & - & $0.0084+/-0.0003$ \\
\hline
\end{tabular}


Table S35: UV-Vis Spectrophotometric Observed Rates and Average $k_{\text {obsd }}\left(\mathrm{s}^{-1}\right)$ for 4-(Trifluoromethyl)- $\alpha$-hydroxyhippuric Acid (2e) at $\mathrm{pH} 10.0$ buffered with Potassium Bicarbonate, in $\mathrm{H}_{2} \mathrm{O}$ at $25^{\circ} \mathrm{C}, I=1.0 \mathrm{M}(\mathrm{KCl})$.

\begin{tabular}{|c|c|c|c|c|c|c|}
\hline [Carbonate $^{\text {tot }}(\mathrm{M})$ & $\mathrm{p} H$ & \multicolumn{4}{|c|}{ Observed Experimental Rates $\left(\mathrm{s}^{-1}\right)$} & $k_{\text {obsd }}\left(\mathrm{s}^{-1}\right)$ \\
\hline 0.1000 & 9.75 & 0.0018 & 0.0019 & 0.0020 & 0.0020 & $0.0019+/-0.0001$ \\
\hline 0.0667 & 9.74 & 0.0017 & 0.0018 & 0.0017 & - & $0.0017+/-0.0001$ \\
\hline 0.0500 & 9.72 & 0.0018 & 0.0018 & 0.0020 & - & $0.0018+/-0.0001$ \\
\hline
\end{tabular}

Table S36: UV-Vis Spectrophotometric Observed Rates and Average $k_{\text {obsd }}\left(\mathrm{s}^{-1}\right)$ for 4-(Trifluoromethyl)- $\alpha$-hydroxyhippuric Acid (2e) at $\mathrm{pH} \sim 9.5$ buffered with Potassium Pyrophosphate, in $\mathrm{H}_{2} \mathrm{O}$ at $25^{\circ} \mathrm{C}, I=1.0 \mathrm{M}(\mathrm{KCl})$.

\begin{tabular}{|c|c|c|c|c|c|c|}
\hline$\left[\right.$ Pyro $^{\text {tot }}(\mathrm{M})$ & $\mathrm{p} H$ & \multicolumn{3}{|c|}{ Observed Experimental Rates $\left(\mathrm{s}^{-1}\right)$} & $k_{\text {obsd }}\left(\mathrm{s}^{-1}\right)$ \\
\hline 0.1000 & 9.55 & 0.0010 & 0.0010 & 0.0010 & - & $0.00098+/-0.00003$ \\
\hline 0.0667 & 9.39 & 0.0006 & 0.0007 & 0.0008 & - & $0.0007+/-0.0001$ \\
\hline 0.0500 & 9.30 & 0.0006 & 0.0006 & 0.0006 & - & $0.000563+/-0.000003$ \\
\hline
\end{tabular}

Table S37: UV-Vis Spectrophotometric Observed Rates and Average $k_{\text {obsd }}\left(\mathrm{s}^{-1}\right)$ for 4-(Trifluoromethyl)- $\alpha$-hydroxyhippuric Acid (2e) at $\mathrm{pH} \sim 9.0$ buffered with Potassium Pyrophosphate, in $\mathrm{H}_{2} \mathrm{O}$ at $25^{\circ} \mathrm{C}, I=1.0 \mathrm{M}(\mathrm{KCl})$.

\begin{tabular}{|c|c|c|c|c|c|c|}
\hline$[\text { Pyro }]^{\text {tot }}(\mathrm{M})$ & $\mathrm{p} H$ & \multicolumn{4}{|c|}{ Observed Experimental Rates $\left(\mathrm{s}^{-1}\right)$} & $k_{\text {obsd }}\left(\mathrm{s}^{-1}\right)$ \\
\hline 0.1000 & 9.11 & 0.0005 & 0.0005 & 0.0005 & - & $0.000459+/-0.000002$ \\
\hline 0.0667 & 9.01 & 0.0004 & 0.0004 & 0.0004 & - & $0.00038+/-0.00001$ \\
\hline 0.0500 & 9.03 & 0.0003 & 0.0003 & 0.0003 & - & $0.000332+/-0.000007$ \\
\hline
\end{tabular}


Table S38: UV-Vis Spectrophotometric Observed Rates and Average $k_{\mathrm{obsd}}\left(\mathrm{s}^{-1}\right)$ for 4-(Trifluoromethyl)- $\alpha$-hydroxyhippuric Acid (2e) at $\mathrm{p} H \sim 8.5$ buffered with Potassium Pyrophosphate, in $\mathrm{H}_{2} \mathrm{O}$ at $25^{\circ} \mathrm{C}, I=1.0 \mathrm{M}(\mathrm{KCl})$.

\begin{tabular}{|c|c|c|c|c|c|c|}
\hline Pyro $^{\text {tot }}(\mathrm{M})$ & $\mathrm{p} H$ & \multicolumn{3}{|c|}{ Observed Experimental Rates $\left(\mathrm{s}^{-1}\right)$} & $k_{\text {obsd }}\left(\mathrm{s}^{-1}\right)$ \\
\hline 0.1000 & 8.63 & 0.00016 & 0.00015 & 0.000015 & - & $0.00011+/-0.00008$ \\
\hline 0.0667 & 8.59 & 0.00013 & 0.00011 & 0.00012 & - & $0.00012+/-0.00001$ \\
\hline 0.0500 & 8.54 & 0.00012 & 0.00012 & 0.00012 & - & $0.000121+/-0.000001$ \\
\hline
\end{tabular}

